NBER WORKING PAPER SERIES

\title{
EXCHANGE RATES AND MONETARY POLICY WITH HETEROGENEOUS AGENTS: SIZING UP THE REAL INCOME CHANNEL
}

\author{
Adrien Auclert \\ Matthew Rognlie \\ Martin Souchier \\ Ludwig Straub \\ Working Paper 28872 \\ http://www.nber.org/papers/w28872 \\ NATIONAL BUREAU OF ECONOMIC RESEARCH \\ 1050 Massachusetts Avenue \\ Cambridge, MA 02138 \\ May 2021, Revised June 2021
}

We are grateful to George Alessandria, Manuel Amador, Luigi Bocola, Ariel Burstein, Julian di Giovanni, Sebastian Fanelli, Mark Gertler, Pierre-Olivier Gourinchas, Guido Lorenzoni, Oleg Itskhoki, Sebnem Kalemli-Özcan, Matteo Maggiori, Kurt Mitman, Tommaso Monacelli, Brent Neiman, Pablo Ottonello, Diego Perez, Fabrizio Perri, Jesse Schreger, Vincent Sterk and Iván Werning for helpful comments. Jan Ertl provided excellent research assistance. This research is supported by the National Science Foundation grant awards SES-1851717 and SES-2042691 The views expressed herein are those of the authors and do not necessarily reflect the views of the National Bureau of Economic Research.

NBER working papers are circulated for discussion and comment purposes. They have not been peer-reviewed or been subject to the review by the NBER Board of Directors that accompanies official NBER publications.

(C) 2021 by Adrien Auclert, Matthew Rognlie, Martin Souchier, and Ludwig Straub. All rights reserved. Short sections of text, not to exceed two paragraphs, may be quoted without explicit permission provided that full credit, including (C) notice, is given to the source. 
Exchange Rates and Monetary Policy with Heterogeneous Agents: Sizing up the Real Income Channel

Adrien Auclert, Matthew Rognlie, Martin Souchier, and Ludwig Straub

NBER Working Paper No. 28872

May 2021, Revised June 2021

JEL No. E52,F32,F41

\begin{abstract}
Introducing heterogeneous households to a New Keynesian small open economy model amplifies the real income channel of exchange rates: the rise in import prices from a depreciation lowers households' real incomes, and leads them to cut back on spending. When the sum of import and export elasticities is one, this channel is offset by a larger Keynesian multiplier, heterogeneity is irrelevant, and expenditure switching drives the output response. With plausibly lower short-term elasticities, however, the real income channel dominates, and depreciation can be contractionary for output. This weakens monetary transmission and creates a dilemma for policymakers facing capital outflows. Delayed import price pass-through weakens the real income channel, while heterogeneous consumption baskets can strengthen it.
\end{abstract}

Adrien Auclert

Department of Economics

Stanford University

579 Jane Stanford Way

Stanford, CA 94305

and NBER

aauclert@stanford.edu

Matthew Rognlie

Department of Economics

Northwestern University

2211 Campus Drive

Evanston, IL 60208

and NBER

matthew.rognlie@northwestern.edu
Martin Souchier

Department of Economics

Stanford University

579 Jane Stanford Way

Stanford, CA 94305

souchier@stanford.edu

Ludwig Straub

Department of Economics

Harvard University

Littauer 211

Cambridge, MA 02139

and NBER

ludwigstraub@fas.harvard.edu

A online appendix is available at http://www.nber.org/data-appendix/w28872 


\section{Introduction}

How do open economies respond to exchange rate shocks, such as those caused by capital flows? What is the role of exchange rates in monetary transmission? The canonical answers to these questions are derived from models with a representative agent. ${ }^{1}$ In these models, marginal propensities to consume are small, muting the income effects of exchange rates for shocks at business cycle frequencies.

In this paper, we revisit these questions in a Heterogeneous Agent New Keynesian model that features higher marginal propensities to consume, in line with empirical evidence. ${ }^{2}$ We first provide novel neutrality results under which heterogeneity is irrelevant. We then argue that, in the empirically relevant case, heterogeneity generates a powerful real income channel that limits or even undoes the expansionary effects of depreciations and weakens monetary transmission. This provides an explanation for the common policy view that depreciations can cause declines in output, even when foreign currency borrowing is not an issue. ${ }^{3}$

To isolate the forces that make heterogeneity relevant, we take as our benchmark the canonical representative-agent (RA) model of Galí and Monacelli (2005). This is a complete-market model of a small open economy, in which the law of one price holds for individual goods. Instead of complete markets, we consider incomplete markets for both aggregate and idiosyncratic risk. A large mass of domestic residents faces idiosyncratic income uncertainty and borrowing constraints. We consider two main types of shocks: exchange rate shocks (shocks to the foreign interest rate that do not affect foreign demand) and domestic monetary policy shocks.

For exchange rate shocks, we show, using a sequence-space representation of the model (Auclert, Rognlie and Straub 2018, Auclert, Bardóczy, Rognlie and Straub 2021b) that the output response combines three effects: an expenditure switching channel, a real income channel, and a Keynesian multiplier channel. The RA model only has expenditure switching, whose magnitude is governed by the composite parameter $\chi$, equal to

\footnotetext{
${ }^{1}$ See Obstfeld and Rogoff (1995), Corsetti and Pesenti (2001), Clarida, Galí and Gertler (2002) and Galí and Monacelli (2005), as well as the textbook treatments in Galí (2008) and Uribe and Schmitt-Grohé (2017).

${ }^{2}$ High MPCs have been documented in advanced economies and emerging markets alike, see for instance Johnson, Parker and Souleles (2006) for the United States, Jappelli and Pistaferri (2014) for Italy, Fagereng, Holm and Natvik (2020) for Norway, and Hong (2020) for Peru.

${ }^{3}$ On contractionary devaluations, Frankel (2005) says: "Why are devaluations so costly? Many of the currency crises of the last 10 years have been associated with output loss. Is this, as alleged, because of excessive reliance on raising the interest rate as a policy response? More likely, it is because of contractionary effects of devaluation." Although widespread, this policy view is difficult to back up empirically because it is very challenging to identify exogenous exchange rate shocks in the data. This makes it even more important to study the conditions under which contractionary depreciations can emerge in microfounded general equilibrium models.
} 
the sum of the price elasticities of imports and exports (the trade elasticity). ${ }^{4}$ This channel is unchanged in the heterogeneous agent (HA) model. Instead, there are two new forces, both of which work through households' real income: the "real income channel" through which rising import prices reduce aggregate consumption, and the multiplier on aggregate output. Since the multiplier depends on the overall output response, its importance grows with $\chi$. Our first neutrality result states that, when $\chi=1$, the two new forces exactly cancel, and the RA and HA models have identical responses to any exchange rate shock. In fact, the response is independent of the market structure both across and within countries. Intuitively, when the trade elasticity is equal to 1 , the rise in output from expenditure switching is exactly enough to offset rising import prices, leaving each household's real income and therefore its consumption unchanged. The trade balance also remains constant, as reallocation from foreign to domestic goods offsets higher prices on the foreign goods.

When the trade elasticity $\chi$ is below 1 instead, the real income channel dominates. This makes the output response in the HA model lower than in the RA model. For $\chi$ sufficiently below one, this response turns negative: a contractionary depreciation emerges. Qualitatively, the same effect is also at play in a representative-agent model with incomplete markets for aggregate risk (RA-IM). But we show that it is quantitatively much larger in an HA model calibrated to feature realistically high MPCs. In other words, heterogeneity "sizes up" the real income channel that Díaz Alejandro (1963) and Krugman and Taylor (1978) had emphasized as a potential source of contractionary devaluations. ${ }^{5}$ By contrast, when $\chi>1$, the multiplier effect dominates, and depreciations are even more expansionary. Hence, our theoretical result is one of complementarity between heterogeneity and trade elasticities. Later, we argue that the relevant empirical counterpart of $\chi$ is the short-run trade elasticity, which tends to be less than 1.

We next study the case where the country's export prices, just like its import prices, are sticky in foreign currency - the so-called "dollar currency pricing" (DCP) paradigm, which the literature has recently argued to be the relevant empirical benchmark for a broad set of countries (Gopinath 2016, Boz et al. 2020). Working with representative-agent models, this literature has emphasized the fact that there is less expenditure switching under DCP than in the producer currency pricing (PCP) setting, so that the output response

\footnotetext{
${ }^{4}$ This is the elasticity that enters the well-known Marshall-Lerner condition, which states that, in partial equilibrium, depreciations improve the trade balance when $\chi>1$. We show that in our model, this condition also applies in general equilibrium.

${ }^{5}$ We show that a two agent (TA) model calibrated to the same MPCs as our HA model also generates quantitatively large contractionary devaluations at low $\chi$. To our knowledge, this result is new to the literature on two agent models. However, in the HA model, the contraction is larger and more persistent, due to the larger "intertemporal marginal propensities to consume" (Auclert, Rognlie and Straub 2018).
} 
to depreciations is lower under DCP than under PCP. In an HA model, however, we show that there is another force, because the depreciation causes an increase in exporter profit margins that can in turn spur increased spending at home. We find that, when $\chi$ is sufficiently small, this new force can dominate: then, our HA model with DCP has less of a contraction in response to a depreciation than our HA model with PCP.

Turning to monetary policy, we show that there also exists a threshold level of the trade elasticity for which heterogeneity is irrelevant. This result requires an elasticity of intertemporal substitution of 1 , and a trade elasticity of $\chi=2-\alpha$, with $\alpha \in(0,1)$ denoting the openness of the country. As in the exchange rate case, this involves a constant trade balance; here we need a higher trade elasticity $\chi$ to offset the increase in import demand from rising consumption in a monetary expansion. The $\chi=2-\alpha$ level includes the Cole-Obstfeld parametrization, in which both domestic and foreign agents have unitary elasticities of substitution. In fact, our neutrality result is reminiscent of the original Cole and Obstfeld (1991) result, which established that with Cobb-Douglas elasticities, market structure was irrelevant for the effect of productivity shocks. Our result shows that the same is true for monetary policy shocks, and also for a much broader set of market structures including within-country incomplete markets with respect to idiosyncratic shocks. In that sense, our result also generalizes Werning (2015)'s seminal neutrality result for closed economies to an open economy setting. ${ }^{6}$

Away from this benchmark, when $\chi<2-\alpha$, the output response is lower in the HA model than in the RA model-another manifestation of a dominant real income effect. One way to understand this result is that, with elasticities below Cobb-Douglas, a temporary monetary expansion induces a current account deficit, as in Tille (2001). The resulting negative net foreign asset position must be repaid later. However, absent further monetary stimulus, repayment must occur without a depreciated exchange rate, and hence without increased exports. Instead, the trade balance improves via depressed imports - which can only be achieved through a domestic contraction. Thus, in an HA model with $\chi<2-\alpha$, monetary easing raises current demand at the expense of a future contraction: it "steals demand from the future". Since this mechanism operates through the current account, it is different from the effect of durable goods or indebted demand in closed economies (McKay and Wieland, 2019, Mian, Straub and Sufi, 2020).

Our benchmark model allows for clean analytical results, but it says nothing of the empirically relevant level of the trade elasticity $\chi$. A simple quantification is difficult because trade elasticities are well documented to be dynamic: smaller in the short run than in the

\footnotetext{
${ }^{6}$ We show that our neutrality result can be extended to productivity shocks, as in the original Cole and Obstfeld (1991) paper.
} 
medium to long run. ${ }^{7}$ We address this shortcoming of our baseline model by building a quantitative extension. In it, we incorporate a tractable model of "delayed substitution", in which consumers can only substitute between goods with a given Calvo probability. ${ }^{8}$ Calibrating to the evidence in Boehm, Levchenko and Pandalai-Nayar (2020), we find that our model generates a " $J$ curve", with a trade elasticity that is smaller than 1 in the short-run, but larger than 1 in the long-run. As a consequence, our quantitative model finds that transitory depreciation shocks are contractionary in the short run.

Aside from accounting for dynamic trade elasticities, the quantitative model also allows us to speak to several other issues: we show that when consumption baskets of the poor are skewed towards imported goods (as in e.g. Cravino and Levchenko, 2017), the real income channel is amplified and a depreciation is more likely to be contractionary; we find that the real income channel is larger than a balance sheet channel calibrated to the net currency exposure of a typical country (which has shrunk in recent decades, e.g. Lane and Shambaugh 2010); and we find that the real income channel is stronger the faster exchange rates pass through to retail prices of imported goods-and hence, likely stronger in emerging markets.

Our model can speak to the common perception of a dilemma for policymakers facing capital outflows-captured in our model as exchange rate depreciation shocks. On the one hand, outflows are contractionary, and fighting them with accommodative monetary policy exacerbates the depreciation. On the other hand, stabilizing the exchange rate by tightening monetary policy comes with the negative side effects of higher interest rates domestically, as in Gertler, Gilchrist and Natalucci (2007) and Gourinchas (2018). We use our model to derive the unique output-stabilizing monetary policy. For countries with fast import price pass-through, such as many emerging markets, this policy involves hiking interest rates to stabilize the exchange rate; for countries with slow import price passthrough, such as many advanced economies, this policy involves easing interest rates to stabilize output. This finding aligns well with the contrasting responses of developed and emerging markets to U.S. monetary policy shocks documented in Kalemli-Özcan (2019).

Our paper relates to a literature that stresses the importance of the real income channel, which was first studied by Díaz Alejandro (1963) and Krugman and Taylor (1978) in the context of IS-LM models. Working with a first-generation new open economy model

\footnotetext{
${ }^{7}$ See, e.g., Hooper, Johnson and Marquez (2000), Fitzgerald and Haller (2018), Feenstra, Luck, Obstfeld and Russ (2017), Auer, Burstein, Erhardt and Lein (2019), Amiti, Itskhoki and Konings (2020), Boehm, Levchenko and Pandalai-Nayar (2020), and Auer, Burstein and Lein (2021).

${ }^{8}$ This approach complements a structural literature on models of delayed adjustment of firms export and import decisions, as in e.g., Baldwin (1988), Baldwin and Krugman (1989), Ruhl (2008), Drozd and Nosal (2012), Alessandria and Choi (2019). See Alessandria, Arkolakis and Ruhl (2020) for a review of this literature.
} 
with prices set one period in advance, Corsetti and Pesenti (2001) analytically showed that monetary accommodations have a "beggar-thyself effect" through this channel. Their model featured unitary elasticities, so while this effect reduced country welfare, it did not lower aggregate consumption or output. Later, Tille (2001) extended this model to feature a non-unitary elasticity substitution between goods and noted that, when this elasticity was low enough, his model "allow[ed] for the possibility of a devaluation to reduce consumption", though not output. ${ }^{9}$

Our two neutrality results relate to a large international macro literature that, building on the original Cole and Obstfeld (1991) result, studies how the structure of asset markets matters for the aggregate effects of international shocks (Baxter and Crucini 1995, Heathcote and Perri 2002). In the context of a representative-agent model, Itskhoki (2020) generalizes the Cole-Obstfeld equivalence between complete markets and financial autarky to a broader range of shocks, including monetary policy shocks. We provide similar neutrality results for monetary policy and exchange rate shocks, showing that this requires different trade elasticities, and consider a much broader set of market structures.

Finally, our paper relates to an emerging literature that analyzes the effects of international shocks in the context of heterogeneous-agent, New Keynesian open economy models. ${ }^{10}$ This literature has mostly focused on heterogeneous effects of shocks. Giagheddu (2020) studies the distributional effects of fiscal devaluations. de Ferra, Mitman and Romei (2020) study the distributional effect of depreciations when agents hold different amounts of foreign currency debt. Guo, Ottonello and Perez (2021) study the distributional effects of international shocks when agents differ by their sector of work and their financial integration, finding that these sources of heterogeneity can play a major role, and create trade-offs in the conduct of monetary policy. Other recent papers studying the redistributive effects of external shocks include Zhou (2020), Oskolkov (2021) and Otten (2021). Relative to these papers, ours focuses on aggregate rather than distributional effects, provides sharp benchmark results on when heterogeneity matters and when it does not, and shows that heterogeneity can cause contractionary depreciations.

Layout. Section 2 sets up our baseline model. Section 3 considers the effect of exchange rate shocks, while section 4 considers the transmission of monetary policy. Section 5 introduces our quantitative model, which we use to study the role of delayed substitution, delayed import price pass-through, heterogeneous consumption baskets, and the response

\footnotetext{
${ }^{9}$ In related work, Corsetti, Dedola and Leduc (2008) showed that the real income effect can explain the Backus-Smith correlation in response to productivity shocks.

${ }^{10}$ See Farhi and Werning (2016), Farhi and Werning (2017), and Cugat (2019) for New Keynesian open economy models with two agents.
} 
of monetary policy to contractionary capital outflows. Appendix A contains details on our benchmark model, appendix B collects all proofs, and appendix $C$ contains details on our quantitative model. Appendix D presents three alternative models, which we show can reinterpreted as versions of ours: one with nontraded goods, one with imported intermediates, and one in which the country is a commodity exporter.

\section{A baseline heterogeneous-agent open economy model}

Our modeling approach merges two New Keynesian traditions: the heterogeneous-agent ("HANK") framework for closed economies and the New Open Economy macro framework for open economies. Specifically, our model builds on the open-economy model of Galí and Monacelli (2005). To this model we add incomplete markets, heterogeneous households, and sticky wages as in Auclert, Rognlie and Straub (2018).

Model setup. Time is discrete and the horizon is infinite. We focus directly on the problem of a small open economy understood, as in Galí and Monacelli (2005), as part of a world economy consisting of a continuum of countries. We denote variables with a star superscript when they correspond to the world economy as a whole. We consider perfectforesight impulse responses to shocks starting from a steady state without aggregate uncertainty ("MIT shocks"). We use the solution method from Auclert et al. (2021b), which linearizes with respect to these shocks. By certainty equivalence, its impulse responses are therefore the same as those of the model with aggregate risk.

There are two goods in the economy: domestically produced "home" goods $H$, which can be exported, and "foreign" goods $F$, which are produced abroad and imported.

Domestic households. The economy is populated by a continuum of households. Each household is subject to idiosyncratic income risk in the form of productivity shocks $e_{i t}$, which follow a first-order Markov chain with mean $\mathbb{E} e_{i t}=1$. Households can only insure this risk by investing their assets in a domestic mutual fund, whose returns cannot be indexed to idiosyncratic productivity. A household with asset position $a$ and productivity level $e$ at time $t$ optimally chooses her consumption of the two goods, $c_{H}, c_{F}$, and saving $a^{\prime}$, by solving the dynamic program

$$
\begin{aligned}
V_{t}(a, e)= & \max _{c_{F}, c_{H}, a^{\prime}} u\left(c_{F}, c_{H}\right)-v\left(N_{t}\right)+\beta \mathbb{E}_{t}\left[V_{t+1}\left(a^{\prime}, e^{\prime}\right)\right] \\
\text { s.t. } \quad & \frac{P_{F t}}{P_{t}} c_{F}+\frac{P_{H t}}{P_{t}} c_{H}+a^{\prime}=\left(1+r_{t}^{p}\right) a+e \frac{W_{t}}{P_{t}} N_{t} \\
& a^{\prime} \geq \underline{a}
\end{aligned}
$$


Here, $P_{F t}$ is the nominal price of foreign goods in domestic currency units, $P_{H t}$ is the price of domestic goods, $r_{t}^{p}$ denotes the ex-post mutual fund return in units of the consumer price index $P_{t}, W_{t}$ is the nominal wage, $N_{t}$ denotes labor supplied by households, determined by union demand as specified below; and $\underline{a} \leq 0$ parametrizes the borrowing constraint agents face. Households share the common per period utility function

$$
u\left(c_{F}, c_{H}\right)=\frac{c^{1-\sigma}}{1-\sigma}, \quad v(N)=\psi \frac{N^{1+\varphi}}{1+\varphi}
$$

where $c$ is the consumption basket

$$
c=\left[\alpha^{1 / \eta} c_{F}^{(\eta-1) / \eta}+(1-\alpha)^{1 / \eta} c_{H}^{(\eta-1) / \eta}\right]^{\eta /(\eta-1)}
$$

The parameter $\sigma>0$ is the inverse elasticity of intertemporal substitution, $\varphi>0$ the inverse Frisch elasticity of labor supply, and $\eta>0$ is the elasticity of substitution between home and foreign goods. $\alpha$ measures the openness of the economy $(1-\alpha$ is the degree of home bias in preferences). $\psi>0$ is a normalization constant. The consumer price index for these preferences is

$$
P_{t} \equiv\left[\alpha P_{F t}^{1-\eta}+(1-\alpha) P_{H t}^{1-\eta}\right]^{1 /(1-\eta)}
$$

Households differ in their level of spending but have the same consumption basket and use the same price index. ${ }^{11}$ Standard results imply that a household in state $(a, e)$, with consumption $c_{t}(a, e)$, splits her purchases between foreign and home goods according to

$$
\begin{aligned}
& c_{F t}(a, e)=\alpha\left(\frac{P_{F t}}{P_{t}}\right)^{-\eta} c_{t}(a, e) \\
& c_{H t}(a, e)=(1-\alpha)\left(\frac{P_{H t}}{P_{t}}\right)^{-\eta} c_{t}(a, e)
\end{aligned}
$$

Monetary policy abroad keeps the price of foreign goods in foreign currency constant, $P_{F t}^{*}=P_{t}^{*}=1$. For now, we assume that imports are denominated in foreign currency and that there is perfect pass-through of exchange rates into domestic goods prices: the law of one price holds at the good level, so that $P_{F t}=\mathcal{E}_{t}$, where $\mathcal{E}_{t}$ is the nominal exchange rate. ${ }^{12}$ The real exchange rate is then given by

$$
Q_{t} \equiv \frac{\mathcal{E}_{t}}{P_{t}}
$$

\footnotetext{
${ }^{11}$ Section 5 considers non-homothetic preferences, under which poor households can consume foreign goods in different proportions than rich households.

${ }^{12}$ We relax this assumption in section 5 .
} 
With this convention, an increase in $\mathcal{E}_{t}$ indicates a nominal depreciation, and an increase in $Q_{t}$ a real depreciation.

Foreign households. Foreign households face the same problem as domestic households. We set up their problem in appendix A.1 along the lines of Galí and Monacelli (2005), so that they consume an exogenous and constant quantity $C^{*}$ of worldwide goods, and spread their own consumption of foreign goods across all foreign countries, with an elasticity of substitution across countries of $\gamma>0$. Denoting by $P_{H t}^{*}$ the foreign-currency price of domestically produced goods, export demand for home goods is given by

$$
C_{H t}^{*}=\alpha\left(\frac{P_{H t}^{*}}{P^{*}}\right)^{-\gamma} C^{*}
$$

We assume that the law of one price holds for foreign goods as well, so that $P_{H t}^{*}$ is equal to the cost $P_{H t} / \mathcal{E}_{t}$ of a domestic good in foreign currency units:

$$
P_{H t}^{*}=\frac{P_{H t}}{\mathcal{E}_{t}}
$$

This formulation effectively assumes the producer currency pricing ( $\mathrm{PCP}$ ) paradigm from the celebrated Mundell-Fleming model, adopted by Galí and Monacelli (2005) and many others, in which exchange rates fully pass through to foreign-currency prices of exported goods. Below, we also consider dollar currency pricing (DCP), where the foreign currency price of home goods $P_{H t}^{*}$ is sticky in foreign currency.

Trade elasticities of imports and exports. Aggregating equation (4) across consumers, the volume of aggregate imports is $C_{F t}=\alpha\left(\frac{P_{F t}}{P_{t}}\right)^{-\eta} C_{t}$. Holding aggregate consumption $C_{t}$ fixed, the elasticity of imports with respect to the relative price of imports $P_{F t} / P_{H t}$ is $\eta(1-\alpha)$. The volume of exports is given by $C_{H t}^{*}$ in equation (7). The elasticity of exports with respect to the relative price that foreigners see, $P_{H t}^{*} / P_{F t}^{*}$, holding foreign consumption $C^{*}$ fixed, is equal to $\gamma \cdot{ }^{13}$ We denote by $\chi$ the sum of these two elasticities,

$$
\chi \equiv \eta(1-\alpha)+\gamma
$$

which we henceforth refer to as the trade elasticity. It plays a key role in our analysis.

Production of home goods. Home goods are produced from domestic labor with constant returns,

$$
Y_{t}=Z N_{t}
$$

\footnotetext{
${ }^{13}$ That is, $\frac{\partial \log C_{F t}}{\partial \log P_{F t} / P_{H t}}=-\eta \frac{\partial \log P_{F t} / P_{t}}{\partial \log P_{F t} / P_{H t}}=-\eta(1-\alpha)$, while $\frac{\partial \log C_{H t}^{*}}{\partial \log P_{H t}^{*} / P_{F t}^{*}}=-\gamma \frac{\partial \log P_{H t}^{*} / P_{t}^{*}}{\partial \log P_{H t}^{*} / P_{F t}^{*}}=-\gamma$. The latter does not depend on foreign home bias because the home country is too small to affect the foreign CPI.
} 
where $N_{t}$ is aggregate labor supplied and $Z$ is the constant level of labor productivity. There is a continuum of monopolistically competitive firms producing home goods with technology (10). Let $\epsilon$ denote the elasticity of substitution between varieties produced within a country. For now, we assume that prices are fully flexible, so that the price of home goods is set at a constant markup $\mu$ over nominal marginal costs,

$$
P_{H t}=\mu \frac{W_{t}}{Z}
$$

where $\mu=\epsilon /(\epsilon-1)$. Real dividends by firms are equal to

$$
D_{t}=\frac{P_{H t} Y_{t}-W_{t} N_{t}}{P_{t}}+\frac{\mathcal{E}_{t} P_{H t}^{*}-P_{H t}}{P_{t}} C_{H t}^{*}
$$

The second term is zero under PCP, and captures profits from exporters' unhedged currency exposure under DCP. Firms have a unit mass of shares outstanding, with end-ofperiod price $p_{t}$. As is usual, their objective is to maximize firm value $D_{t}+p_{t}$.

Financial sector. We assume frictionless capital flows across countries. At home, an unconstrained, risk-neutral mutual fund issues claims to households, with aggregate real value $A_{t}$ at the end of period $t$, and can invest in four types of assets: domestic nominal bonds with an interest rate $i_{t}$, foreign nominal bonds with an interest rate $i_{t}^{*}$, domestic firm shares with return $\left(p_{t+1}+D_{t+1}\right) / p_{t}$, and foreign firm shares. Its objective is to maximize the (expected) real rate of return on its liabilities $r_{t+1}^{p}$. In equilibrium, this implies that expected returns on all four assets are equal, and that the mutual fund's portfolio choice is indeterminate. ${ }^{14}$ Appendix A.1 shows that equality of expected returns implies the standard uncovered interest parity (UIP) condition,

$$
1+i_{t}=\left(1+i_{t}^{*}\right) \frac{\mathcal{E}_{t+1}}{\mathcal{E}_{t}}
$$

Moreover, defining the ex-ante real interest rate as

$$
1+r_{t} \equiv\left(1+i_{t}\right) \frac{P_{t}}{P_{t+1}}
$$

gives the ex-post return at $t+1$ on the mutual fund, as well as the ex-ante return on domestic stocks:

$$
1+r_{t}=1+r_{t+1}^{p}=\frac{p_{t+1}+D_{t+1}}{p_{t}}
$$

\footnotetext{
${ }^{14}$ Note that our MIT shock assumption implies that markets are effectively incomplete with respect to country risk. Solving for the complete market allocation while maintaining incomplete markets for idiosyncratic risk is technically challenging. We will show that our effects remain in a two-agent model with complete markets across countries; see also Kekre and Lenel (2020) for a related setting.
} 
The ex-post mutual fund return $r_{0}^{p}$ at date 0 depends on its portfolio, and our baseline is to resolve portfolio indeterminacy by assuming that coming into date 0 , the mutual fund is invested entirely in domestic stocks. Given this assumption, which we relax in section 5.6 , the second equality in (15) holds for $t=-1$ as well, with $p_{-1}=p_{s s}$.

Combining (6), (13), and (14), we obtain a real version of the UIP condition

$$
1+r_{t}=\left(1+i_{t}^{*}\right) \frac{Q_{t+1}}{Q_{t}}
$$

which we appeal to extensively in our analysis. We define the net foreign asset position to be the difference between the value of assets accumulated domestically, $A_{t}$, and the total value of assets in net supply domestically, $p_{t}$, i.e.

$$
\mathrm{nfa}_{t} \equiv A_{t}-p_{t}
$$

The foreign interest rates $i_{t}^{*}$ in equation (16) are exogenous. Appendix A.1 microfounds their variation at fixed aggregate foreign demand $C^{*}$ by assuming exogenous variations in the time preference rate of foreign households. This assumption allows us to derive a clear complete market benchmark. ${ }^{15}$

Unions. We assume a standard formulation for sticky wages with heterogeneous households, similar to Auclert, Rognlie and Straub (2018). A union employs all households for an equal number of hours $N_{t}$, and is in charge of setting nominal wages by maximizing the welfare of the average household. We choose the union objective function so that this problem leads to the wage Phillips curve

$$
\pi_{w t}=\kappa_{w}\left(\frac{v^{\prime}\left(N_{t}\right)}{\frac{1}{\mu_{w}} \frac{W_{t}}{P_{t}} u^{\prime}\left(C_{t}\right)}-1\right)+\beta \pi_{w t+1}
$$

where $\pi_{w t}$ denotes nominal wage inflation,

$$
\pi_{w t} \equiv \frac{W_{t}}{W_{t-1}}-1
$$

Wage inflation rises when marginal disutility of average work $v^{\prime}\left(N_{t}\right)$ is higher than the product of the marked-down real wage by the marginal utility of average consumption

\footnotetext{
${ }^{15}$ We show in appendix A.2 that we obtain an identical model if we instead microfound exogenous movements in $i_{t}^{*}$ as exogenous "UIP shocks", such as risk premium or noise trader shocks, as in e.g. Farhi and Werning (2014), Gabaix and Maggiori (2015) and Itskhoki and Mukhin (2020). In section 5.7, we also consider an extension of this model in which UIP deviations are endogenous to the country's net foreign asset position.
} 
$\frac{1}{\mu_{w}} \frac{W_{t}}{P_{t}} u^{\prime}\left(C_{t}\right)$, now or in the future. ${ }^{16}$ If we derive this equation from a Calvo specification where the probability of keeping the wage fixed is $\theta_{w}$, then $\kappa_{w}=\frac{\left(1-\beta \theta_{w}\right)\left(1-\theta_{w}\right)}{\theta_{w}}$.

Fiscal policy and monetary policy. The government does not spend, tax or use transfers, and domestic bonds are in zero net supply. The monetary authority sets the nominal interest rate according to a monetary rule. It is standard in the open-economy literature to consider a few of these rules. For the analytical results that we develop in the next two sections, we consider a specification in which monetary policy holds the real interest rate constant:

$$
i_{t}=r_{s S}+\pi_{t+1}+\epsilon_{t}
$$

This is a CPI-based Taylor rule with a coefficient of 1 on expected inflation. This monetary rule achieves a middle ground between standard CPI-based Taylor rules with responsiveness larger than 1, and zero-lower-bound specifications with a fixed nominal interest rate, and is widely used in the literature as a device to partial out the effects of monetary policy in the study of the effects of shocks to aggregate demand (e.g. Woodford 2011, McKay, Nakamura and Steinsson 2016, Auclert, Rognlie and Straub 2018). In section 5 and in appendix B.9, we consider, as an alternative, a standard Taylor rule based on producer prices,

$$
i_{t}=r_{S S}+\phi \pi_{H t}+\epsilon_{t}
$$

with $\pi_{H t}=\frac{P_{H t}}{P_{H t-1}}-1$ and $\phi>1$, which, as we show below, yields similar results to (19).

Equilibrium. We define an equilibrium as follows.

Definition. Given sequences of foreign interest rate shocks $\left\{i_{t}^{*}\right\}$ and monetary shocks $\left\{\epsilon_{t}\right\}$, an initial wealth distribution $\mathcal{D}_{0}(a, e)$, and an initial portfolio allocation for the mutual fund, a competitive equilibrium is a path of policies $\left\{c_{H t}(a, e), c_{F t}(a, e), c_{t}(a, e), a_{t+1}(a, e)\right\}$ for households, distributions $\mathcal{D}_{t}(a, e)$, prices $\left\{\mathcal{E}_{t}, Q_{t}, P_{t}, P_{H t}, P_{F t}, W_{t}, p_{t}, i_{t}, r_{t}, r_{t}^{p}\right\}$, and aggregate quantities $\left\{C_{t}, C_{H t}, C_{F t}, Y_{t}, A_{t}, D_{t}, \mathrm{nfa}_{t}\right\}$, such that all agents optimize, firms optimize, and the domestic goods market clears:

$$
C_{H t}+C_{H t}^{*}=Y_{t}
$$

where $C_{H t} \equiv \sum_{e} \pi_{e} \int c_{H t}(a, e) \mathcal{D}_{t}(a, e)$ denotes aggregate consumption of home goods, and $C_{t}, C_{F t}, A_{t}$ are defined similarly. We focus on equilibria in which the long-run exchange rate returns to its steady state level, $Q_{\infty}=Q_{s s}$.

\footnotetext{
${ }^{16}$ In Auclert, Rognlie and Straub (2018)'s formulation of the union problem, the consumption level that enters the Phillips curve in (18) is equal to a consumption aggregator $\overline{C_{t}} \equiv\left(u^{\prime}\right)^{-1}\left(\mathbb{E}\left[e_{i t} u^{\prime}\left(c_{i t}\right)\right]\right)$ that takes into account inequality in labor earnings. Here we opt for the simpler formulation in (18), because it helps streamline some of our analytical results.
} 
Appendix A.3 shows that, in equilibrium, the current account identity holds:

$$
\mathrm{nfa}_{t}-\mathrm{nfa}_{t-1}=\frac{P_{H t}}{P_{t}} Y_{t}-C_{t}+r_{t-1} \mathrm{nfa}_{t-1}+\left(r_{t}^{p}-r_{t-1}\right) A_{t-1}
$$

where $\frac{P_{H t}}{P_{t}} Y_{t}-C_{t} \equiv N X_{t}$ is the value of net exports (or, equivalently, the trade balance) in units of the CPI, and the valuation effect term $\left(r_{t}^{p}-r_{t-1}\right) A_{t-1}$ is zero for all $t \geq 1$.

We consider a steady state with no inflation and no initial gross positions across borders. That is, the domestic mutual fund owns all stocks issued by domestic firms and the net foreign asset position is zero. Without loss of generality, we normalize prices to 1 in this steady state, implying that $P_{H s s}, P_{F s s}, P_{s s}, P_{H s s}^{*}, \mathcal{E}_{s s}, Q_{s s}$ are all equal to 1 . Moreover, we normalize domestic steady-state output $Y_{s S}$ to 1 . Hence, $C_{s S}$ and $C^{*}$ also equal 1 . Appendix A.4 shows that the unique $Q_{\infty}=1$ steady state, to which the economy returns after transitory shocks, also has no net foreign asset position and $C_{\infty}=Y_{\infty}=1$. Hence, our heterogeneous-agent model is stationary without the need for a debt-elastic interest rate, as in Schmitt-Grohé and Uribe (2003) or the large literature that followed. ${ }^{17}$

Complete-market representative-agent model ("RA model"). Throughout the paper, we compare the heterogeneous-agent model just described with the canonical representativeagent model of Galí and Monacelli (2005), in which there are complete markets across households and across countries. We spell out the details of this model in appendix A.5, where we show that that the consumption behavior of the representative domestic household is described by the Backus-Smith condition

$$
\frac{Q_{t}}{\mathcal{B}_{t}} C_{t}^{-\sigma}=C_{s s}^{-\sigma}
$$

where $\mathcal{B}_{t} \equiv \prod_{s \geq t}\left(\frac{1+i_{s}^{*}}{1+r_{s s}}\right)$ is the exogenous preference shifter of foreign households, assumed to satisfy $\mathcal{B}_{\infty}=1 .{ }^{18}$ We further show that this complete-market model admits the exact same log-linear equations as the original Galí and Monacelli (2005) model, extended to allow for foreign discount factor shocks. In particular, since we are not considering productivity shocks, our assumption that wages rather than prices are sticky is innocuous. ${ }^{19}$

\footnotetext{
${ }^{17}$ Ghironi (2006) also observed that his non-Ricardian model, based on overlapping generations, automatically achieved stationarity. Another way to achieve stationarity, at least in principle, is to solve for the global, nonlinear solution amidst idiosyncratic shocks to each country, as in Clarida (1990).

${ }^{18}$ In this model, the primitive is the path of $\mathcal{B}_{t}$. Foreign interest rates follow from $1+i_{t}^{*}=\left(1+r_{s s}\right) \frac{\mathcal{B}_{t}}{\mathcal{B}_{t+1}}$.

${ }^{19}$ As explained in Auclert, Bardóczy and Rognlie (2021a) and Broer, Hansen, Krusell and Öberg (2020), the assumption of sticky wages and flexible prices is better suited to heterogenous-agent models than the opposite assumption of sticky prices and flexible wages.
} 
Incomplete-market representative-agent model ("RA-IM model"). We briefly touch on two additional models in section 3 below. The incomplete-market representative-agent model is identical to our baseline heterogeneous-agent model, except that there is no heterogeneity or idiosyncratic income risk in (1). Here, the Backus-Smith condition (23) does not hold, and the representative agent's consumption behavior is characterized by its budget constraint and the Euler equation

$$
C_{t}^{-\sigma}=\beta\left(1+r_{t}\right) C_{t+1}^{-\sigma}
$$

This model is not stationary, and we describe its solution in appendix A.6.

Two-agent model ("TA model"). We also compare our model to a two-agent model (as in the closed-economy work of Galí, López-Salido and Vallés 2007 and Bilbiie 2008, and the open-economy work of Farhi and Werning 2017 and Cugat 2019). In this model, we assume a fraction $\lambda$ of hand-to-mouth households, and a fraction $1-\lambda$ of households with access to complete international markets, for whom an equation analogous to (23) holds. We describe this model further in appendix A.7.

\section{Exchange rate shocks}

We start by considering shocks to foreign interest rates $i_{t}^{*}$ in (16), caused by preference shocks $\mathcal{B}_{t}=\prod_{s \geq t}\left(\frac{1+i_{s}^{*}}{1+r_{s s}}\right)$ to foreign households. Combining the real UIP condition (16), the fact that $Q_{\infty}=1$, and the constant real rate (19), we find that the real exchange rate is given by

$$
Q_{t}=\prod_{s \geq t}\left(\frac{1+i_{s}^{*}}{1+r_{s S}}\right)=\mathcal{B}_{t}
$$

Intuitively, when foreign households become more impatient (rising $\mathcal{B}_{t}$ ), they push up foreign interest rates $i_{t}^{*}$, leading to capital outflows that depreciate the exchange rate (rising $Q_{t}$ ). Given (25), the real exchange rate is effectively exogenous in this section.

Our analysis is centered around the home goods market clearing condition (21). After substituting in the demands (5)-(7) and the price-setting condition for PCP (8), we can write this condition as

$$
Y_{t}=(1-\alpha)\left(\frac{P_{H t}}{P_{t}}\right)^{-\eta} C_{t}+\alpha\left(\frac{P_{H t}}{\mathcal{E}_{t}}\right)^{-\gamma} C^{*}
$$

The relative prices in equation (26) are tied to the real exchange rate $Q_{t}$. A depreciation 
Figure 1: The exchange rate shock
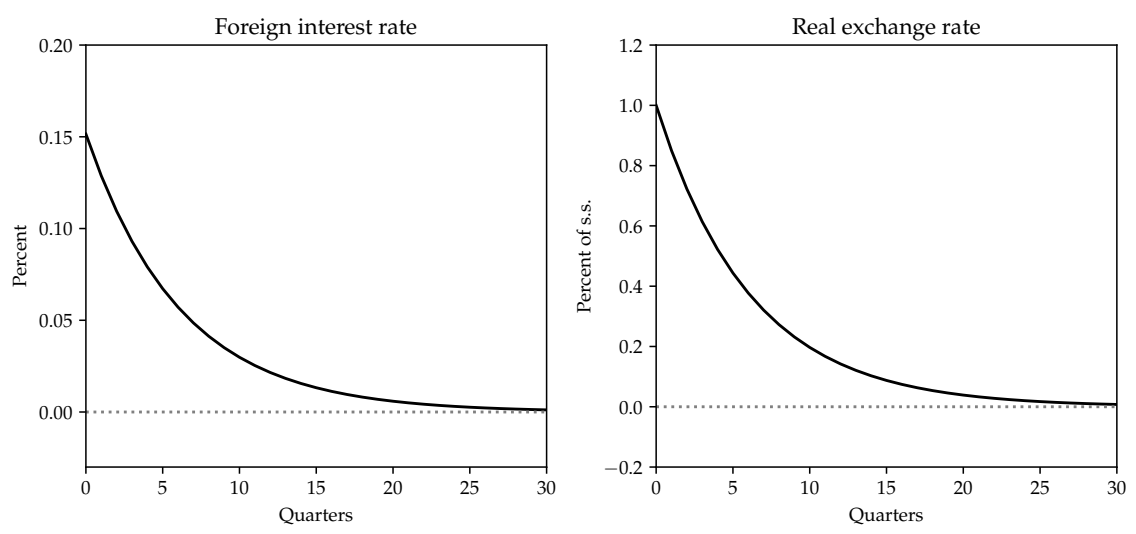

Note: $\mathrm{AR}(1)$ shock to $i_{t}^{*}$ with persistence 0.85 , and corresponding impulse response of the real exchange rate $Q_{t}$. The shock is normalized so that the real exchange rate depreciates by $1 \%$ on impact.

lowers the price of home goods relative to the domestic CPI, $P_{H t} / P_{t}$, and relative to the foreign CPI, $P_{H t} / \mathcal{E}_{t}$. This leads domestic and foreign consumers to substitute towards home goods. In addition to these traditional expenditure switching effects, the volume of domestic spending $C_{t}$ may change. In this section, we characterize how this response is affected by the market structure and heterogeneity among agents.

Throughout this section and the next, we illustrate our results with a numerical calibration, which we describe in detail in section 5 . We intentionally leave the trade elasticity $\chi$ (and thus $\eta, \gamma$ ) unspecified for now. We choose an openness of $\alpha=0.40$ as in Galí and Monacelli (2005). We assume that $i_{t}^{*}$ follows an AR(1) shock with quarterly persistence of $\rho=0.85$, and that it is normalized to have an impact effect of 1 on the real exchange rate $d Q_{0}$ (see figure 1$) .^{20}$

\subsection{Complete-market benchmark}

We start by considering the complete-market representative-agent model ("RA model"). Combining (25) with the Backus Smith condition (23), we immediately find that consumption does not respond to the shock, $C_{t}=C_{s s}=1 .{ }^{21}$ Equation (26) then implies that domestic production is only affected by expenditure switching.

Proposition 1. In the complete-market representative-agent model with real interest rate rule (19), the linearized deviations from steady state consumption over output, $d C_{t}=\left(C_{t}-C_{s s}\right) / Y_{s s}$

\footnotetext{
${ }^{20}$ This quarterly persistence is typical for exchange rate shocks in estimated models (see e.g. Eichenbaum, Johannsen and Rebelo 2021 for a recent example), as well as to standard estimates of the (HP-filtered) unconditional persistence of the real exchange rate, such as those in Chari, Kehoe and McGrattan (2002).

${ }^{21}$ Consumption comoves negatively with real exchange rates in response to other shocks that keep $\mathcal{B}_{t}=$ 1 , since the Backus-Smith condition (23) dictates that $Q_{t} C_{t}^{-\sigma}$ is constant in response to these shocks.
} 
Figure 2: Effect of exchange rate shocks on output for various $\chi^{\prime} \mathrm{s}$
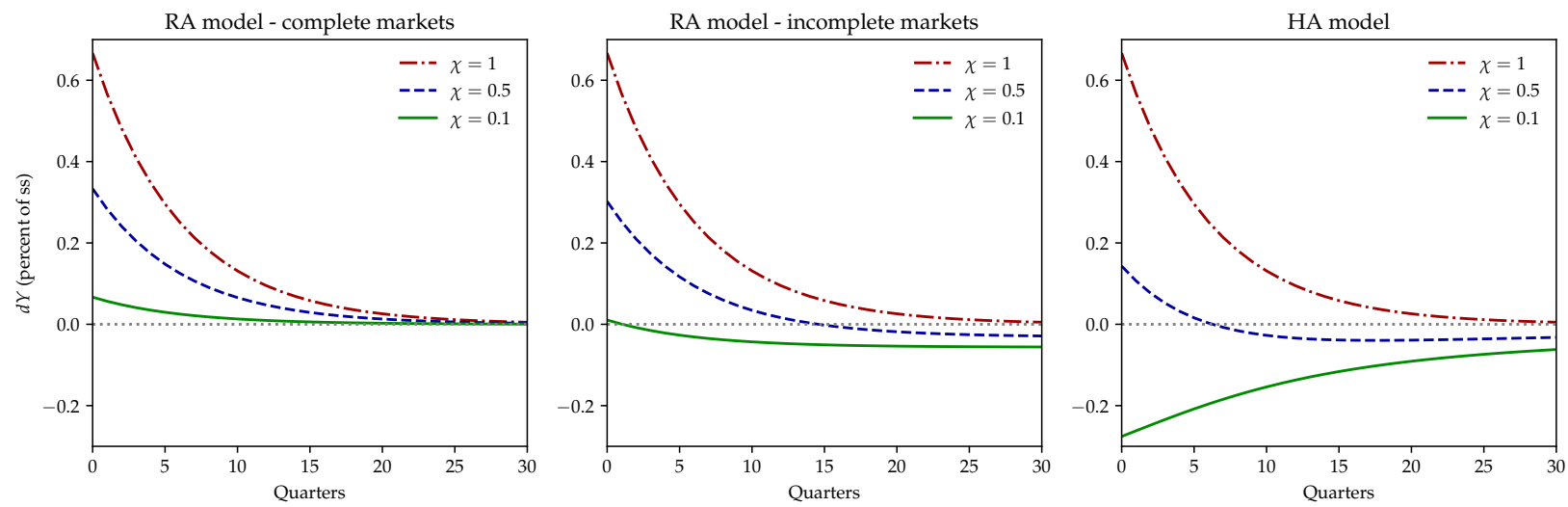

Note: impulse response in all three models to the shock to $i_{t}^{*}$ displayed in Figure 1. $\chi$ is the trade elasticity (the sum of the import and export elasticity to the exchange rate). The HA model generates a contraction on impact for $\chi<\chi^{*}=0.37$.

and output $d Y_{t}=\left(Y_{t}-Y_{s s}\right) / Y_{s s}$ in response to shocks to the real exchange rate $d Q_{t}=\left(Q_{t}-Q_{s s}\right) / Q_{s s}$ are given by

$$
\begin{aligned}
d C_{t} & =0 \quad \forall t \\
d Y_{t} & =\frac{\alpha}{1-\alpha} \chi d Q_{t} \quad \forall t
\end{aligned}
$$

Proposition 1 captures a common view in the literature: depreciations are expansionary due to expenditure switching, and a greater trade elasticity $\chi$ leads to a greater expansion $d Y_{t}$. The left panel of figure 2 shows the output response for various values of $\chi$. A $1 \%$ real depreciation lowers the relative price of home goods by $\frac{1}{1-\alpha} \%$, with a combined effect on imports and exports of $\frac{\chi}{1-\alpha} \%$ of initial imports, so of $\frac{\alpha}{1-\alpha} \chi \%$ of GDP.

Going forward, it will be convenient to express impulse responses as vectors, e.g. $d \mathbf{Y}=\left(d Y_{0}, d Y_{1}, \ldots\right)$. With this notation, (27)-(28) become $d \mathbf{C}=0$ and $d \mathbf{Y}=\frac{\alpha}{1-\alpha} \chi d \mathbf{Q}$.

\subsection{Incomplete markets and the real income channel}

We next examine the effects of exchange rate shocks in our heterogeneous-agent model. In that model-as in any incomplete-market model-consumption is no longer insulated from movements in real income. To see this, consider the two components of real income: wages and dividends. First, the price-setting condition (11) combined with the production function (10) implies that households' real wage income is given by

$$
\frac{W_{t}}{P_{t}} N_{t}=\frac{1}{\mu} \frac{P_{H t}}{P_{t}} Y_{t}
$$


Combining (29) with equation (12), we see that real dividends are equal to

$$
D_{t}=\left(1-\frac{1}{\mu}\right) \frac{P_{H t}}{P_{t}} Y_{t}
$$

Both wage income and dividends matter for aggregate consumption. Wage income enters households' budget constraints (1). Dividends affect the value of home firms, pinning down $r_{0}^{p}$ via (15), given our assumption on the initial mutual fund portfolio. ${ }^{22}$ Hence, real wage income and dividends are the only two aggregate variables needed to solve the consumption-saving problem of domestic households, and therefore their consumption policy functions at each date $t$. Aggregating up and using (29) and (30), we find that that the path of aggregate consumption $C_{t}$ is entirely a function of the path of aggregate real income $\frac{P_{H t}}{P_{t}} Y_{t}$. We denote this "consumption function" by $C_{t}=\mathcal{C}_{t}\left(\left\{\frac{P_{H s}}{P_{s}} Y_{s}\right\}_{s=0}^{\infty}\right) \cdot{ }^{23}$ Around the steady state, we denote the derivative (Jacobian) of $\mathcal{C}$ by $\mathbf{M}$, a matrix with elements $M_{t, s} \equiv \frac{\partial \mathcal{C}_{t}}{\partial Y_{s}}$ that characterize the date- $t$ consumption response to a date-s change in real income. Following Auclert, Rognlie and Straub (2018), we refer to the elements of $\mathbf{M}$ as "intertemporal MPCs". ${ }^{24}$

Since $Y_{t}$ enters the consumption function, the equilibrium response $d Y_{t}$ to an exchange rate shock $d Q_{t}$ is now the solution to the following fixed point problem.

Proposition 2. In response to a shock to the real exchange rate $d \mathbf{Q}$, the impulse response of consumption is given by

$$
d \mathbf{C}=-\underbrace{\frac{\alpha}{1-\alpha} \mathbf{M} d \mathbf{Q}}_{\text {Real income channel }}+\underbrace{\mathbf{M} d \mathbf{Y}}_{\text {Multiplier }}
$$

and the impulse response of output $d \mathbf{Y}$ is determined by an "international Keynesian cross"

$$
d \mathbf{Y}=\underbrace{\frac{\alpha}{1-\alpha} \chi d \mathbf{Q}}_{\text {Exp. switching channel }}-\underbrace{\alpha \mathbf{M} d \mathbf{Q}}_{\text {Real income channel }}+\underbrace{(1-\alpha) \mathbf{M} d \mathbf{Y}}_{\text {Multiplier }}
$$

Proposition 2 shows that the impulse responses of consumption and output only depend on the openness parameter $\alpha$, the trade elasticity $\chi$, and the matrix of intertemporal MPCs M. Equation (31) finds that there are two ways in which real income $\frac{P_{H t}}{P_{t}} Y_{t}$, and hence consumption $d \mathbf{C}$, are affected by an exchange rate depreciation $d \mathbf{Q}$. First, a depre-

\footnotetext{
${ }^{22}$ For $t>0, r_{t}^{p}$ is equal to $r_{t-1}$, which is held constant by monetary policy in this experiment.

${ }^{23}$ A similar logic underlies the consumption functions used in Kaplan, Moll and Violante (2018), Farhi and Werning (2019), and Auclert, Rognlie and Straub (2018).

${ }^{24}$ The MPC is most often defined as the immediate response of an individual to a transitory increase in income. Our $M_{0,0}$ corresponds to the average of this MPC, weighted by each individual's share of total income.
} 
ciation lowers $\frac{P_{H t}}{P_{t}}$ by $\frac{\alpha}{1-\alpha} d Q_{t}$, that is, it lowers the price of the goods that the country produces relative to the price of those that it buys. This reduces real income, leading agents to cut consumption by $\mathbf{M} \times \frac{\alpha}{1-\alpha} d \mathbf{Q}$. We refer to this as the real income channel. Second, a depreciation affects the path of output $d \mathbf{Y}$, which also enters real income, and changes consumption by $\mathbf{M} \times d \mathbf{Y}$. This is a standard (Keynesian) multiplier effect.

Linearizing goods market clearing (26) and substituting in (31), we obtain equation (32), whose form is like that of a standard Keynesian cross, where the relevant multiplier is the product of MPCs $\mathbf{M}$ by the degree of home bias $(1-\alpha)$. Including expenditure switching, there are altogether three distinct channels that jointly determine the output response to any given shock. The next proposition derives the general solution to (32).

Proposition 3. Assuming $\mathbf{M} \geq 0$, the equilibrium output response is unique and given by

$$
d \mathbf{Y}=\underbrace{\left(\sum_{k \geq 0}(1-\alpha)^{k} \mathbf{M}^{k}\right)}_{=(\mathbf{I}-(1-\alpha) \mathbf{M})^{-1}}\left(\frac{\alpha}{1-\alpha} \chi d \mathbf{Q}-\alpha \mathbf{M} d \mathbf{Q}\right)
$$

Alternative models of consumption. One advantage of these results is that they apply not only to any calibration of our heterogeneous-agent model, but also to any model that admits a consumption function of the form $C_{t}=\mathcal{C}_{t}\left(\left\{\frac{P_{H s}}{P_{s}} Y_{s}\right\}_{s=0}^{\infty}\right)$ with derivative $\mathbf{M}$. This includes the (complete-market) RA model above, for which $\mathbf{M}=0$, but also the TA model and the RA-IM model, whose closed-form solutions we derive in appendices B.7 and B.8, respectively. ${ }^{25}$ In addition, appendices D.1 and D.2 show that our results also apply in a model with nontradable goods or with imported intermediate goods. These models are isomorphic to our baseline model, under a reinterpretation of parameters.

We use the result in proposition 3 to solve for $d \mathbf{Y}$ in both the RA and RA-IM models as well as the HA model, and decompose $d \mathbf{Y}$ following (32). Figure 3 presents the outcome of this exercise for the case where $\chi=1$. As we noted already, the output response in the RA model (left panel) is entirely driven by expenditure switching. In the RA-IM model (middle panel), there is a small negative real income channel, and a small positive multiplier effect. Both are an order of magnitude larger in the HA model (right panel). In other words, the HA model "sizes up" the real income channel.

An intriguing property of figure 3 is that the multiplier effect exactly undoes the increased real income channel, in both the RA-IM and the HA model. The aggregate output

\footnotetext{
${ }^{25}$ Bianchi and Coulibaly (2021) independently arrived at a decomposition for consumption in a tradablenontradable RA-IM model. Their decomposition is distinct from ours, in that they allow $i_{t}^{*}$ to enter the consumption function directly.
} 
Figure 3: Exchange rate shock when $\chi=1$ and its transmission channels
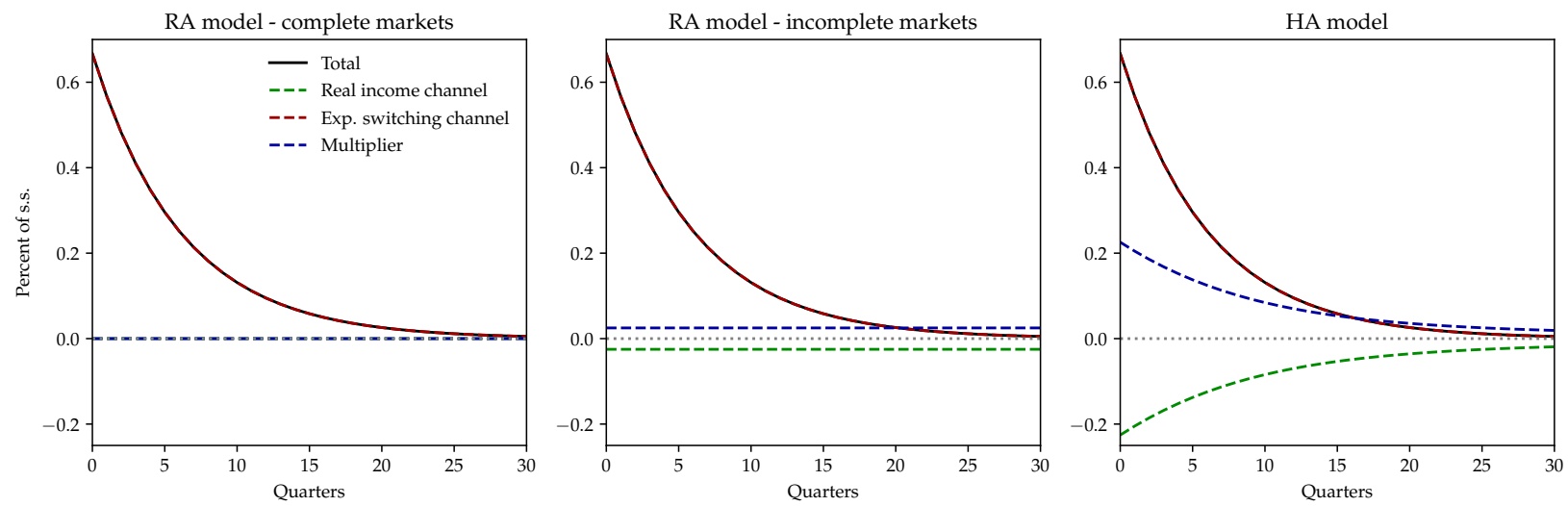

Note: impulse response in all three models to the shock to $i_{t}^{*}$ displayed in Figure 1, with decomposition from proposition 2.

responses $d \mathbf{Y}$ are therefore identical across models in figure 3. Our next result proves that this is no coincidence.

Proposition 4. Consider any model of consumption characterized by a matrix $\mathbf{M}$, and an arbitrary exchange rate shock $d \mathbf{Q}$. If $\chi=1$, all aggregate quantities and prices are the same as in the $R A$ model, and in particular, $d \mathbf{Y}=d \mathbf{Y}^{R A}$. Moreover, provided that $\mathbf{M}>0$, for a depreciation shock $d \mathbf{Q} \geq 0$, we have

$$
d \mathbf{Y} \lessgtr d \mathbf{Y}^{R A} \text { and } d \mathbf{C} \lessgtr 0 \quad \Leftrightarrow \quad \chi \lessgtr 1
$$

The first part of proposition 4 formally establishes a neutrality result for exchange rate shocks: when $\chi=1$, the details of household behavior and market structure are irrelevant as long as there exists an aggregate consumption function of the form $C_{t}=$ $\mathcal{C}_{t}\left(\left\{\frac{P_{H s}}{P_{s}} Y_{s}\right\}_{s=0}^{\infty}\right)$. This result follows directly from substituting $\chi=1$ into (33). To understand why this works, note that when we substitute $d \mathbf{Y}=d \mathbf{Y}^{R A}=\frac{\alpha}{1-\alpha} d \mathbf{Q}$ into (31), we get $d \mathbf{C}=0$ : for $\chi=1$, the rise in output from expenditure switching is just large enough to offset the loss of real income from higher prices, leaving total real income and therefore consumption unchanged in every period. Since consumption is unchanged, the only effect on output is from expenditure switching, just as in the RA model.

Our result in proposition 4 is closely related to the Marshall-Lerner condition, which posits that the response of the trade balance after an exchange rate shock depends on the position of $\chi$, the sum of import and export elasticities, relative to 1 . Indeed, appendix B. 3 shows that, in our model, the response of the trade balance is given by

$$
d N X_{t}=\frac{\alpha}{1-\alpha}(\chi-1) d Q_{t}-\alpha d C_{t}
$$


Figure 4: Complementarity between expenditure switching elasticity $\chi$ and high MPCs
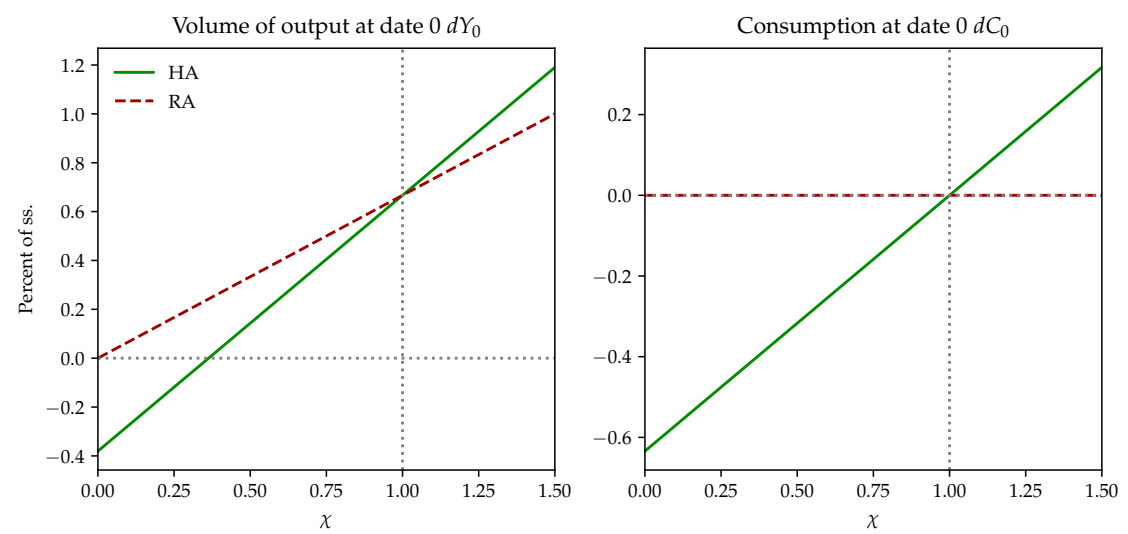

Note: changes on impact in output and consumption following the shock to $i_{t}^{*}$ displayed in Figure 1 . The HA model generates a contraction for output on impact for $\chi<\chi^{*}=0.37$ and a contraction for consumption on impact for $\chi<1$. The complete-market RA model never generates a contraction.

Since the sign of $d C_{t}$ depends on $\chi-1$, the Marshall-Lerner condition holds here in general equilibrium. ${ }^{26}$ At the threshold $\chi=1$, reduced imports and increased exports exactly offset increased import prices, and the trade balance is unchanged.

Going beyond the neutrality result, proposition 4 shows that when $\chi$ lies below 1 , expenditure switching is weaker, reducing the output response $Y_{t}$, and therefore reducing the multiplier term. The real income channel is now no longer fully offset, pushing the output response in the HA model below that in the RA model. The opposite happens when $\chi>1$.

Proposition 4 therefore describes a complementarity between the trade elasticity $\chi$ and incomplete markets. Reducing $\chi$ below 1 has a disproportionate effect on output in the heterogeneous-agent model, as it reduces the multiplier channel while the real income channel remains unchanged. We illustrate this point in figure 4 , which shows the impact responses of output $d Y_{0}$ and consumption $d C_{0}$ for the shock considered in figure 1 at various values of $\chi$.

As the right panel in figure 4 illustrates, an interesting implication of $\chi<1$ is that aggregate consumption falls in response to an exchange rate depreciation in our setting. This finding is in line with the empirical Backus-Smith correlation, and complements the recent results of Itskhoki and Mukhin (2020), who show that a similar correlation can be obtained in a representative-agent model with an active Taylor rule.

\footnotetext{
${ }^{26}$ Observe that $\chi=1$ does not correspond to the well-known Cole and Obstfeld (1991) parametrization, which, using (9), is given by $\chi=2-\alpha$. The Cole and Obstfeld (1991) parametrization turns out to be the relevant one for monetary policy (see section 4 ).
} 


\subsection{Contractionary depreciations}

A novel feature of the model is that, with $\chi$ sufficiently below 1 , consumption falls by so much after an exchange rate depreciation that it causes a contraction in output. In other words, the economy displays contractionary depreciations.

Proposition 5. If $\chi<1-\alpha$, the output response to a depreciation shock $d Q_{t} \geq 0$ has negative net present value, $\sum_{t=0}^{\infty}(1+r)^{-t} d Y_{t}<0$ in the heterogeneous-agent model. Moreover, given a depreciation shock, there is a threshold $\chi^{*}$ between $(1-\alpha) M_{0,0}$ and 1 such that for any $\chi<\chi^{*}$, the output response is negative on impact, $d Y_{0}<0$.

When $\chi<1-\alpha$, the present value of the real income channel overwhelms the expenditure switching channel in (32), leading to an output response with negative present value. $^{27}$ For low enough $\chi$, expenditure switching is overwhelmed by the real income channel on impact as well. For instance, if there is a one-time shock to $d Q_{0}$, the real income effect at $t=0$ is $-\alpha M_{0,0} d Q_{0}$, compared to expenditure switching of $\frac{\alpha}{1-\alpha} \chi d Q_{0}$. When $\chi<(1-\alpha) M_{0,0}$, the former dominates. This dominant real income channel is only reinforced by the multiplier in (32), since the real income effect on consumption persists after the shock has passed, and this persistence feeds back to date 0 via the multiplier. Overall, for any depreciation, there is a threshold $\chi^{*}$ at which it becomes contractionary: $\chi^{*}$ is at least $(1-\alpha) M_{0,0}$, and usually greater due to multiplier effects.

Since this result is driven by the real income channel, it is different from, and complementary to, the commonly studied balance sheet channel with currency mismatch (e.g. Aghion, Bacchetta and Banerjee 2004, Céspedes, Chang and Velasco 2004). It can potentially explain the continued relevance of fear of floating (Ilzetzki, Reinhart and Rogoff 2019) and reserve hoarding (Bianchi and Lorenzoni 2021) among countries for which currency mismatch is no longer an issue (see appendix C.4).

The right panel of figure 2 illustrates contractionary depreciations. Since $\alpha=0.4$, the present value of the output response is negative whenever $\chi<0.6$-for instance, the $\chi=0.5$ impulse response features this property. The threshold trade elasticity $\chi^{*}$ for this calibration is given by $\chi^{*}=0.37$.

\subsection{Dollar currency pricing}

We have seen that the degree of expenditure switching crucially influences whether a depreciation is expansionary in the HA model. One reason for a weaker expenditure

\footnotetext{
${ }^{27}$ Since $\mathbf{M}$ conserves present value, taking the present value of both sides of (32) gives $P V(d \mathbf{Y})=$ $\left(\frac{\alpha}{1-\alpha} \chi-\alpha\right) P V(d \mathbf{Q})+(1-\alpha) P V(d \mathbf{Y})$, so for $d \mathbf{Q} \geq 0, P V(d \mathbf{Y})$ has the same sign as $\chi-(1-\alpha)$.
} 
switching channel is the prevalence of dollar (or dominant) currency pricing (DCP). With DCP, exports are invoiced in dollars. This means that export prices do not immediately adjust in response to exchange rate fluctuations (Gopinath, 2016), limiting the response of export demand (Gopinath et al., 2020).

To explore the effects of DCP for our model, we replace equation (8) with $P_{H t}^{*}=\overline{P_{H}^{*}}$. Hence, all exports are invoiced in dollars, and for simplicity these dollar prices are fixed. ${ }^{28}$ This influences our analysis in two ways. First, it lowers the trade elasticity $\chi$ from $\eta(1-\alpha)+\gamma$ to simply $\eta(1-\alpha)$ : the volume of export demand no longer responds to a depreciation. We refer to this as the "standard effect" of DCP. Second, domestic firms' markups on exports are now endogenous to the exchange rate: after a depreciation, markups increase, raising profits via equation (12). ${ }^{29}$ These profits are earned by domestic shareholders, generating a positive effect on spending. We refer to this as the "profit effect" of DCP.

To investigate the role of the two effects of DCP, figure 5 compares the output response to a depreciation under PCP to the responses under DCP with (i) only the standard effect and (ii) both effects. ${ }^{30}$ The left panel shows the case of larger elasticities $\eta=\gamma=1 /(2-$ $\alpha$ ), chosen to give $\chi=1$. Here, the standard DCP effect causes a large reduction in the output response, as it effectively sets $\gamma$ to zero. The profit effect is positive for output, as asset owners spend some of the additional profit earned on exports, but here this is not enough to overturn the lack of export demand, since these asset owners have low MPCs.

The right panel shows the case of smaller elasticities. There, since $\gamma$ is already small, the standard effect is much weaker, and it is now reversed by the profit effect: DCP increases the output response, making the depreciation less contractionary.

To shed further light on this effect, consider the effect of a one-time depreciation $d Q_{0}$ on output. For any given agent $i$, the depreciation causes a reduction in real wage income of $\frac{1}{\mu} e_{i 0}$, where $e_{i 0}$ is the idiosyncratic productivity of agent $i$ at date 0 , and it raises real dividend income by $\frac{1}{\mu} \frac{a_{i 0}}{A_{s s}}$ where $\frac{a_{i 0}}{A_{s s}}$ is the wealth owned by agent $i$ relative to mean wealth. Let us define the net exchange rate exposure $N X E_{i}$ of agent $i$ by

$$
N X E_{i} \equiv\left(\frac{a_{i 0}}{A_{s s}}-e_{i 0}\right) \cdot \frac{1}{\mu}
$$

\footnotetext{
${ }^{28}$ In section 5 we relax this assumption by allowing for dynamic adjustment of the dollar price.

${ }^{29}$ Barbiero (2020) empirically documents these foreign-exchange-induced variations in the profits of French firms that price in foreign currency.

${ }^{30}$ One can think of (i) as the case in which exporters are perfectly hedged against exchange rate movements.
} 
Figure 5: Capital outflows under dollar currency pricing
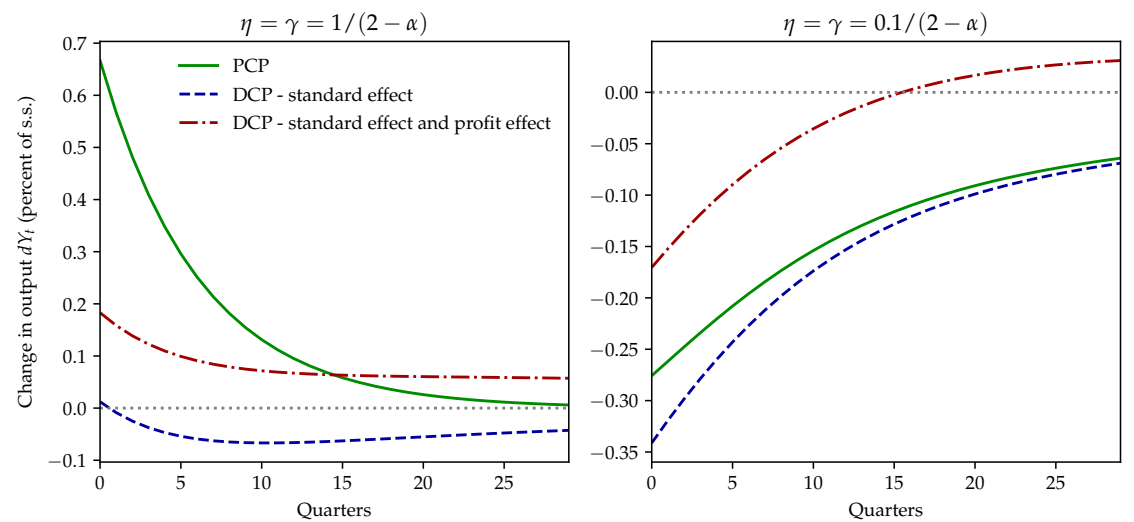

Note: impulse responses to the shock to $i_{t}^{*}$ displayed in Figure 1. PCP corresponds to producer currency pricing, DCP to dollar currency pricing. The standard (reduced expenditure switching) and the profit effect are discussed in the main text.

We show in appendix B.4 that the impact output response is then given by

$$
d Y_{0}=\frac{\alpha}{1-\alpha} \chi d Q_{0}+\alpha \operatorname{Cov}\left(M P C_{i}, N X E_{i}\right) d Q_{0}+(1-\alpha) \sum_{s \geq 0} M_{0, s} d Y_{s}
$$

Compared with (32), we see that the real income channel is now given by the crosssectional covariance of MPCs and net exchange rate exposures. In our model, this covariance is endogenously negative, since firms' shareholders tend to be richer and have lower MPCs than agents who predominantly rely on labor income. Our model thus provides a micro-founded counterpart to Díaz Alejandro (1963) and Krugman and Taylor (1978), who previously discussed this mechanism in the context of IS-LM models. We regard measuring net exchange rate exposures such as (35) in the data, and analyzing their aggregate implications using equation (36), as a very promising avenue for future research.

In commodity exporting countries, exchange rate depreciations also create a profit effect: they raise the domestic price at which commodity exporting firms sell, so that depreciations redistribute from workers, whose real income falls, to the owners of these firms. Appendix D.3 proves that there is, in fact, a formal analogy: by reinterpreting $\alpha$ and $\chi$, a model with produced nontradables and endowed tradables (e.g. commodities) is exactly equivalent to the model with DCP and fixed dollar prices studied here.

\section{Monetary policy}

We next ask how monetary transmission is affected by heterogeneous agents and incomplete markets. Throughout this section we assume $\log$ preferences $\sigma=1$, which allow for 
a clean analytical characterization. In the interest of space we focus on real interest rate rules; appendix B.9 considers Taylor rules and shows that our equivalence result extends to that case, including for the response to productivity shocks.

\subsection{Transmission of real interest rates}

Given our monetary policy rule (19), monetary policy affects aggregate activity in our model by directly changing the path of domestic real interest rates $\left\{r_{t}\right\}$. This has two distinct effects on household behavior. First, it affects the path of the real exchange rate $\left\{Q_{t}\right\}$ through the real UIP condition (16). Given that $Q_{\infty}=1$ and $i^{*}=r_{s s}$, we now have

$$
Q_{t}=\prod_{s \geq t}\left(\frac{1+r_{s s}}{1+r_{s}}\right)
$$

These changes in the real exchange rate operate through the expenditure switching and real income channels analyzed in section 3.

Second, changes in domestic interest rates affect the economy directly as $r_{t}$ moves asset prices and therefore returns at all dates, including by revaluating wealth at date 0 . This induces income and substitution effects that are well-studied in the closed economy literature (e.g. Auclert 2019). We refer to these effects as the interest rate channel. Formally, aggregate consumption is now also directly affected by real interest rates, $C_{t}=\mathcal{C}_{t}\left(\left\{r_{s}, \frac{P_{H s}}{P_{s}} Y_{s}\right\}\right)$. The interest rate response matrix $\mathbf{M}^{r}$, which we define as $M_{t, s}^{r} \equiv$ $(1+r) \cdot \partial \mathcal{C}_{t} / \partial r_{s}$, captures these closed-economy effects.

To characterize the effect of monetary policy on output, we again proceed by linearizing the goods market clearing condition. Consider a change $\left\{d r_{t}\right\}$ to real interest rates, and let $d \mathbf{r} \equiv\left(\frac{d r_{0}}{1+r_{s s}}, \frac{d r_{1}}{1+r_{s s}}, \ldots\right)^{\prime}$. Given (37), the real exchange rate responds by $d Q_{t}=-\sum_{s \geq t} \frac{d r_{s}}{1+r_{s s}}$, or in matrix notation, $d \mathbf{Q}=-\mathbf{U} d \mathbf{r}$, where $\mathbf{U}$ is a matrix with 1's on and above the diagonal. Linearizing (21) again, we obtain a generalized version of the international Keynesian cross (32):

$$
d \mathbf{Y}=\underbrace{(1-\alpha) \mathbf{M}^{r} d \mathbf{r}}_{\text {Interest rate channel }}+\underbrace{\frac{\alpha}{1-\alpha} \chi d \mathbf{Q}}_{\text {Exp. switching channel }}-\underbrace{\alpha \mathbf{M} d \mathbf{Q}}_{\text {Real income channel }}+\underbrace{(1-\alpha) \mathbf{M} d \mathbf{Y}}_{\text {Multiplier }}
$$

The representative-agent model is still covered as a special case of equation (38), in which $\mathbf{M}=0$ and $\mathbf{M}^{r}=-\mathbf{U} \cdot{ }^{31}$ In that case, equation (38) delivers the simple expression $d \mathbf{Y}^{R A}=$ $-\left((1-\alpha)+\frac{\alpha}{1-\alpha} \chi\right) \mathbf{U} d \mathbf{r}$.

\footnotetext{
${ }^{31}$ Recall that $\sigma=1$ in this section. In general, $\mathbf{M}^{r}=-\frac{1}{\sigma} \mathbf{U}$.
} 
In the HA model, it is well-understood from the closed-economy literature that the interest rate channel is less powerful, since agents have less ability to substitute intertemporally. In a closed economy, this weaker interest rate channel can be offset by a stronger multiplier (Werning 2015). In the open economy, however, the multiplier is weaker, since only a share $1-\alpha$ of domestic demand is spent on home goods. Hence, with $\chi=1$, the HA model has a weaker output response to monetary policy. However, as we prove next, equivalence is restored at a greater value for $\chi$, namely $\chi=2-\alpha$.

Proposition 6. Assume $\sigma=1$, and consider an arbitrary first-order monetary policy shock $d r$. If $\chi=2-\alpha$, all aggregate quantities and prices are identical in heterogeneous and representativeagent models. Moreover, provided that $\mathbf{M}>0$, for an accommodative shock $d \mathbf{r} \leq 0$,

$$
d \mathbf{Y} \lessgtr d \mathbf{Y}^{R A} \quad \Leftrightarrow \quad \chi \lessgtr 2-\alpha
$$

Proposition 6 is the analogue of Proposition 4 for monetary policy. The neutral case, $\chi=2-\alpha$, applies in particular to the commonly-studied Cole and Obstfeld (1991) parameterization in which $\eta=\gamma=\sigma=1 .^{32}$ This result generalizes the representative-agent result in Itskhoki (2020) to heterogeneous-agent models, and the closed economy result of Werning (2015) to the open economy.

To understand this result, it is helpful to consider the effects of monetary policy on the trade balance. Suppose that consumption changes as in the RA model: the BackusSmith condition then implies that $d C_{t}=d Q_{t}$. Then, equation (34) implies that $d N X_{t}=$ $\frac{\alpha}{1-\alpha}(\chi-(2-\alpha)) d Q_{t}$. Hence, at $\chi=2-\alpha$, expenditure switching offsets both the increase in import prices and the higher import demand, and the economy behaves as if it were a closed economy. Given this, we can apply Werning (2015)'s result for closed economies to validate our guess that consumption behaves as if there was a representative agent.

The top panels of figure 6 illustrate this neutrality result. We consider an accommodative interest rate shock that generates the same path for the real exchange rate as that considered in section 3. In the right panel, we show the output response in the HA model, as well as its decomposition using equation (38). Compared to the RA model (left panel), it shows a clearly negative real income effect, and a weaker interest rate effect. Both are exactly offset by a positive multiplier effect from the increased production (not shown), so that the output response is identical. In the bottom panels of figure 6 , we consider what happens when $\chi=0.5$ instead. The interest rate and real income channels are unchanged relative to $\chi=2-\alpha$, but after a few quarters, the muted expenditure switching channel

\footnotetext{
${ }^{32}$ In fact, in this special case, it is even possible to prove that proposition 6 holds for unanticipated nonlinear shocks. We can generalize our results further when $\chi=2-\alpha$, e.g. by allowing for arbitrary monetary policy rules. See appendix B.9.
} 
Figure 6: The effects of monetary policy

(a) Neutral case: $\chi=2-\alpha$
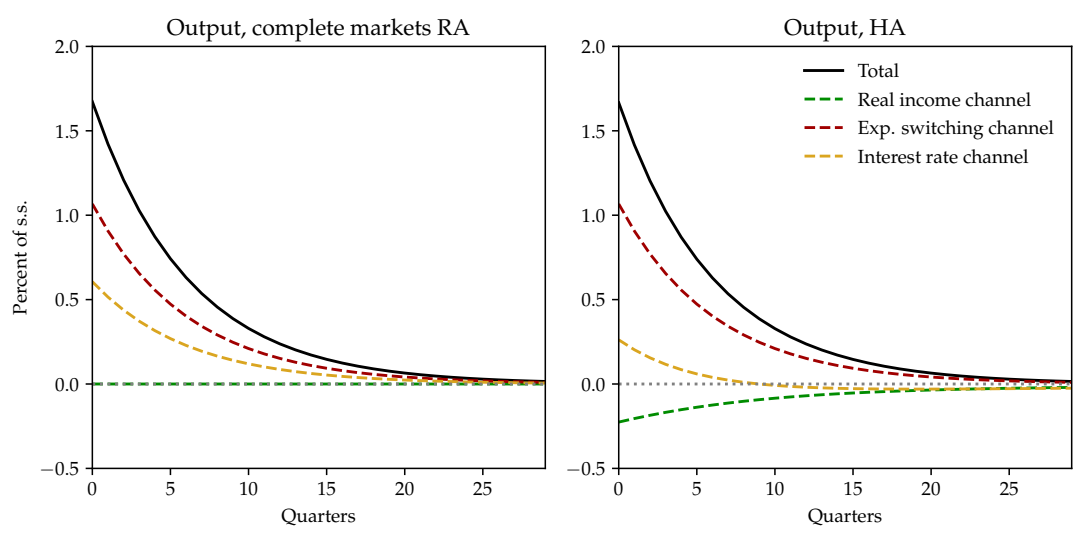

(b) Lower trade elasticity: $\chi=0.5$
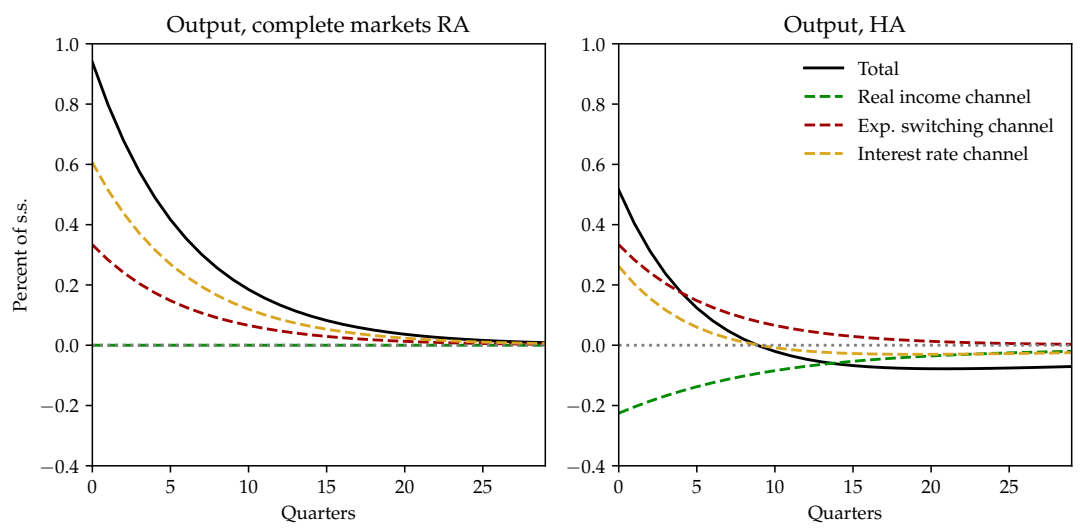

Note: impulse response to a shock to $r_{t}$ that has the same shape and magnitude as the $i_{t}^{*}$ shock in figure 1 , but with opposite sign. This leads to the same real exchange rate path as in the right panel of that figure. The decomposition follows equation (38).

no longer undoes their negative influence on output. Overall, the response of output is below that of the RA model everywhere, consistent with proposition 6.

\subsection{Stealing demand from the future through current account deficits}

An intriguing aspect of the bottom right panel of figure 6 is that the output response in the HA model turns negative after 9 quarters. In other words, monetary stimulus successfully raises aggregate demand for a few quarters, but at the cost of lowering it afterward. It "steals" demand from the future.

What explains this pattern? As discussed above, when $\chi<2-\alpha$, monetary stimulus generates a current account deficit: agents borrow from abroad, both to finance higher spending today, spurred by the low rates, and to smooth the real income losses from 
higher import prices. These current account deficits accumulate into a negative net foreign asset position over time, which remains even after the interest rate and exchange rate have converged most of the way back to steady state. To rebalance the current account, agents cut back on spending, causing a downturn in aggregate demand.

The following proposition derives a simple expression for the present value of the consumption adjustment needed to close a given net foreign asset position $d$ nfa $_{t}$.

Proposition 7. If the real exchange rate is at steady state from date $t+1$ onward $\left(d Q_{t+s}=0\right.$ for $s \geq 1$ ), the date-t present value of consumption and output is given by

$$
\sum_{s=1}^{\infty}\left(1+r_{s s}\right)^{-s} d C_{t+s}=\frac{1}{\alpha} d \mathrm{nfa}_{t} \quad \sum_{s=1}^{\infty}\left(1+r_{s s}\right)^{-s} d Y_{t+s}=\frac{1-\alpha}{\alpha} d \mathrm{nfa}_{t}
$$

Intuitively, in present value terms, any negative net foreign asset position will eventually be repaid. If there is no depreciation, this must involve a recession. Proposition 7 shows that the more closed the economy (the smaller $\alpha$ ), the larger the reduction of spending and output required for repayment, since most of the reduced spending falls on home goods, which does not contribute to the international adjustment. ${ }^{33}$

Our "stealing demand from the future" effect is a close cousin to the "limited ammunition" effect in closed-economy models that has been recently described by McKay and Wieland (2019), Caballero and Simsek (2020) and Mian, Straub and Sufi (2020). There is one crucial difference, however. In our open economy setting, the effect of monetary policy can be so weak that the present value of the output response to monetary stimulus, $P V(d \mathbf{Y})$, is negative. Appendix B.6 shows that this happens in our model when $\chi<1-\alpha$.

\section{Quantitative model}

We have shown that the extent to which heterogeneity matters for the effects of exchange rates or monetary policy depends on the level of the trade elasticity $\chi$. We derived these results under the standard assumption of static CES demand, for which $\chi$ is a constant structural parameter. Yet a host of empirical evidence suggests that the response of the trade balance to exchange rate shocks takes time to play out and depends on the nature of the shock, notably on agents' expectations of its persistence (e.g. Ruhl 2008, Fitzgerald and Haller 2018). For transitory shocks to exchange rates, the elasticity can be close to 0 in the short run (e.g. Hooper, Johnson and Marquez 2000); for more permanent shocks,

\footnotetext{
${ }^{33}$ See Krugman (1987) for an earlier articulation of this point. Of course, a less open economy is less likely to accumulate a large negative NFA in the first place.
} 
such as tariff changes, it can be 4 or more in the long run (e.g. Caliendo and Parro 2015). Any plausible quantification exercise needs to confront this evidence.

In this section, we develop a quantitative version of the benchmark model studied so far. To this benchmark, we add a stylized model of delayed substitution, which exhibits shock-dependent and time-varying elasticities of imports and exports to movements in relative prices (a "J curve"). The model's aggregate dynamics are similar to those of the richer models in Ruhl (2008), Drozd and Nosal (2012) and Alessandria and Choi (2019), but it abstracts away from the behavior of firms and focuses directly on that of of households. In doing so, it captures the essence of these theories in reduced form, and is straightforward to integrate into broader general equilibrium environments, such as that of our heterogeneous-agent model. ${ }^{34}$

In addition to delayed substitution, our quantitative model allows for price rigidities on top of wage rigidity (and hence intermediate degrees of exchange rate pass-through), non-homotheticities in consumption, currency mismatch in balance sheets, and a standard Taylor rule for monetary policy.

\subsection{Additional model elements}

We next introduce our new model elements.

Non-homothetic preferences. Cravino and Levchenko (2017) document that, in Mexico, households at the bottom of the income distribution consume a larger share of imported goods than households at the top, implying that they experience larger declines in real income during a depreciation. ${ }^{35}$ Since poor households typically have higher MPCs, accounting for this fact could magnify the importance of the real income channel. To allow for this possibility, we follow Carroll and Hur (2020) and Fanelli and Straub (2020) and assume agents consume a Stone-Geary CES bundle, with a positive subsistence need $\underline{\underline{c}}$ for imported tradables, ${ }^{36}$

$$
c=\left[\alpha^{1 / \eta}\left(c_{F}-\underline{c}\right)^{(\eta-1) / \eta}+(1-\alpha)^{1 / \eta} c_{H}^{(\eta-1) / \eta}\right]^{\eta /(\eta-1)}
$$

Monetary policy. Galí and Monacelli (2005) show that, in their framework, optimal

\footnotetext{
${ }^{34}$ See Arkolakis, Eaton and Kortum (2012) and Drozd, Kolbin and Nosal (2021) for alternative reducedform models that share the same objective.

${ }^{35}$ The importance of this phenomenon in other countries is subject to an empirical debate. Borusyak and Jaravel (2018) argue that the share of imports in consumption baskets is flat across the income distribution in the United States. Bems and di Giovanni (2016) argue that the fall in aggregate income during the 2008 crisis in Latvia caused consumers to shift towards lower-quality, domestically produced goods.

${ }^{36}$ Appendix C.1 describes how to modify our solution method to incorporate this form of non-homothetic demand.
} 
policy targets producer-price-index (PPI) based inflation. We replace the constant- $r$ monetary rule in the previous sections by the PPI inflation based Taylor rule (20).

Sticky prices and imperfect exchange rate pass-through. We allow for price stickiness in domestic prices, modeled a la Calvo with a price stickiness coefficient of $\theta_{H}$. This leads to a Phillips curve for inflation in domestic prices $P_{H t}$ of

$$
\pi_{H t}=\kappa_{H}\left(\mu \frac{W_{t}}{Z_{t} P_{H t}}-1\right)+\frac{1}{1+r} \mathbb{E}_{t}\left[\pi_{H, t+1}\right]
$$

with $\kappa_{H}=\left(1-\theta_{H}\right)\left(1-\frac{1}{1+r} \theta_{H}\right) / \theta_{H}$.

We also allow for imperfect pass-through of the exchange rate into import and export prices. To model imperfect pass-through to import prices, we assume that foreign exporters produce differentiated goods a flat cost of $\mathcal{E}_{t}$ per unit and sell them domestically at a sticky price $P_{F t}$. The elasticity of substitution between these varieties is $\mu_{F} /\left(\mu_{F}-1\right)$. This formulation leads to a Phillips curve for imported goods $P_{F t}$ of

$$
\pi_{F t}=\kappa_{F}\left(\mu_{F} \frac{\mathcal{E}_{t}}{P_{F t}}-1\right)+\frac{1}{1+r} \mathbb{E}_{t}\left[\pi_{F, t+1}\right]
$$

with $\kappa_{F}=\left(1-\theta_{F}\right)\left(1-\frac{1}{1+r} \theta_{F}\right) / \theta_{F}$. We make the same assumption for home exporters to model imperfect pass-through to export prices. Then, inflation in the price $P_{H, t}^{*}$ of home goods that foreigners see, expressed in their currency, is

$$
\pi_{H t}^{*}=\kappa_{H^{*}}\left(\mu_{H^{*}} \frac{P_{H t}}{\mathcal{E}_{t} P_{H t}^{*}}-1\right)+\frac{1}{1+r} \mathbb{E}_{t}\left[\pi_{H, t+1}^{*}\right]
$$

with $\kappa_{H^{*}}=\left(1-\theta_{H^{*}}\right)\left(1-\frac{1}{1+r} \theta_{H^{*}}\right) / \theta_{H^{*}}$. Domestic equity earns the dividends of both home producers and home exporters.

Delayed substitution. We introduce delayed substitution by modifying the household problem. Instead of being able to flexibly adjust their relative consumption of different countries' goods in each period, we now assume that households can only do so with a certain probability $1-\theta$. With probability $\theta$, they are forced to keep the ratio of each country's good to total consumption constant, although they can still adjust overall expenditure.

We obtain general results for this delayed substitution model in appendix C.2. In our problem, this model generates first-order dynamics for the target ratios $\hat{x}_{H t}$ and $\hat{x}_{H t}^{*}$, for households who can adjust, of domestic and foreign home good consumption to overall 
consumption: ${ }^{37}$

$$
\begin{aligned}
& d \log \hat{x}_{H t}=-(1-\beta \theta) \eta d \log \frac{P_{H t}}{P_{t}}+\beta \theta d \log \hat{x}_{H t+1} \\
& d \log \hat{x}_{H t}^{*}=-(1-\beta \theta) \gamma d \log \frac{P_{H t}}{\mathcal{E}_{t}}+\beta \theta d \log \hat{x}_{H t+1}^{*}
\end{aligned}
$$

This is similar to a Calvo model of pricesetting, but here, consumers reset their consumption bundles based on their perceptions of current and future relative prices. The aggregate ratios $C_{H t} / C_{t}$ and $C_{H t}^{*} / C^{*}$, in turn, evolve sluggishly as only a fraction $1-\theta$ adjusts each period, with dynamics described by

$$
\begin{aligned}
d \log \frac{C_{H t}}{C_{t}} & =(1-\theta) d \log \hat{x}_{H t}+\theta d \log \frac{C_{H t-1}}{C_{t-1}} \\
d \log C_{H t}^{*} & =(1-\theta) d \log \hat{x}_{H t}^{*}+\theta d \log C_{H t-1}^{*}
\end{aligned}
$$

This delivers a model in which the trade elasticity is both shock- and time-dependent. For instance, for foreign consumption $C_{H t}^{*}$ of the home good, the long-run elasticity to a permanent shock is simply $\gamma$. By constrast, the short-run elasticity to the same permanent shock is lower, at $\gamma(1-\theta)$, since it takes time for consumers to adjust. Finally, the shortrun elasticity to a one-time shock is even lower, at $\gamma(1-\theta)(1-\beta \theta)$, since even those who change their bundles choose to adjust little, as they anticipate wanting to adjust back in the other direction after the shock has passed.

\subsection{Calibration}

Aggregate calibration. We calibrate the model at a quarterly frequency. Our aggregate calibration is standard. Our goal is to capture the essential features of a typical Latin American economy such as Mexico. Table 1 summarizes this calibration. We assume discount factor heterogeneity, a standard feature in the literature to deliver a realistic level of average MPCs with a non-trivial amount of aggregate wealth. We opt for permanent heterogeneity, with a three point distribution at $\left\{\beta-\frac{\Delta}{2}, \beta, \beta+\frac{\Delta}{2}\right\}$ and a third of agents in each. We set $\beta$ to achieve an annualized real interest rate of $r=4 \%$ in steady state. We set the initial steady state net foreign asset position to 0 , with all mutual fund assets invested in domestic stocks, to avoid interactions between exchange rates and pre-existing trade deficits. We consider standard values of $\sigma=1$ for the elasticity of intertemporal

\footnotetext{
${ }^{37}$ For the heterogeneous domestic households, the simple form of (43) and (45) requires our assumption that $\sigma=1$. Otherwise, as shown in appendix C.2, there is a more complex expression for the target ratio, which can vary between heterogeneous households.
} 


\begin{tabular}{cccccc}
\hline Parameter & Benchmark model & Quantitative model & Parameter & Benchmark model & Quantitative model \\
\hline \hline$\sigma$ & 1 & 1 & $\mu$ & 1.03 & 1.028 \\
$\varphi$ & 2 & 2 & s.s. nfa & 0 & 0 \\
$\eta$ & $\frac{\{0.1,0.5,1,2-\alpha\}}{2-\alpha}$ & 4 & $\sigma_{e}$ & 0.6 & 0.6 \\
$\gamma$ & $=\eta$ & $=\eta$ & $\rho_{e}$ & 0.92 & 0.92 \\
$\theta$ & n.a. & 0.987 & $\theta_{w}$ & 0.95 & 0.95 \\
$\beta$ & 0.954 & 0.947 & $\theta_{H}$ & 0 & 0.66 \\
$\Delta$ & 0.06 & 0.067 & $\theta_{H^{*}}$ & 0 & 0.66 \\
$\alpha$ & 0.4 & 0.323 & $\theta_{F}$ & 0 & 0 \\
$c$ & 0 & 0.114 & $\phi$ & n.a. & 1.5 \\
\hline \multicolumn{5}{r}{} \\
$\quad$ Average annual MPC & 0.632 & 0.636 & Quantitative Model \\
& Std of annual MPC & 0.152 & 0.151 & 0.637 \\
& Average tradable share & 0.400 & 0.400 & 0.149 \\
& Std of tradable share & 0.042 & n.a. & 0.400 \\
& & Moment & 0.042 \\
\hline
\end{tabular}

Notes: all parameters are for the quarterly calibration, but MPCs are annual. Average and standard deviations are computed across deciles of income. $\beta$ heterogeneity is discretized with 3 points, and $\Delta$ is the spread between the highest and the lowest $\beta$. The income process is discretized with 7 points.

Table 1: Calibration

substitution, and $\varphi^{-1}=0.5$ for the Frisch elasticity of labor supply. For the elasticity of substitution across goods, we proceed as follows. Since there is limited evidence that this elasticity is different for imported vs domestic goods relative to between imported goods, we set $\gamma=\eta$. This implies that $\chi=(2-\alpha) \gamma$. In our benchmark model, we considered a range of values for $\chi$. By contrast, our quantitative model relies on delayed substitution, which we calibrate below.

MPCs. To calibrate the aggregate consumption behavior of the model, and in the absence of good disaggregated MPC evidence from Mexico, we target moments of the Peruvian MPC data from Hong (2020). Hong (2020) reports an estimated MPC at each decile of the income distribution in Peru. Table 1 reports the average and the standard deviation of MPCs from his estimation exercise. We assume an AR(1) process for log income, with a persistence of $\rho_{e}=0.92$ and a cross-sectional standard deviation of logs of $\sigma_{e}=0.60$, reflecting typical estimates. ${ }^{38}$ We set the borrowing constraint to $\underline{a}=0$. We adjust the markup $\mu$, which mostly affects the level of steady-state liquidity in the model, so as to target the average (annual) MPC, and set the discount factor spread $\Delta$ to target the standard deviation of MPCs across income deciles. This delivers $\mu=1.03$, so an average

\footnotetext{
${ }^{38}$ Since our quantitative model has subsistence needs, we make sure that our discretization procedure respects the constraint that the agent at the lowest level of income can always afford the subsistence level of consumption.
} 
Figure 7: Calibration targets and outcomes
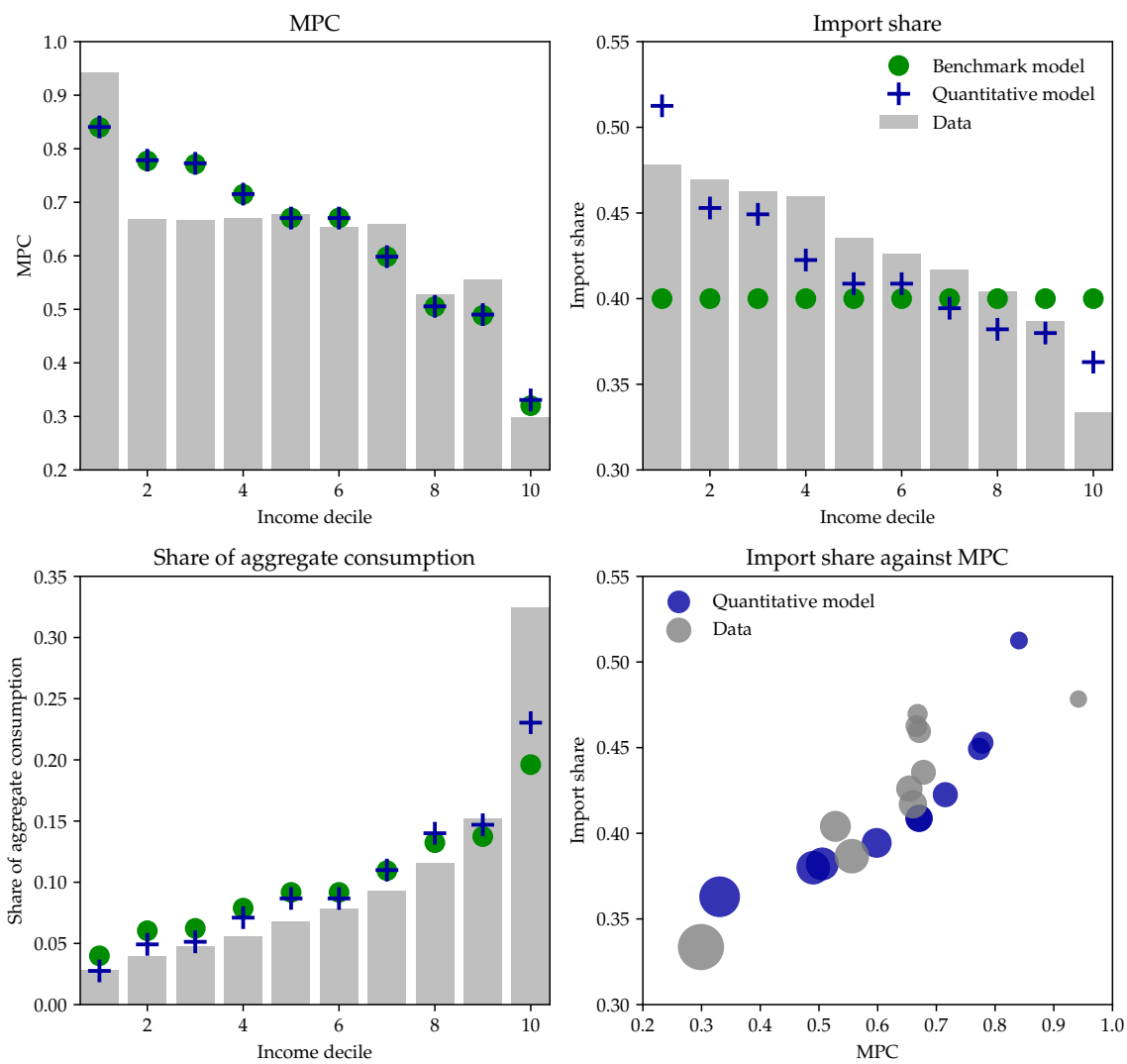

Note: calibration of the benchmark model from section 2 and of the quantitative model from section 5 . The benchmark model targets the average and standard deviation of MPC across income deciles and the average consumption share of foreign goods. The quantitative model also targets the standard deviation of consumption share of foreign good across income deciles.

wealth to GDP ratio of $73 \% .^{39}$

Foreign good shares. To calibrate the spending behavior of households across goods, we target moments of the Mexican spending survey reported in Cravino and Levchenko (2017), and summarized in Figure 7. From their data, we obtain the average tradable share at each income decile, as well as that decile's share of aggregate consumption. We then assume that the share of imports within tradables is the same across the income distribution, and compute income-specific import shares so that the economy-wide share lines up with the Mexican import/GDP ratio of 40\%, as reported in appendix table A.1. ${ }^{40}$ In the benchmark model, we set $\alpha=0.4$, while in the quantitative model we adjust $\alpha$, the asymptotic import share, and $\underline{c}$, the subsistence level on the imported good, to target an

\footnotetext{
${ }^{39}$ This compares to a Mexican wealth-GDP ratio of 350\% in 2018. Our estimate is smaller and best understood as capturing liquid wealth. We decided not to target aggregate wealth to GDP in order to hit realistic MPCs, whose importance is emphasized by our theoretical results.

${ }^{40}$ Appendix D.1 spells out a formal model with nontradables, domestically produced tradables and imported tradables, and shows that it is equivalent to our model provided that $\alpha$ is calibrated to the import/GDP ratio.
} 
average import share of 0.4 together with the standard deviation of import shares across income groups from Figure 7.

Figure 7 compares the calibration of our household model against the data by income decile. Overall our model does a very good job at capturing both the MPC variation and the import share variation across the income distribution. In particular, the spending share on imported goods is strongly declining in income, as emphasized by Cravino and Levchenko (2017).

Phillips curve parameters. Appendix C.3 provides details on our calibration of Phillips curve parameters. Among the price rigidity parameters, the Calvo coefficient for import prices $\theta_{F}$ is the most important as it directly affects the magnitude of the real income effect. We calibrate $\theta_{F}$ using evidence from the 1994 Mexican devaluation as reported by Burstein and Gopinath (2015). For this particular devaluation, we find perfect passthrough to import prices, so $\theta_{F}=0 .{ }^{41}$ By contrast, given the widespread evidence in Boz et al. (2020) for dollar pricing of exports in Latin American countries, we set $\theta_{H^{*}}>0$. We assume that the degree of price rigidity in dollar prices, like the price rigidity of domestic goods prices, corresponds to an average price reset frequency of 9 months, as is standard in the literature. This leads us to set $\theta_{H}=\theta_{H^{*}}=0.66$. We then find the wage stickiness parameter that is able to simultaneously replicate the path of home good prices after the Mexican devaluation and keep dividends reasonably acyclical in response to exchange rate shocks (see figure A.2). We set the Taylor rule coefficient on PPI inflation to $\phi=1.5$.

Delayed substitution model. We assume that our delayed substitution model applies equally to domestic and foreign households, with the same parameter $\theta$. We calibrate the model to the evidence in Boehm, Levchenko and Pandalai-Nayar (2020) (henceforth, BLP). BLP identify plausibly exogenous changes in tariffs and trace out the entire dynamic response of trade flows. To be precise, BLP observe how a country A's exports within an industry to a specific importing country $B$ respond to a persistent increase in tariffs levied by $B$ on imports from A. This elasticity captures $\gamma$, the elasticity of export demand by the rest of the world. Figure 8 plots the evidence from their estimates. The left panel shows the changes in tariffs. The right panel shows the response of trade flows.

We replicate this experiment in our model as follows. We begin by setting the long-run $\gamma$ to 4 , since this is a consensus estimate for the long-term trade elasticity (e.g. Caliendo and Parro 2015). We then interpret the tariff change in the BLP data as a change in the relative price $d \log \frac{P_{H t}}{\mathcal{E}_{t}}$, which we assume follows an AR(1) with persistence $\rho$. We choose $\rho$ to minimize the sum of squared distances to the tariff response in the left panel in figure 8, finding $\rho=0.989$ quarterly. We then feed this process into (44) and (46) and

\footnotetext{
${ }^{41}$ We recalibrate to evidence from other countries in appendix C.3.
} 
Figure 8: Calibrating delayed substitution in the quantitative model
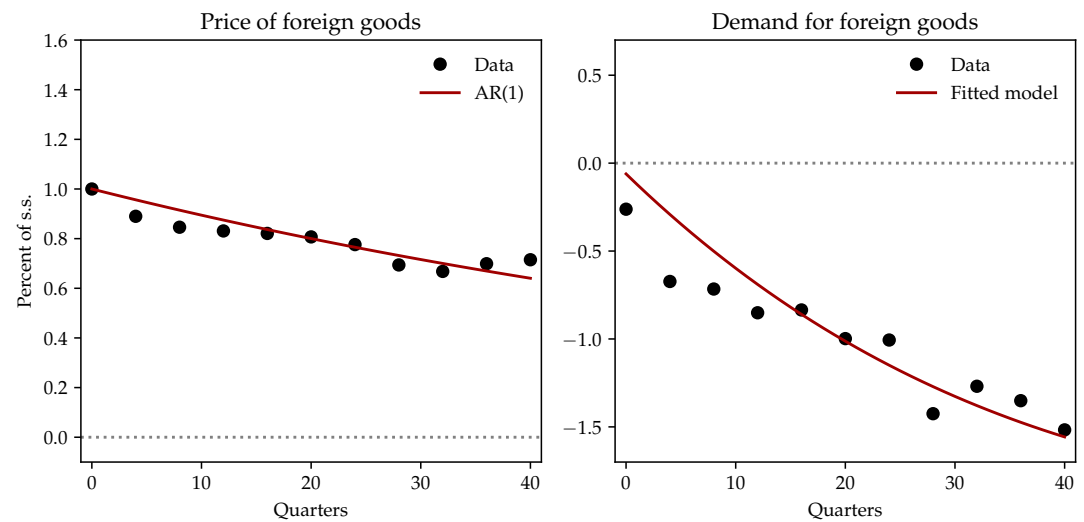

Note: calibration of delayed substitution in the quantitative model. We fit an AR(1) to the change in tariffs from Boehm, Levchenko and Pandalai-Nayar (2020) and estimate $\theta$ to minimize the sum of squared residuals between the model response and the data response of the demand for foreign goods.

calibrate $\theta$ to minimize the sum of squared distances to the estimates displayed in the right panel in figure 8 . This delivers $\theta=0.987$ quarterly. Finally, we also set $\eta=\gamma$.

\subsection{Revisiting contractionary depreciations}

We use our quantitative model to revisit the effect of exogenous depreciation shocks. Proposition 5 showed that, in the benchmark model, these shocks generate output contractions when the trade elasticity $\chi$ is small enough. Figure 9 shows that in our quantitative model (green line), depreciations are also contractionary, in spite of an active Taylor rule and a high long-run trade elasticity. This is because, in the short run, the quantitative model behaves similarly to a model with a real rate rule and a low static trade elasticity (red line). As delayed substitution kicks in, however, the quantitative model delivers a better recovery in the long term. ${ }^{42}$

\subsection{Managing contractionary depreciations}

Our analysis shows that depreciations can be contractionary because of a real income channel. We now discuss how monetary policy should respond if its goal is to stabilize output. The question is non-trivial, due to the following dilemma: should monetary policy hike interest rates to fight the depreciation, which is the root cause of the recession? Or should it stimulate by cutting interest rates, as is traditional to fight a recession? To illustrate this tradeoff, we first consider two simple policies.

\footnotetext{
${ }^{42}$ See the gap between the blue line (with delayed substitution) and the red line (without delayed substitution, but with a very low trade elasticity at all dates), which grows over time.
} 
Figure 9: Contractionary depreciations
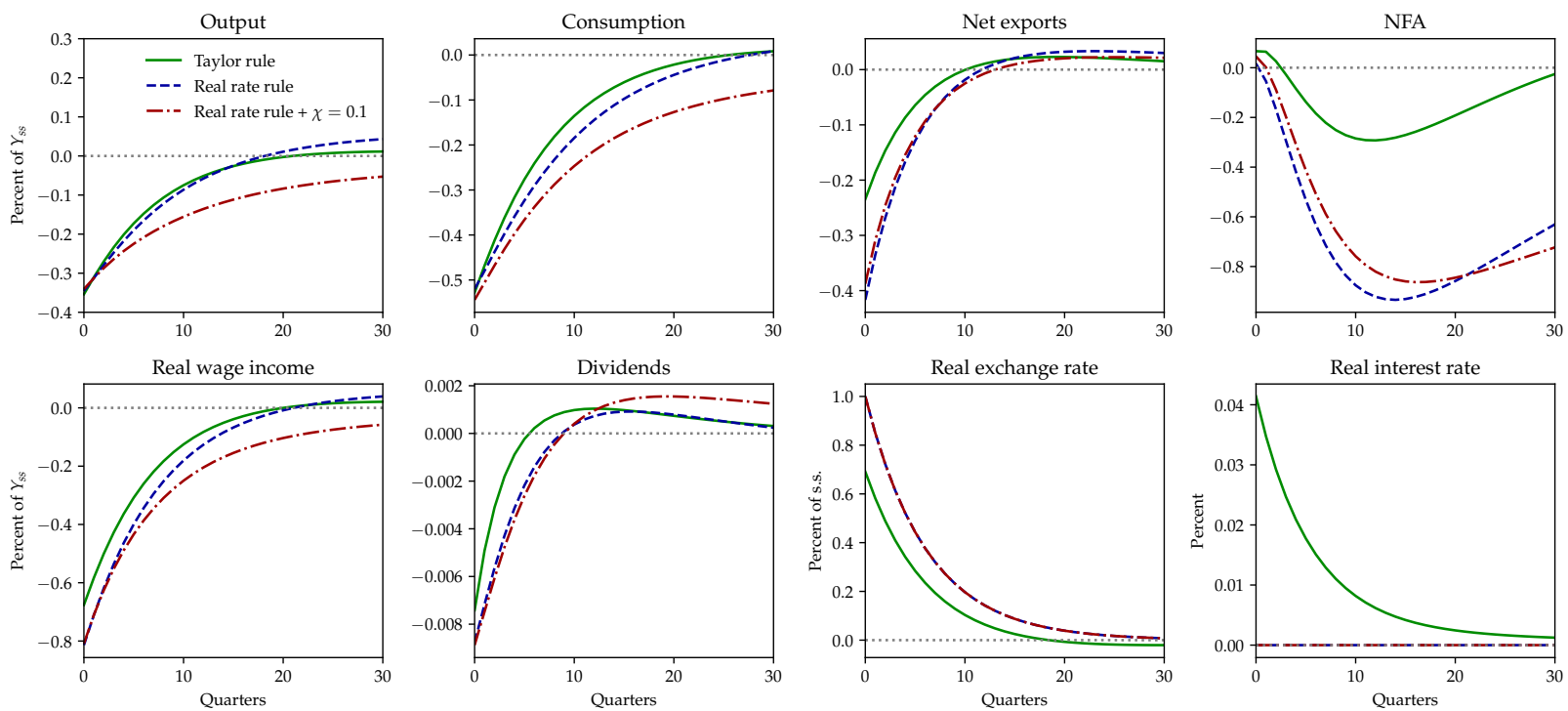

Note: impulse response in the quantitative model to the shock to $i_{t}^{*}$ displayed in Figure 1 . The model with Taylor rule is our quantitative model; the one with real rate rule is our quantitative model without the Taylor rule; the model with real rate and $\chi=0.1 \mathrm{drops}$ delayed substitution and allows households to immediately adjust their consumption baskets across countries.

Panel (a) of figure 10 shows what happens when the central bank stabilizes the exchange rate. This policy leads to an even worse recession in the short run, but it helps improve output further out. The intuition for this finding is that hiking rates replaces one evil (contractionary depreciation) with another (contractionary monetary policy), as highlighted by Gourinchas (2018) and Kalemli-Özcan (2019). For our baseline calibration, the additional contraction is short lived. The contraction is greater for less open economies.

Panel (b) of figure 10 illustrates what happens if monetary policy instead stabilizes output for four quarters. As can be seen, this is achieved with aggressive monetary easing. However, lower interest rates depreciate the exchange rate by even more. This worsens the real income channel, deteriorating the current account even further, and leading to an even greater recession after the four quarters of output stabilization.

These two scenarios suggest that the policy that fully stabilizes output in all periods is complex. The dashed blue line of panel (c) displays it. ${ }^{43}$ Here, monetary policy does not change interest rates much initially, and instead promises to hike them later on. By relying on forward guidance in this way, monetary policy not only manages to fight the depreciation: it even appreciates the exchange rate. Meanwhile, because interest rate hikes come in the future, the appreciation does not come at the cost of an immediate

\footnotetext{
${ }^{43}$ This is the unique output-stabilizing policy, which is simple to obtain with our methods by setting the path of the real interest rate as an additional unknown, and the stable output path as an additional target. Optimal policy would be very interesting to study, but is still out of reach at present.
} 


\section{Figure 10: Policies to deal with contractionary depreciations}

(a) Fighting the depreciation
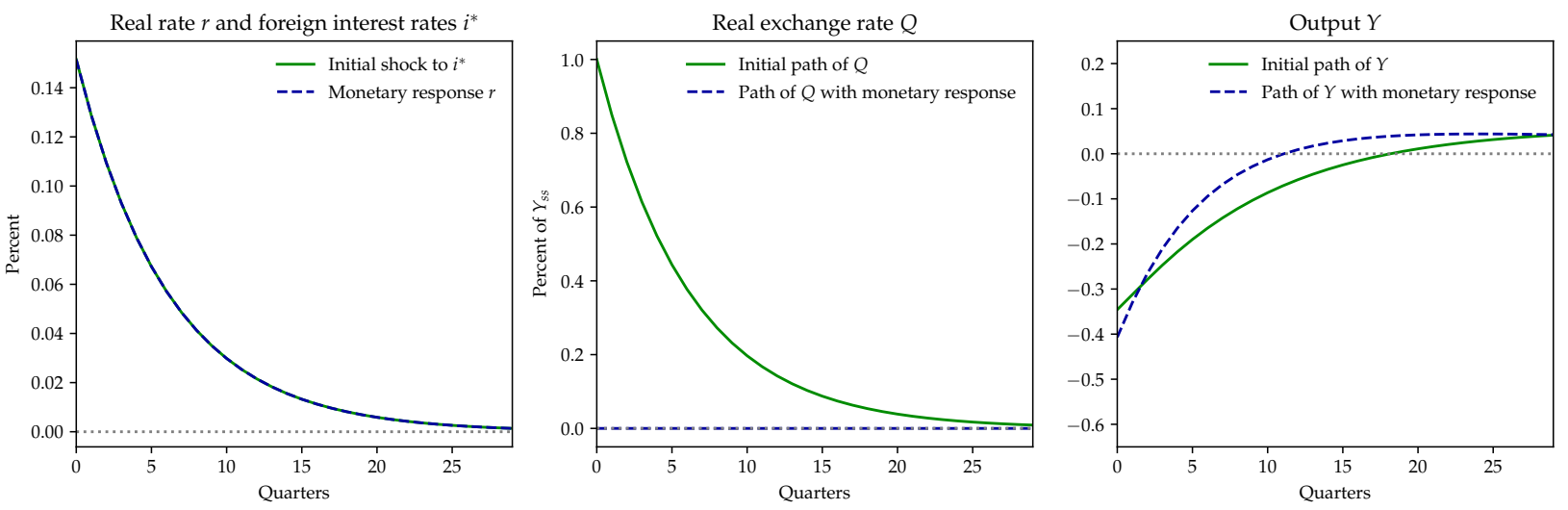

(b) Fighting the recession
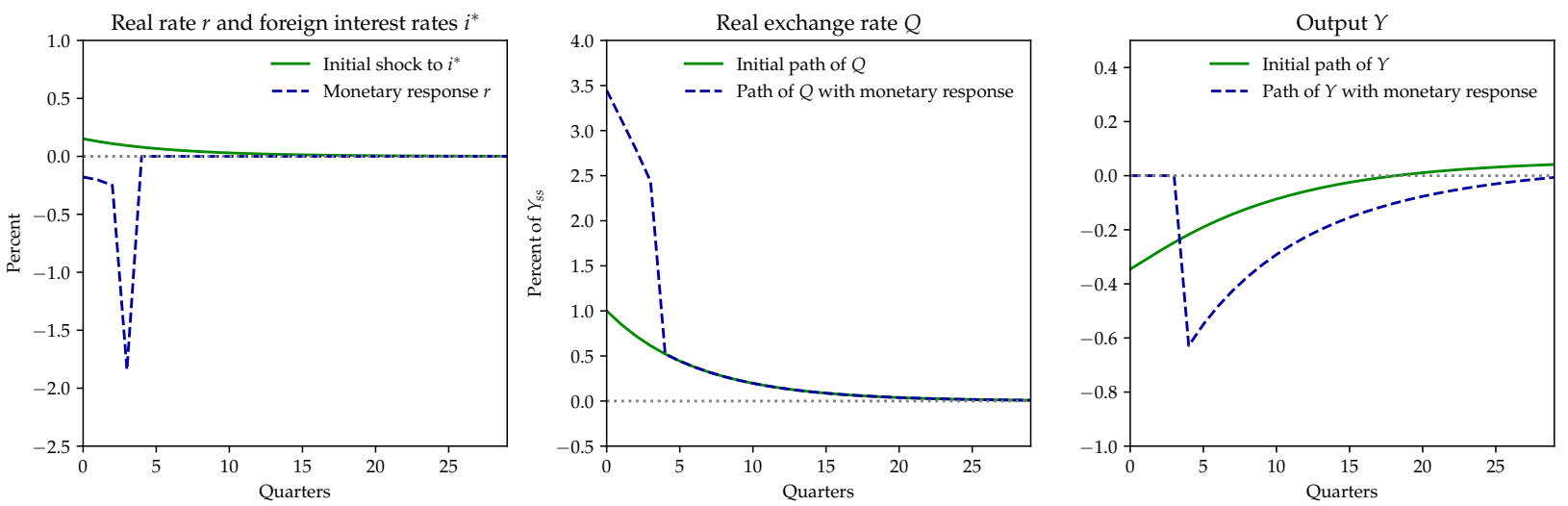

(c) Fully stabilizing output: full import pass-through (baseline $\left.\theta_{F}=0\right)$ vs limited pass-through $\left(\theta_{F}=0.7\right)$
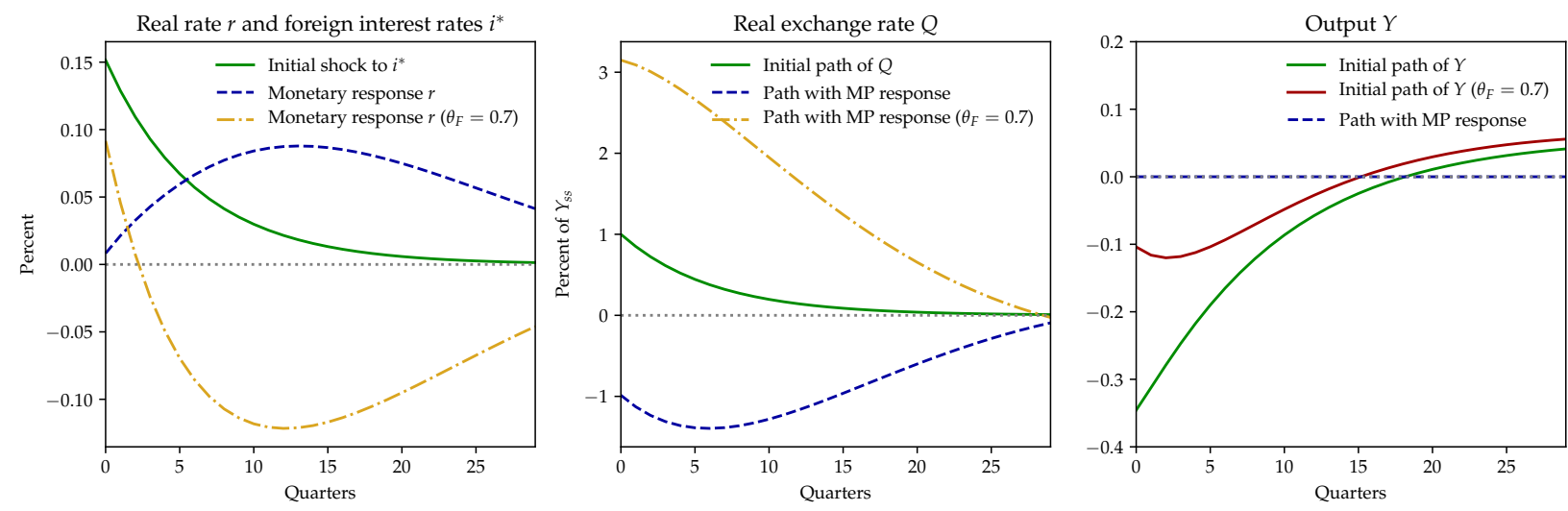

Note: impulse responses to the shock to $i_{t}^{*}$ displayed in Figure 1 with and without monetary policy. In panel (a), the green line shows the impulse without monetary policy response. The blue dotted lines show the impulse when monetary policy stabilizes the real exchange rate. In panel (b), the blue dotted lines show the impulse when monetary policy stabilizes output for 4 quarters. In panel (c), the blue dotted lines show the impulse when monetary policy stabilizes output permanently in our quantitative economy with full import pass-through. The orange dotted lines show the impulse when monetary policy stabilizes output permanent for an economy with limited import pass-through. 
recession, and interest rates increase later on when the economy, having built a positive net foreign asset position, is in a better situation to weather them.

The dashed yellow line of panel (c) shows the output-stabilizing policy in an economy with less import price pass-through. In this case, interest rates are cut for an extended period of time. The reason here is that, with less import price pass-through, the economy is more insulated from the real income channel-the recession at constant policy is smaller, as the solid red line shows-so the cost in terms of a depreciation of the exchange rate is smaller, and the benefits of monetary accommodation dominate. This starkly contrasting behavior of monetary policy with high and low import price pass-through may rationalize why, in response to hikes in foreign interest rates, emerging markets tend to hike even more, while advanced economies hike by less or even ease (e.g. Kalemli-Özcan 2019).

\subsection{When does the real income channel matter?}

Table 2 explores the role of economy-wide characteristics more systematically. For each column, we vary a single parameter in the model, and we report both the on impact response of output and its two-year cumulative response. The first column, labeled "Baseline", corresponds to our quantitative model, as displayed in the green line of Figure 9.

The second column shows that lower openness reduces the impact effect of an exchange rate shock on output. This is natural, as both the real income channel and the expenditure switching channel of exchange rates scale with $\alpha$. Notably, however, the two-year cumulative change is reduced by less: this is because the multiplier channel is larger at lower $\alpha$, as any given change in aggregate consumption has a stronger effect on domestic output in a more closed economy.

Next, we vary the steady state level of markups $\mu$ to generate a higher MPC. This amplifies the real income and multiplier channels, leading depreciations to be more contractionary. DCP, as in section 3.4, slightly softens the contraction, as do homothetic preferences and a higher short-term substitution elasticity. Less exchange rate pass-through into import prices significantly reduces the strength of the real income channel. Since it also dampens domestic expenditure switching, the output response is mostly scaled down, rather than flipping sign.

These patterns suggest that different countries are likely to respond differently to exchange rate depreciations. In appendix C.3, we calibrate the model to seven countries that have experienced depreciation episodes. We find that the degree of inferred import price pass-through is the most important cross-country determinant of the magnitude of the contraction after a depreciation. 


\begin{tabular}{ccccccccc}
\hline & Baseline & Low $\alpha$ & High MPC & Full DCP & Homothetic & High ST $\chi$ & $\theta_{F}=0.7$ & $\theta_{F}=0.9$ \\
\hline \hline$d Y_{0}$ & -0.35 & -0.26 & -0.39 & -0.31 & -0.32 & -0.30 & -0.09 & -0.02 \\
\hline$\sum_{t=0}^{7} d Y_{t}$ & -1.81 & -1.48 & -1.85 & -1.53 & -1.54 & -1.14 & -0.95 & -0.22 \\
\hline
\end{tabular}

Note: change on impact and 2-year cumulated impulse response of output to the shock to $i_{t}^{*}$ displayed in Figure 1 for various parametric assumptions. The baseline corresponds to our quantitative model. For low alpha we target a share of tradable of $20 \%$ instead of $40 \%$; for high MPC we target an average annual MPC of $80 \%$ instead of $63 \%$; for full DCP we assume no pass-through of exchange rate into export prices $\left(\theta_{H^{*}}=0.99\right)$ instead of an intermediate pass-through $\left(\theta_{H^{*}}=0.66\right)$; for homothetic we target a constant tradable share across the income distribution; for high short-term elasticity we target an elasticity of substitution between home and foreign goods of 1 after 1 year, relative to 0.3 in our baseline.

Table 2: Effects of exchange rate shock under various assumptions

\subsection{Comparison with balance sheet effects}

A well-documented feature of international investment positions is that the net foreign asset position consists of the difference between gross assets and gross liabilities that are both very large, and often differ in terms of their risk profile and currency composition (e.g. Gourinchas and Rey 2007, Lane and Shambaugh 2010). While we cannot easily capture the risk dimension, we can accommodate currency mismatch in the net foreign asset position.

We relax the assumption that the domestic mutual fund holds $100 \%$ of its assets in domestic stocks, and that the government has no gross assets or liabilities. Instead, we assume that one of these has initially borrowed in foreign currency to invest in domestic stocks, while keeping their net position unchanged. Throughout, we assume that gross foreign currency liabilities are 50\% of GDP and have an average duration of 18 quarters. Appendix C.4 provides details and shows that this calibration provides an upper bound on the magnitude of valuation effects: data from Bénétrix, Gautam, Juvenal and Schmitz (2020) show that few countries have historically had such large gross currency mismatches in their external balance sheets, and that most countries have dramatically reduced these gross mismatches in the past two decades.

In Table 3 we report how our results for the output effect of the devaluation (repeated in the first column) are altered in this scenario. We consider four cases. In the first, called "mutual fund", the gross foreign currency debt is held by the same mutual fund that holds all other financial positions. This brings down the output response by a further $0.06 \%$ on impact, and by $0.38 \%$ over 2 years. In other words, foreign currency debt causes some amplification of the contractionary effect of the depreciation, but even in this calibration to a very large net currency mismatch, this effect is small in comparison to the real income effect. This is because exposed households, who own wealth through the mutual fund, have low MPCs. 


\begin{tabular}{cccccc}
\hline & Baseline & Mutual fund & Gov, lump-sum & Gov, proportional tax & Gov, deficit-finance \\
\hline \hline$d Y_{0}$ & -0.35 & -0.41 & -0.70 & -0.63 & -0.53 \\
\hline$\sum_{t=0}^{7} d Y_{t}$ & -1.81 & -2.19 & -2.58 & -2.53 & -2.53 \\
\hline
\end{tabular}

Note: change on impact and 2-year cumulated impulse response of output to the shock to $i_{t}^{*}$ displayed in Figure 1 for different balance sheet specifications. The baseline corresponds to our quantitative model. In the second column we assume that the mutual fund holds the equivalent of $50 \%$ of annual GDP in debt denominated in foreign currency; for government with lump-sum transfers we assume that the government owes foreign currency debt and owns local currency assets, and adjusts following the depreciation using lump sum taxes to balance budget period by period; for government with proportional taxes we assume that taxes are proportional to labor income; for government deficit financed we assume that the government does not balance budget period by period but can run a deficit. In all our specifications we assume that debt takes the form of long-term bonds with average duration of 18 quarters.

Table 3: Balance sheet effects under various distribution assumptions

In the next three columns, we consider what happens if instead the foreign currency exposure is held on the government balance sheet, and then rebated to households according to various tax schemes. The first two columns report the effect of immediately taxing households lump sum or proportionally, while the third reports the effect of deficitfinancing and taxing later with a proportional tax. The amplification is largest with an immediate lump-sum tax, which is most regressive. This echoes the findings in de Ferra, Mitman and Romei (2020) and Zhou (2020), who show that that valuation effects are especially powerful at reducing output when they are concentrated on high-MPC households. Even in the most extreme case, however, the balance sheet effect is no greater than the real income effect on impact, and cumulatively over 2 years it is much smaller: an additional decline of $0.77 \%$, compared with $1.81 \%$ in our main model.

\subsection{Endogenous UIP deviations}

We finally consider an extension with endogenous UIP deviations, as in Gabaix and Maggiori (2015) and Itskhoki and Mukhin (2020). In this extension, which we spell out in appendix A.2, we assume that the mutual fund cannot directly access foreign asset markets. Instead, foreign financial intermediaries trade in both domestic and foreign bond markets, with an imperfectly elastic demand for domestic bonds. This gives the standard condition

$$
\left(1+i_{t}\right)\left(\frac{\mathcal{E}_{t}}{\mathcal{E}_{t+1}}\right)=1+i_{t}^{*}-\Gamma \cdot \mathrm{nfa}_{t}
$$

which, compared to the UIP (13), includes a UIP deviation term $\Gamma \cdot \mathrm{nfa}_{t}$. The deviation captures the idea that when the country borrows from the rest of the world, $\mathrm{nfa}_{t}<0$, it is required to pay a greater interest rate $i_{t}$.

Figure 11 simulates an $i_{t}^{*}$ shock in this extension. As before, the shock depreciates the exchange rate and leads to increased domestic interest rates $i_{t}$. As the NFA declines 
Figure 11: Depreciations with endogenous UIP deviations
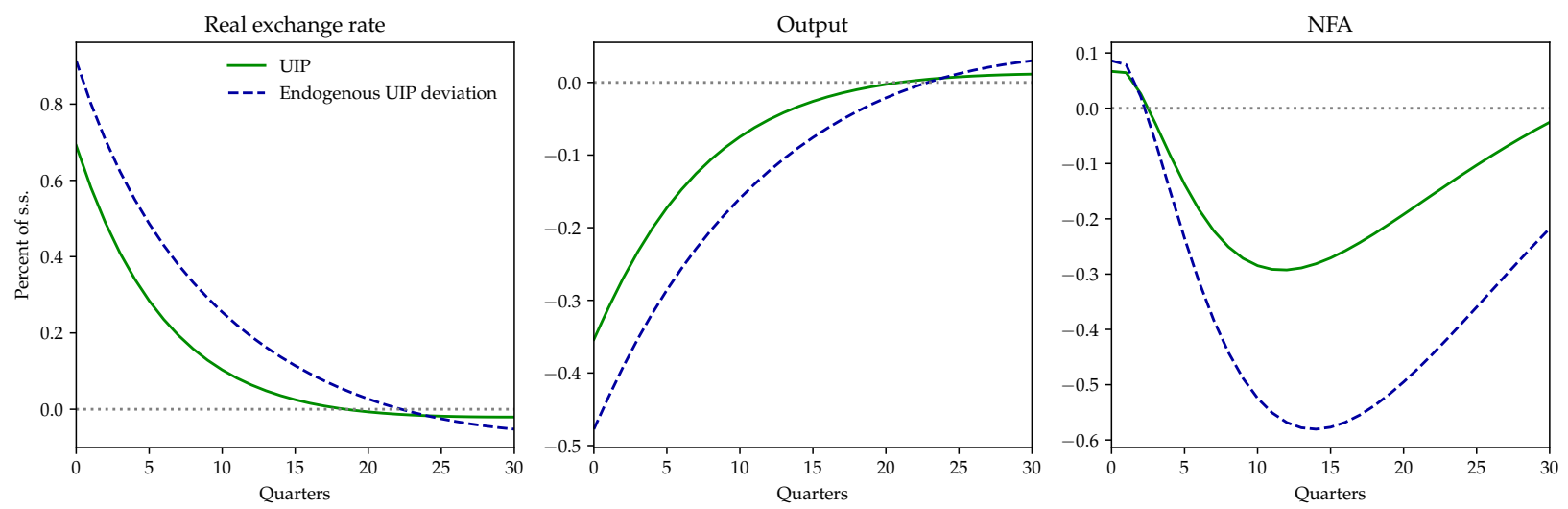

Note: impulse response to the shock to $i_{t}^{*}$ displayed in Figure 1. The green line shows the impulse in the quantitative model (UIP) while the blue dotted line shows the impulse in the model with endogenous UIP deviations.

due to greater import prices, however, foreign intermediaries require even higher domestic interest rates $i_{t}$, captured by a more positive UIP deviation $-\Gamma n f a{ }_{t}$. This amplifies the exchange rate depreciation and ultimately worsens the contractionary effects of the depreciation. Thus, endogenous UIP deviations amplify contractionary depreciations, especially in countries with high $\Gamma$. This presents another reason why interest rates may be procyclical in open economies, especially in emerging markets prone to having greater UIP deviations (higher $\Gamma$ ).

\section{Conclusion}

We introduce heterogeneous households in a New Keynesian model of a small open economy. Our model matches both the size and heterogeneity of MPCs observed in the data. We show that this new feature is critical to understand the effects of capital flows and monetary policy. When depreciations pass through quickly to consumer prices but it takes time for consumers to substitute toward domestic varieties, depreciations become contractionary. Monetary easing comes with the negative side effects of a depreciated exchange rate; it leads to current account deficits, and depresses demand in the future. Stabilization policy balances the costs of high interest rates against the costs of depreciation created by the real income channel. 


\section{References}

Aghion, Philippe, Philippe Bacchetta, and Abhijit Banerjee, "A Corporate Balance-Sheet Approach to Currency Crises," Journal of Economic Theory, November 2004, 119 (1), 6-30.

Alejandro, Carlos F. Díaz, "A Note on the Impact of Devaluation and the Redistributive Effect," Journal of Political Economy, 1963, 71 (6), 577-580.

Alessandria, George A. and Horag Choi, "The Dynamics of the U.S. Trade Balance and Real Exchange Rate: The J Curve and Trade Costs?," Working Paper 25563, National Bureau of Economic Research, February 2019.

_, Costas Arkolakis, and Kim J. Ruhl, “Firm Dynamics and Trade," Working Paper 27934, National Bureau of Economic Research, October 2020.

Alvarez, Fernando, Andrew Atkeson, and Patrick J. Kehoe, "Time-Varying Risk, Interest Rates, and Exchange Rates in General Equilibrium," Review of Economic Studies, July 2009, 76 (3), 851878.

Amiti, Mary, Oleg Itskhoki, and Jozef Konings, "Dominant Currencies: How Firms Choose Currency Invoicing and Why it Matters," Working Paper 27926, National Bureau of Economic Research, October 2020.

Arkolakis, Costas, Jonathan Eaton, and Samuel Kortum, "Staggered Adjustment and Trade Dynamics," Manuscript, July 2012.

Auclert, Adrien, "Monetary Policy and the Redistribution Channel," American Economic Review, June 2019, 109 (6), 2333-2367.

_ , Bence Bardóczy, and Matthew Rognlie, "MPCs, MPEs and Multipliers: A Trilemma for New Keynesian Models," Review of Economics and Statistics, 2021, Forthcoming.

_, _, _, and Ludwig Straub, "Using the Sequence-Space Jacobian to Solve and Estimate Heterogeneous-Agent Models," Econometrica, 2021, Forthcoming.

_ , Matthew Rognlie, and Ludwig Straub, "The Intertemporal Keynesian Cross," Working Paper 25020, National Bureau of Economic Research, September 2018.

_ , , , and _ , "Micro Jumps, Macro Humps: Monetary Policy and Business Cycles in an Estimated HANK Model," Working Paper 26647, National Bureau of Economic Research, January 2020.

Auer, Raphael, Ariel Burstein, and Sarah M. Lein, "Exchange Rates and Prices: Evidence from the 2015 Swiss Franc Appreciation," American Economic Review, February 2021, 111 (2), 652-686.

_ , _ , Katharina Erhardt, and Sarah M. Lein, "Exports and Invoicing: Evidence from the 2015 Swiss Franc Appreciation," AEA Papers and Proceedings, May 2019, 109, 533-538.

Baldwin, Richard, "Hysteresis In Import Prices: The Beachhead Effect," American Economic Review, September 1988, 78 (4), 773-785. 
- and Paul Krugman, "Persistent Trade Effects of Large Exchange Rate Shocks," Quarterly Journal of Economics, November 1989, 104 (4), 635-654.

Barbiero, Omar, “The Valuation Effects of Trade," Manuscript, December 2020.

Baxter, Marianne and Mario J. Crucini, "Business Cycles and the Asset Structure of Foreign Trade," International Economic Review, 1995, 36 (4), 821-854.

Bems, Rudolfs and Julian di Giovanni, "Income-Induced Expenditure Switching," American Economic Review, December 2016, 106 (12), 3898-3931.

Bénétrix, Agustín S., Deepali Gautam, Luciana Juvenal, and Martin Schmitz, "Cross-Border Currency Exposures: New Evidence Based on an Enhanced and Updated Dataset," SSRN Scholarly Paper No 3611655, Social Science Research Network, May 2020.

Bianchi, Javier and Guido Lorenzoni, "The Prudential Use of Capital Controls and Foreign Currency Reserves," in "Handbook of International Economics," Vol. Forthcoming, 2021.

- and Louphou Coulibaly, "Liquidity Traps, Prudential Policies and International Spillovers," Manuscipt, May 2021.

Bilbiie, Florin O., "Limited Asset Markets Participation, Monetary Policy and (inverted) Aggregate Demand Logic," Journal of Economic Theory, May 2008, 140 (1), 162-196.

_ , "The New Keynesian Cross," Journal of Monetary Economics, October 2020, 114, 90-108.

Boehm, Christoph E., Andrei A. Levchenko, and Nitya Pandalai-Nayar, "The Long and Short (Run) of Trade Elasticities," Working Paper 27064, National Bureau of Economic Research, April 2020 .

Borusyak, Kirill and Xavier Jaravel, "The Distributional Effects of Trade: Theory and Evidence from the United States," SSRN Scholarly Paper No 3269579, Social Science Research Network October 2018.

Boz, Emine, Camila Casas, Georgios Georgiadis, Gita Gopinath, Helena Le Mezo, Arnaud Mehl, and Tra Nguyen, "Patterns in Invoicing Currency in Global Trade," Working Paper 3670607, Social Science Research Network, July 2020.

Broer, Tobias, Niels-Jakob Harbo Hansen, Per Krusell, and Erik Öberg, "The New Keynesian Transmission Mechanism: A Heterogeneous-Agent Perspective," Review of Economic Studies, January 2020, 87 (1), 77-101.

Burstein, Ariel and Gita Gopinath, "Chapter 7 - International Prices and Exchange Rates," in Elhanan Helpman, Kenneth Rogoff, and Gita Gopinath, eds., Handbook of International Economics, Vol. 4, Elsevier, 2015, pp. 391-451.

_ , Martin Eichenbaum, and Sergio Rebelo, "Large Devaluations and the Real Exchange Rate," Journal of Political Economy, August 2005, 113 (4), 742-784.

Caballero, Ricardo J. and Alp Simsek, "A Model of Asset Price Spirals and Aggregate Demand Amplification of a 'COVID-19' shock," Working Paper 3576979, Social Science Research Network, 2020. 
Caliendo, Lorenzo and Fernando Parro, "Estimates of the Trade and Welfare Effects of NAFTA," Review of Economic Studies, January 2015, 82 (1), 1-44.

Carroll, Daniel R. and Sewon Hur, "On the Heterogeneous Welfare Gains and Losses from Trade," Journal of Monetary Economics, January 2020, 109, 1-16.

Cavallo, Alberto, Gita Gopinath, Brent Neiman, and Jenny Tang, "Tariff Pass-Through at the Border and at the Store: Evidence from US Trade Policy," American Economic Review: Insights, March 2021, 3 (1), 19-34.

Céspedes, Luis Felipe, Roberto Chang, and Andrés Velasco, "Balance Sheets and Exchange Rate Policy," American Economic Review, 2004, 94 (4), 1183-1193.

Chari, V. V., Patrick J. Kehoe, and Ellen R. McGrattan, "Can Sticky Price Models Generate Volatile and Persistent Real Exchange Rates?," Review of Economic Studies, July 2002, 69 (3), 533563.

Clarida, Richard H., "International Lending and Borrowing in a Stochastic, Stationary Equilibrium," International Economic Review, August 1990, 31 (3), 543-558.

Clarida, Richard, Jordi Galí, and Mark Gertler, "A Simple Framework for International Monetary Policy Analysis," Journal of Monetary Economics, July 2002, 49 (5), 879-904.

Cole, Harold L. and Maurice Obstfeld, "Commodity Trade and International Risk Sharing: How Much Do Financial Markets Matter?," Journal of Monetary Economics, August 1991, 28 (1), 3-24.

Corsetti, Giancarlo and Paolo Pesenti, "Welfare and Macroeconomic Interdependence," Quarterly Journal of Economics, May 2001, 116 (2), 421-445.

_, Luca Dedola, and Sylvain Leduc, "International Risk Sharing and the Transmission of Productivity Shocks," Review of Economic Studies, April 2008, 75 (2), 443-473.

Cravino, Javier and Andrei A. Levchenko, "The Distributional Consequences of Large Devaluations," American Economic Review, November 2017, 107 (11), 3477-3509.

Cugat, Gabriela, "Emerging Markets, Household Heterogeneity, and Exchange Rate Policy," Manuscript, October 2019.

de Ferra, Sergio, Kurt Mitman, and Federica Romei, "Household Heterogeneity and the Transmission of Foreign Shocks," Journal of International Economics, May 2020, 124, 1-18.

Doepke, Matthias and Martin Schneider, "Inflation and the Redistribution of Nominal Wealth," Journal of Political Economy, December 2006, 114 (6), 1069-1097.

Drozd, Lukasz A and Jaromir B Nosal, "Understanding International Prices: Customers as Capital," American Economic Review, February 2012, 102 (1), 364-395.

Drozd, Lukasz A., Sergey Kolbin, and Jaromir B. Nosal, "The Trade-Comovement Puzzle," American Economic Journal: Macroeconomics, April 2021, 13 (2), 78-120.

Eichenbaum, Martin S., Benjamin K. Johannsen, and Sergio T. Rebelo, "Monetary Policy and the Predictability of Nominal Exchange Rates," Review of Economic Studies, January 2021, 88 (1), 192-228. 
Fagereng, Andreas, Martin B. Holm, and Gisle J. Natvik, "MPC Heterogeneity and Household Balance Sheets," Manuscript, March 2020.

Fanelli, Sebastián and Ludwig Straub, "A Theory of Foreign Exchange Interventions," Working Paper 27872, National Bureau of Economic Research, September 2020.

Farhi, Emmanuel and Iván Werning, "Dilemma Not Trilemma? Capital Controls and Exchange Rates with Volatile Capital Flows," IMF Economic Review, November 2014, 62 (4), 569-605.

_ and _ , "Chapter 31 - Fiscal Multipliers: Liquidity Traps and Currency Unions," in Harald Uhlig and John B. Taylor, eds., Handbook of Macroeconomics, Vol. 2, Elsevier, 2016, pp. 2417-2492.

_ and _ , "Fiscal Unions," American Economic Review, December 2017, 107 (12), 3788-3834.

_ and _ , "Monetary Policy, Bounded Rationality, and Incomplete Markets," American Economic Review, November 2019, 109 (11), 3887-3928.

Feenstra, Robert C., Philip Luck, Maurice Obstfeld, and Katheryn N. Russ, "In Search of the Armington Elasticity," Review of Economics and Statistics, August 2017, 100 (1), 135-150.

Fitzgerald, Doireann and Stefanie Haller, "Exporters and Shocks," Journal of International Economics, July 2018, 113, 154-171.

Frankel, Jeffrey A., "Mundell-Fleming Lecture: Contractionary Currency Crashes in Developing Countries," IMF Staff Papers, April 2005, 52 (2), 149-192.

Gabaix, Xavier and Matteo Maggiori, “International Liquidity and Exchange Rate Dynamics," Quarterly Journal of Economics, August 2015, 130 (3), 1369-1420.

Galí, Jordi, Monetary Policy, Inflation, and the Business Cycle: An Introduction to the New Keynesian Framework, Princeton University Press, February 2008.

_ and Tommaso Monacelli, "Monetary Policy and Exchange Rate Volatility in a Small Open Economy," Review of Economic Studies, July 2005, 72 (3), 707-734.

_ , J. David López-Salido, and Javier Vallés, "Understanding the Effects of Government Spending on Consumption," Journal of the European Economic Association, 2007, 5 (1), 227-270.

Gertler, Mark, Simon Gilchrist, and Fabio M. Natalucci, "External Constraints on Monetary Policy and the Financial Accelerator," Journal of Money, Credit and Banking, 2007, 39 (2-3), 295330.

Ghironi, Fabio, "Macroeconomic Interdependence Under Incomplete Markets," Journal of International Economics, December 2006, 70 (2), 428-450.

Giagheddu, Marta, "The Distributional Implications of Fiscal Devaluations," Working Paper 3651258, Social Science Research Network, March 2020.

Gopinath, Gita, "The International Price System," Jackson Hole Symposium Proceedings, 2016.

_, Emine Boz, Camila Casas, Federico J. Díez, Pierre-Olivier Gourinchas, and Mikkel Plagborg-Møller, "Dominant Currency Paradigm," American Economic Review, March 2020, 110 (3), 677-719. 
Gourinchas, Pierre-Oliver, "Monetary Policy Transmission in Emerging Markets: An Application to Chile," Series on Central Banking Analysis and Economic Policies no. 25, 2018.

Gourinchas, Pierre-Olivier and Helene Rey, "From World Banker to World Venture Capitalist: U.S. External Adjustment and the Exorbitant Privilege," in "G7 Current Account Imbalances: Sustainability and Adjustment," University of Chicago Press, 2007, pp. 11-66.

Guo, Xing, Pablo Ottonello, and Diego Perez, "Monetary Policy and Redistribution in Open Economies," Working Paper 28213, National Bureau of Economic Research, March 2021.

Heathcote, Jonathan and Fabrizio Perri, "Financial Autarky and International Business Cycles," Journal of Monetary Economics, 2002, 49 (3), 601-627.

Hong, Seungki, "MPCs and Liquidity Constraints in Emerging Economies," Manuscript, September 2020 .

Hooper, Peter, Karen H. Johnson, and Jaime R. Marquez, Trade elasticities for the G-7 countries number no. 87. In 'Princeton Studies in International Economics.' 2000.

Ilzetzki, Ethan, Carmen M Reinhart, and Kenneth S Rogoff, "Exchange Arrangements Entering the Twenty-First Century: Which Anchor will Hold?," Quarterly Journal of Economics, May 2019, 134 (2), 599-646.

Itskhoki, Oleg, "The Story of the Real Exchange Rate," Annual Review of Economics, December 2020, forthcoming.

- and Dmitry Mukhin, "Exchange Rate Disconnect in General Equilibrium," Manuscript, November 2020.

Jappelli, Tullio and Luigi Pistaferri, "Fiscal Policy and MPC Heterogeneity," American Economic Journal: Macroeconomics, October 2014, 6 (4), 107-136.

Johnson, David S., Jonathan A. Parker, and Nicholas S. Souleles, "Household Expenditure and the Income Tax Rebates of 2001," American Economic Review, December 2006, 96 (5), 1589-1610.

Kalemli-Özcan, Ṣebnem, "U.S. Monetary Policy and International Risk Spillovers," Jackson Hole Symposium Proceedings, September 2019.

Kaplan, Greg, Benjamin Moll, and Giovanni L. Violante, "Monetary Policy According to HANK," American Economic Review, March 2018, 108 (3), 697-743.

Kekre, Rohan and Moritz Lenel, "Dollar Demand and International Risk Sharing," Manuscript, October 2020.

Krugman, Paul, "Adjustment in the World Economy," Working Paper 2424, National Bureau of Economic Research, October 1987.

- and Lance Taylor, "Contractionary Effects of Devaluation," Journal of International Economics, August 1978, 8 (3), 445-456.

Lane, Philip R. and Jay C. Shambaugh, "Financial Exchange Rates and International Currency Exposures," American Economic Review, March 2010, 100 (1), 518-540. 
McKay, Alisdair and Johannes F Wieland, "Lumpy Durable Consumption Demand and the Limited Ammunition of Monetary Policy," Working Paper 26175, National Bureau of Economic Research, August 2019.

_ , Emi Nakamura, and Jón Steinsson, "The Power of Forward Guidance Revisited," American Economic Review, October 2016, 106 (10), 3133-3158.

Mian, Atif R., Ludwig Straub, and Amir Sufi, "Indebted Demand," Working Paper 26940, National Bureau of Economic Research, April 2020.

Obstfeld, Maurice and Kenneth Rogoff, "Exchange Rate Dynamics Redux," Journal of Political Economy, June 1995, 103 (3), 624-660.

Oskolkov, Aleksei, "Exchange Rate Policy and Heterogeneity in Small Open Economies," Manuscript, March 2021.

Otten, Julia Isabelle, "Household Heterogeneity and the Adjustment to External Shocks," in "Three Essays on Household Heterogeneity and Macroeconomic Dynamics" March 2021.

Ruhl, Kim J., “The International Elasticity Puzzle," Manuscript, 2008.

Schmitt-Grohé, Stephanie and Martín Uribe, "Closing Small Open Economy Models," Journal of International Economics, October 2003, 61 (1), 163-185.

Tille, Cédric, "The Role of Consumption Substitutability in the International Transmission of Monetary Shocks," Journal of International Economics, April 2001, 53 (2), 421-444.

Uribe, Martín and Stephanie Schmitt-Grohé, Open Economy Macroeconomics, Princeton, NJ: Princeton University Press, April 2017.

Werning, Iván, "Incomplete Markets and Aggregate Demand," Working Paper 21448, National Bureau of Economic Research, August 2015.

Woodford, Michael, "Simple Analytics of the Government Expenditure Multiplier," American Economic Journal: Macroeconomics, 2011, 3 (1), 1-35.

Zhou, Haonan, "Open Economy, Redistribution, and the Aggregate Impact of External Shocks," December 2020, Presentation slides. 


\section{Online Appendix for "Exchange Rates and Monetary Policy with Heterogeneous Agents: Sizing up the Real Income Channel"}

\section{A Model details}

\section{A.1 Model setup}

Here we provide additional details on the setup of the model in section 2.

Preferences across goods. In our baseline model, consumption $c_{i t}$ of any agent $i$ living in any country aggregates their home good $H$ and a composite foreign good $F$ with elasticity $\eta$,

$$
c_{i t}=\left[(1-\alpha)^{\frac{1}{\eta}}\left(c_{i H t}\right)^{\frac{\eta-1}{\eta}}+\alpha^{\frac{1}{\eta}}\left(c_{i F t}\right)^{\frac{\eta-1}{\eta}}\right]^{\frac{\eta}{\eta-1}}
$$

home consumption aggregates goods $j$ produced at home, while foreign consumption aggregates goods produced in a continuum of countries $k$ :

$$
c_{i H t}=\left(\int_{0}^{1} c_{i H t}(j)^{\frac{\epsilon-1}{\epsilon}} d j\right)^{\frac{\epsilon}{\epsilon-1}} \quad c_{i F t}=\left(\int_{0}^{1} c_{i k t}^{\frac{\gamma-1}{\gamma}} d k\right)^{\frac{\gamma}{\gamma-1}}
$$

with $\epsilon>1, \gamma>0$ and $\eta>0$. In turn, consumption from country $k$ aggregates goods produced there with the same elasticity $\epsilon$ as that used to aggregate goods produced at home,

$$
c_{i k t}=\left(\int_{0}^{1} c_{i k t}(j)^{\frac{\epsilon-1}{\epsilon}} d j\right)^{\frac{\epsilon}{\epsilon-1}}
$$

The agent's budget constraint is

$$
\int_{0}^{1} P_{H t}(j) c_{i H t}(j) d j+\int_{0}^{1} \int_{0}^{1} P_{k t}(j) c_{i k t}(j) d j d k+a_{i t+1} \leq\left(1+r_{t}^{p}\right) a_{i t}+e_{i t} \frac{W_{t}}{P_{t}} N_{t}
$$

hence, consumer $i^{\prime}$ s demand for good $j$ in country $k$ is

$$
c_{i k t}(j)=\alpha\left(\frac{P_{k t}(j)}{P_{k t}}\right)^{-\epsilon}\left(\frac{P_{k t}}{P_{F t}}\right)^{-\gamma}\left(\frac{P_{F t}}{P_{t}}\right)^{-\eta} c_{i t}
$$

while their demand for good $j$ in the home country is

$$
c_{i H t}(j)=(1-\alpha)\left(\frac{P_{H t}(j)}{P_{H t}}\right)^{-\epsilon}\left(\frac{P_{H t}}{P_{t}}\right)^{-\eta} c_{i t}
$$

Applying this demand system to the heterogeneous agents at home, indexed by their state $(a, e)$, delivers equations (4) and (5). Applying this demand system to the representative foreign agents, noting that all foreign countries are symmetric and prices are flexible abroad so that $P_{F t}^{*}=P_{t}^{*}$, 
delivers

$$
C_{H t}^{*}=\alpha\left(\frac{P_{H t}^{*}}{P_{t}^{*}}\right)^{-\gamma} C_{t}^{*}
$$

which is equation (7).

Financial sector. Let $\mathcal{A}_{t}$ denote the nominal liabilities of the domestic mutual fund (the amount of shares it sold to households), and $i_{t}^{p}$ denote the nominal return on these assets. Let $s_{t}^{H}$ (resp. $s_{t}^{F}$ ) denote the mutual fund's holdings of domestic (resp. foreign) shares, and $B_{t}^{H}$ (resp. $B_{t}^{F}$ ) denote its holdings of domestic (resp. foreign) bonds. At the beginning of period $t$, the liquidation value of the intermediary's liabilities is equal to the liquidation value of its assets, so that

$$
\left(1+i_{t}^{p}\right) \mathcal{A}_{t-1}=\left(D_{t}+p_{t}\right) P_{t} s_{t-1}^{H}+\left(1+i_{t-1}\right) B_{t-1}^{H}+\left(D_{t}^{*}+p_{t}^{*}\right) P_{t}^{*} \mathcal{E}_{t} s_{t-1}^{F}+\left(1+i_{t-1}^{*}\right) \mathcal{E}_{t} B_{t-1}^{F}
$$

At the end of the period, the value of newly purchased assets must be

$$
\mathcal{A}_{t}=p_{t} P_{t} s_{t}^{H}+B_{t}^{H}+p_{t}^{*} P_{t}^{*} \mathcal{E}_{t} s_{t}^{F}+\mathcal{E}_{t} B_{t}^{F}
$$

Define the ex-post real return to the mutual fund as

$$
1+r_{t}^{p}=\left(1+i_{t}^{p}\right) \frac{P_{t-1}}{P_{t}}
$$

The mutual fund maximizes the (expected) real return on its liabilities, $r_{t+1}^{p}$, for all $t \geq 0$, which here is equivalent to maximizing the (expected) nominal return $i_{t+1}^{p}$. Optimality requires that the nominal returns on all assets is equalized,

$$
\frac{\left(D_{t+1}+p_{t+1}\right) P_{t+1}}{p_{t} P_{t}}=1+i_{t}=\frac{\left(D_{t+1}^{*}+p_{t+1}^{*}\right) P_{t+1}^{*} \mathcal{E}_{t+1}}{p_{t}^{*} P_{t}^{*} \mathcal{E}_{t}}=\frac{\left(1+i_{t}^{*}\right) \mathcal{E}_{t+1}}{\mathcal{E}_{t}}
$$

Combining (A.1) and (A.4), we find that, for all $t \geq 0$,

$$
1+i_{t+1}^{p}=1+i_{t}
$$

Further define the ex-ante real risk free rate as

$$
1+r_{t} \equiv\left(1+i_{t}\right) \frac{P_{t}}{P_{t+1}}
$$

This is equation (14). Using the definition of the real exchange rate in (6), real exchange rate depreciation between time $t-1$ and $t$ can be expressed as

$$
\frac{Q_{t}}{Q_{t-1}}=\frac{\mathcal{E}_{t}}{\mathcal{E}_{t-1}} \frac{P_{t-1}}{P_{t}}
$$

Using (A.3), (A.4), (A.6) and (A.7), together with the fact that $P_{t}^{*}=1$ always, it follows that, for all $t \geq 0$,

$$
1+r_{t+1}^{p}=1+r_{t}=\frac{D_{t+1}+p_{t+1}}{p_{t}}=\frac{\left(D_{t+1}^{*}+p_{t+1}^{*}\right) Q_{t+1}}{p_{t}^{*} Q_{t}}=\frac{\left(1+i_{t}^{*}\right) Q_{t+1}}{Q_{t}}
$$

which delivers equations (15) and (16). 
Finally, let the real asset position of the mutual fund be defined as

$$
A_{t} \equiv \frac{\mathcal{A}_{t}}{P_{t}}
$$

and define the net foreign asset position to be the difference between $A_{t}$ and the total value of assets in net supply domestically,

$$
\mathrm{nfa}_{t} \equiv A_{t}-p_{t}
$$

which is equation (17).

Using (A.9), equation (A.1) rewrites

$$
\left(1+r_{t}^{p}\right) A_{t-1}=\left(D_{t}+p_{t}\right) s_{t-1}^{H}+\left(1+i_{t-1}\right) \frac{P_{t-1}}{P_{t}} \frac{B_{t-1}^{H}}{P_{t-1}}+\left(D_{t}^{*}+p_{t}^{*}\right) Q_{t} s_{t-1}^{F}+\left(1+i_{t-1}^{*}\right) Q_{t} \frac{B_{t-1}^{F}}{P^{*}}
$$

while (A.2) rewrites

$$
A_{t}=p_{t} s_{t}^{H}+\frac{B_{t}^{H}}{P_{t}}+p_{t}^{*} Q_{t} s_{t}^{F}+Q_{t} \frac{B_{t}^{F}}{P^{*}}
$$

From (A.10), we can calculate $1+r_{0}^{p}$ given the initial mutual fund portfolio $s_{-1}^{H}, s_{-1}^{F}, \frac{B_{-1}^{H}}{P_{-1}}$ and $\frac{B_{-1}^{H}}{P^{*}}$, whose value in steady state, given (A.11), must add up to $A_{s s}$,

$$
A_{s s}=p_{s s} s_{-1}^{H}+\frac{B_{-1}^{H}}{P_{-1}}+p_{s s}^{*} Q_{s s} S_{-1}^{F}+Q_{s s} \frac{B_{-1}^{F}}{P^{*}}
$$

In our baseline calibration, we assume that the mutual fund holds all the domestic assets and no other assets, ie $s_{-1}^{H}=1$ and $\frac{B_{-1}^{H}}{P_{-1}}=s_{-1}^{F}=\frac{B_{-1}^{F}}{P^{*}}=0$. This ensures that $A_{s s}=p_{s s}$, and therefore that $\mathrm{nfa}_{-1}=0$.

Foreign agents. All foreign countries are symmetric. In each lives a representative foreign agent with utility

$$
\sum_{t=0}^{\infty}\left(\beta^{*}\right)^{t} \mathcal{B}_{t}\left\{u\left(C_{t}^{*}\right)-v\left(N_{t}^{*}\right)\right\}
$$

where $\beta^{*}$ is the foreign discount factor, and $\mathcal{B}_{t}$ is a utility modifier capturing time-varying patience for the foreign household. We assume that $\mathcal{B}_{t}$ has initial value $\mathcal{B}_{-1}=1$, is nonnegative and bounded, $\mathcal{B}_{t} \in(0, \bar{B})$ for $\bar{B}>0$, and reverts to 1 in the long run: $\lim _{t \rightarrow \infty} \mathcal{B}_{t}=1$.

Foreign countries produce their own good under constant returns to scale with production function

$$
Y_{t}^{*}=Z^{*} N_{t}^{*}
$$

Prices and wages are flexible abroad, so that

$$
P_{t}^{*}=\mu W_{t}^{*}
$$

The home country is infinitesimal, so that market clearing for the composite foreign good is

$$
C_{t}^{*}=Y_{t}^{*}
$$


The first order conditions for a representative foreign agent are

$$
\frac{v^{\prime}\left(N_{t}^{*}\right)}{u^{\prime}\left(C_{t}^{*}\right)}=\frac{W_{t}^{*}}{P_{t}^{*}}
$$

and

$$
\mathcal{B}_{t}\left(C_{t}^{*}\right)^{-\sigma}=\beta^{*}\left(1+r_{t}^{*}\right) \mathcal{B}_{t+1}\left(C_{t+1}^{*}\right)^{-\sigma}
$$

where $r_{t}^{*}$ denotes the foreign interest rate. It follows that the world equilibrium features a constant level of consumption $C^{*}$ (and output $Y^{*}=C^{*}$ ) given by

$$
\frac{v^{\prime}\left(C^{*} / Z^{*}\right)}{u^{\prime}\left(C^{*}\right)}=\frac{1}{\mu}
$$

and that the real interest rate $r_{t}^{*}$ is given by (A.13) when $C_{t}^{*}=C_{t+1}^{*}=C^{*}$. The central bank targets a constant price index $P^{*}$, which it achieves by setting the foreign interest rate according to pricelevel targeting rule with the natural rate $r_{t}^{*}$ as an intercept, $i_{t}^{*}=r_{t}^{*}+\phi \log \left(P_{t}^{*} / P^{*}\right)$. In equilibrium, the foreign nominal and real interest rates are equal, and relate to the discount factor shocks $\mathcal{B}_{t}$ according to

$$
1+i_{t}^{*}=1+r_{t}^{*}=\frac{1}{\beta^{*}} \frac{\mathcal{B}_{t}}{\mathcal{B}_{t+1}}
$$

The primitive shocks in our economy are the sequence of $\mathcal{B}_{t}$ 's. Alternatively, given (A.14), we can construct this sequence for a given exogenous sequence of foreign interest rates $i_{t}^{* \prime} s$ and the fact that $\lim \mathcal{B}_{t}=1$, from

$$
\mathcal{B}_{t}=\prod_{s \geq t}\left(\frac{1+i_{s}^{*}}{1 / \beta^{*}}\right)
$$

so that high $\mathcal{B}_{t}$ corresponds to high current or future foreign interest rate $i_{t}^{*}$ relative to the steady state foreign interest rate $1 / \beta^{*}$.

\section{A.2 Version of the model with UIP deviations}

We consider a version of our model in which we allow for deviations in the UIP condition. In particular, we assume that mutual funds cannot directly hold positions in foreign bonds. Instead, there exist foreign intermediaries that can trade in both foreign and domestic bond markets. Denote the end-of-period positions of these intermediaries by $b_{t}^{I}$. We assume that foreign intermediaries have an imperfectly elastic demand for domestic bonds, that is,

$$
b_{t}^{I}=\frac{1}{\Gamma}\left[\left(1+i_{t}\right)\left(\frac{\mathcal{E}_{t}}{\mathcal{E}_{t+1}}\right)-\left(1+i_{t}^{*}\right)\right]
$$

Such imperfect elasticity can be microfounded by assuming that there is only a limited number of foreign intermediaries (of similar measure as the small open economy itself) and that foreign intermediaries face limited commitment (Gabaix and Maggiori 2015), risk (Itskhoki and Mukhin 2020) or adjustment costs (Alvarez, Atkeson and Kehoe 2009, Fanelli and Straub 2020). These microfoundations are identical for our purposes.

In addition to foreign intermediaries, we also allow for noise traders with exogenous demand $\xi_{t}$ for domestic bonds as in Gabaix and Maggiori (2015) and Itskhoki and Mukhin (2020). Together, foreign intermediaries and noise traders hold the inverse of the country's net foreign asset 
position,

$$
b_{t}^{I}+\xi_{t}=-\mathrm{nfa}_{t}
$$

Rearranging, this implies that the UIP condition (13) no longer holds whenever $\Gamma>0$

$$
\left(1+i_{t}\right)\left(\frac{\mathcal{E}_{t}}{\mathcal{E}_{t+1}}\right)=1+i_{t}^{*}-\Gamma\left(\xi_{t}+\mathrm{nfa}_{t}\right)
$$

The dependence on the NFA in (A.15) captures the idea that the country has to pay a premium when it is a net borrower nfa $t<0$, in terms of a greater interest rate $i_{t}$. The dependence on $\xi_{t}$ captures the idea that noise shocks can also move exchange rates. ${ }^{44}$

In the limit where $\Gamma \rightarrow 0$, we recover the UIP condition (13). On the other hand if, as in Itskhoki and Mukhin (2020), we simultaneously assume $\Gamma \rightarrow 0$ but $\Gamma \xi_{t} \not \rightarrow 0$, we obtain a version of (A.15) with exogenous UIP shocks

$$
\left(1+i_{t}\right)\left(\frac{\mathcal{E}_{t}}{\mathcal{E}_{t+1}}\right)=1+i_{t}^{*}-\Gamma \xi_{t}
$$

Observe that those shocks enter in exactly the same way as the world interest rate shocks $i_{t}^{*}$ that we introduced in section 2. In that sense, our analysis for $i_{t}^{*}$ shocks carries over to exogenous UIP shocks, by simply redefining $i_{t}^{*} \equiv i_{t}^{*}-\Gamma \xi_{t}$.

We study the effects of endogenous UIP deviations (A.15) with $\xi_{t}=0$ in section 5.7.

\section{A.3 Current account identity}

Start by aggregating up household budgets in equation (1), using $\mathbb{E} e_{i t}=1$,

$$
\frac{P_{F t}}{P_{t}} C_{F t}+\frac{P_{H t}}{P_{t}} C_{H t}+A_{t}=\left(1+r_{t}^{p}\right) A_{t-1}+w_{t} N_{t}
$$

Use the definition of the NFA (17), noting that we can always write the aggregate expost return as

$$
\begin{aligned}
\left(1+r_{t}^{p}\right) A_{t-1} & =\left(1+r_{t-1}\right) A_{t-1}+\left(r_{t}^{p}-r_{t-1}\right) A_{t-1} \\
& =\left(1+r_{t-1}\right)\left(p_{t-1}+\mathrm{nfa}_{t-1}\right)+\left(r_{t}^{p}-r_{t-1}\right) A_{t-1} \\
& =D_{t}+p_{t}+\left(1+r_{t-1}\right) \mathrm{nfa}_{t-1}+\left(r_{t}^{p}-r_{t-1}\right) A_{t-1}
\end{aligned}
$$

to obtain

$$
\frac{P_{F t}}{P_{t}} C_{F t}+\frac{P_{H t}}{P_{t}} C_{H t}+p_{t}+\mathrm{nfa}_{t}=D_{t}+p_{t}+\left(1+r_{t-1}\right) \mathrm{nfa}_{t-1}+\left(r_{t}^{p}-r_{t-1}\right) A_{t-1}+w_{t} N_{t}
$$

Substitute in the value of dividends $D_{t}$ in (12),

$$
\underbrace{\frac{P_{F t}}{P_{t}} C_{F t}+\frac{P_{H t}}{P_{t}} C_{H t}}_{\equiv C_{t}}+\text { nfa }_{t}=\frac{P_{H t}}{P_{t}} \underbrace{\left(C_{H t}+C_{H t}^{*}\right)}_{\equiv Y_{t}}+\left(1+r_{t-1}\right) \mathrm{nfa}_{t-1}+\left(r_{t}^{p}-r_{t-1}\right) A_{t-1}
$$

\footnotetext{
${ }^{44}$ An alternative way to think of noise shocks is as movements in risk premia.
} 
Hence,

$$
\mathrm{nfa}_{t}-\mathrm{nfa}_{t-1}=\underbrace{\frac{P_{H t}}{P_{t}} Y_{t}-C_{t}}_{N X_{t}}+r_{t-1} \mathrm{nfa}_{t-1}+\left(r_{t}^{p}-r_{t-1}\right) A_{t-1}
$$

which is the current account identity. Note that we have defined net exports $N X_{t}$ (the trade balance) in units of the consumer price index, so that

$$
N X_{t} \equiv \frac{P_{H t}}{P_{t}} Y_{t}-C_{t}=\frac{P_{H t}}{P_{t}} C_{H t}^{*}-\frac{P_{F t}}{P_{t}} C_{F t}
$$

\section{A.4 Characterizing steady states}

Combining the goods market clearing condition (21) with the equations for demand for domestic goods (5) and (7), and the PCP price-setting condition (8), we see that domestic output is always given by

$$
Y_{t}=(1-\alpha)\left(\frac{P_{H t}}{P_{t}}\right)^{-\eta} C_{t}+\alpha\left(\frac{P_{H t}}{\mathcal{E}_{t}}\right)^{-\gamma} C^{*}
$$

Combining instead the equations for net exports (A.18) with these same equations, together with $P_{F t}=\mathcal{E}_{t}$, we see that the trade balance is always given by

$$
N X_{t}=\alpha \frac{P_{H t}}{P_{t}}\left(\frac{P_{H t}}{\mathcal{E}_{t}}\right)^{-\gamma} C^{*}-\alpha \frac{\mathcal{E}_{t}}{P_{t}}\left(\frac{\mathcal{E}_{t}}{P_{t}}\right)^{-\eta} C_{t}
$$

We next relate all relative prices in equations (A.19) and (A.20) to the real exchange rate $Q_{t}=\frac{\mathcal{E}_{t}}{P_{t}}$. Manipulating the price index equation (3), we see that $Q_{t}$ is related to the relative price of home goods $P_{H t} / P_{t}$ through

$$
1=\left[(1-\alpha)\left(\frac{P_{H t}}{P_{t}}\right)^{1-\eta}+\alpha Q_{t}^{1-\eta}\right]^{\frac{1}{1-\eta}}
$$

Denote by $p_{H}(Q)$ the mapping between $\frac{P_{H}}{P}$ and $Q$ implicit in equation (A.21). We can also rewrite (A.21) to relate the real exchange rate $Q_{t}$ to the relative price of home and foreign goods (the terms of trade) $S_{t} \equiv \mathcal{E}_{t} / P_{H t}$ via

$$
Q_{t}^{-1}=\left[(1-\alpha)\left(\left(\frac{\mathcal{E}_{t}}{P_{H t}}\right)^{-1}\right)^{1-\eta}+\alpha\right]^{\frac{1}{1-\eta}}
$$

We let $s(Q)$ denote the mapping between the terms of trade $\mathcal{E} / P_{H}$ and the real exchange rate $Q$ implicit in this equation.

Taken together, equations (A.19)-(A.22) imply that the level of the real exchange rate $Q_{t}$ and aggregate domestic spending $C_{t}$ uniquely determine the level of domestic output on the one hand,

$$
Y_{t}=(1-\alpha)\left(p_{H}\left(Q_{t}\right)\right)^{-\eta} C_{t}+\alpha\left(s\left(Q_{t}\right)\right)^{\gamma} C^{*}
$$

and the trade balance on the other,

$$
N X_{t}=\alpha p_{H}\left(Q_{t}\right)\left(p_{H}^{*}\left(Q_{t}\right)\right)^{-\gamma} C^{*}-\alpha\left(Q_{t}\right)^{1-\eta} C_{t}
$$


Steady state. Consider a steady state of our model, with a constant level of all aggregates $\left\{C, C_{H}, C_{F}, Y, A, p, D\right.$, nfa $\}$ and relative real prices $\left\{Q, P_{H} / P, W / P, r, i^{*}\right\}$, for given constant foreign discount factor shocks $\mathcal{B}$ and productivity $Z$. The real UIP condition (16) together with the foreign Euler equation (A.14) implies that the domestic real interest rate is $r=i^{*}=\left(\beta^{*}\right)^{-1}-1$. Equations (29) and (30) imply that the long-run real wage and dividends are given, respectively, by

$$
\begin{aligned}
\frac{W}{P} & =\frac{1}{\mu} \frac{P_{H}}{P} Z=\frac{1}{\mu} p_{H}(Q) Z \\
D & =\left(1-\frac{1}{\mu}\right) p_{H}(Q) Z
\end{aligned}
$$

The asset pricing equation (15) then implies that the domestic stock price is

$$
p=\frac{1}{r}\left(1-\frac{1}{\mu}\right) p_{H}(Q) Z
$$

Households accumulate aggregate assets $A$ so that the steady state net foreign asset position is

$$
\mathrm{nfa}=A-p
$$

where $A=A^{H A}\left(r, p_{H}(Q) Z\right)$ is only a function of the steady state real interest rate $r$ and real income $p_{H}(Q) Z$. Equivalently, their aggregate consumption $C$ must, on the one hand, satisfy

$$
C=C^{H A}\left(r, p_{H}(Q) Z\right)
$$

and on the other hand, satisfy equation (A.17),

$$
r \cdot \mathrm{nfa}=-N X=C-p_{H}(Q) Y
$$

Moreover, from (A.23), aggregate output must be

$$
Y=(1-\alpha)\left(p_{H}(Q)\right)^{-\eta} C+\alpha\left(p_{H}^{*}(Q)\right)^{-\gamma} C^{*}
$$

Combining (A.26) with (A.27) implies the steady state net export equation (A.24). Finally, the wage Phillips curve (18), together with the production function $Y=Z N$, implies that long-run wage (and price) inflation rate is equal to

$$
\pi_{w}=\frac{1}{1-\beta} \kappa_{w}\left(\frac{v^{\prime}(Y / Z)}{\frac{1}{\mu_{w}} \frac{1}{\mu} p_{H}(Q) Z u^{\prime}(C)}-1\right)
$$

A steady state in our model is characterized by a 4-tuple $(Y, Q, C, \mathrm{nfa})$ for output, the real exchange rate, consumption and the net foreign position, that simultaneously satisfies equations (A.25), (A.26) and (A.27). A zero-inflation steady state additionally restricts this tuple to satisfy equation (A.28) with $\pi_{w}=0$. Hence, there always is a unique no-inflation steady state.

We always start from such a steady state. We pick $\beta^{*}$ to deliver our target for the real interest rate $r$, and normalize $C^{*}=Q=1$ so that all relative prices are 1 . Then, equation (A.26) implies 
that $C=Y+r n f a$, while equation (A.27) implies that $Y=(1-\alpha) C+\alpha$, so that

$$
Y=1+\frac{1-\alpha}{\alpha} \cdot r \cdot \mathrm{nfa} \quad \text { and } \quad C=1+\frac{1}{\alpha} \cdot r \cdot \mathrm{nfa}
$$

We finally set $Z=1$ and solve for the scaling parameter in labor disutility $v^{\prime}$ such that equation (A.28) holds for these values of $Y$ and $C$, given our choice for $\mu_{w}, \mu$, and the initial steady state nfa. In our baseline calibration we set nfa $=0$, so that these normalizations imply $Y=C=1$.

Unique steady state with $Q=1$. After transitory monetary policy or foreign interest rate shocks, the model always returns to a steady state. There is a one-dimensional set of such steady states, characterized by the 4-tuples $(Y, Q, C, n f a)$ such that (A.25), (A.26) and (A.27) simultaneously hold. The unique steady state with $Q=1$ is therefore the initial steady state, which in our baseline features $Y=C=1$ and $n f a=0$.

\section{A.5 Representative-agent complete-market model}

In the representative-agent complete markets model, all agents can buy and sell Arrow-Debreu securities for each aggregate state $s^{t}$ and in each country. From an "ex-ante" perspective, before any realization of shocks, the domestic agents maximizes

$$
\sum_{t=0}^{\infty} \sum_{s^{t}} \operatorname{Pr}\left(s^{t}\right) \beta^{t}\left\{u\left(C_{t}\right)-v\left(N_{t}\right)\right\}
$$

where $C_{t}$ is the consumption basket in (2), subject to the sequence of budget constraints at each $t$,

$$
P_{t} C_{t}+\sum_{s_{t+1}} M_{t, t+1}\left(s_{t+1}\right) B_{t+1}\left(s_{t+1}\right)+\mathcal{E}_{t} \sum_{s_{t+1}} M_{t, t+1}^{*}\left(s_{t+1}\right) B_{t+1}^{*}\left(s_{t+1}\right) \leq W_{t} N_{t}+D_{t}+B_{t}+\mathcal{E}_{t} B_{t}^{*}
$$

where $B_{t+1}\left(s_{t+1}\right)$ denotes holdings of domestic Arrow securities, paying a unit of domestic currency in state $s_{t+1}, B_{t+1}^{*}\left(s_{t+1}\right)$ denotes holdings of foreign Arrow securities paying a unit of foreign currency in that state, and $M_{t, t+1}\left(s_{t+1}\right)$ (respectively $M_{t, t+1}^{*}\left(s_{t+1}\right)$ ) denotes the domestic-currency (respectively foreign-currency) price at time $t$ of these securities. The first order conditions for the choices of $B_{t+1}$ are

$$
\beta\left(\frac{C_{t+1}}{C_{t}}\right)^{-\sigma}\left(\frac{P_{t}}{P_{t+1}}\right)=M_{t, t+1}
$$

and those for the choices of $B_{t+1}^{*}$ imply

$$
\beta\left(\frac{C_{t+1}}{C_{t}}\right)^{-\sigma}\left(\frac{P_{t}}{P_{t+1}}\right)=M_{t, t+1}^{*}\left(\frac{\mathcal{E}_{t+1}}{\mathcal{E}_{t}}\right)
$$

Combining these two equations implies the standard equilibrium condition linking Arrow-Debreu state prices in different countries and exchange rates,

$$
M_{t, t+1}\left(\frac{\mathcal{E}_{t+1}}{\mathcal{E}_{t}}\right)=M_{t, t+1}^{*}
$$

In particular, since $\frac{1}{1+i_{t}}=\sum_{s_{t+1}} M_{t, t+1}\left(s_{t+1}\right)$ and $\frac{1}{1+i_{t}^{*}}=\sum_{s_{t+1}} M_{t, t+1}^{*}\left(s_{t+1}\right)$, we recover the UIP condition (13). 
The foreign agent maximizes its utility function (A.12) subject to the budget constraint

$$
P_{t}^{*} C_{t}^{*}+\sum_{s_{t+1}} M_{t, t+1}^{*}\left(s_{t+1}\right) B_{t+1}^{*}\left(s_{t+1}\right)+\frac{1}{\mathcal{E}_{t}} \sum_{s_{t+1}} M_{t, t+1}\left(s_{t+1}\right) B_{t+1}\left(s_{t+1}\right) \leq W_{t}^{*} N_{t}^{*}+D_{t}^{*}+\frac{B_{t}}{\mathcal{E}_{t}}+B_{t}^{*}
$$

That agent's first order conditions for the choices of $B_{t+1}$ are

$$
\beta^{*} \frac{\mathcal{B}_{t+1}}{\mathcal{B}_{t}}\left(\frac{C_{t+1}^{*}}{C_{t}^{*}}\right)^{-\sigma}\left(\frac{P_{t}^{*}}{P_{t+1}^{*}}\right)=M_{t, t+1}\left(\frac{\mathcal{E}_{t+1}}{\mathcal{E}_{t}}\right)
$$

with a similar equation for the choice of $B_{t+1}^{*}$. Combining (A.31) and (A.33) we obtain

$$
\beta\left(\frac{\mathcal{E}_{t+1}}{\mathcal{E}_{t}}\right)\left(\frac{C_{t+1}}{C_{t}}\right)^{-\sigma}\left(\frac{P_{t}}{P_{t+1}}\right)=\beta^{*} \frac{\mathcal{B}_{t+1}}{\mathcal{B}_{t}}\left(\frac{C_{t+1}^{*}}{C_{t}^{*}}\right)^{-\sigma}\left(\frac{P_{t}^{*}}{P_{t+1}^{*}}\right)
$$

Stationarity requires that the discount factors of of both agents are equal, $\beta=\beta^{*}$. Since, in addition, $P_{t}^{*}=P_{t+1}^{*}=1$ and $C_{t}^{*}=C_{t+1}^{*}=C^{*}$, we can rewrite equation (A.34) as

$$
\frac{\mathcal{B}_{t}}{\mathcal{B}_{t+1}}\left(\frac{Q_{t+1}}{Q_{t}}\right)\left(\frac{C_{t+1}}{C_{t}}\right)^{-\sigma}=1
$$

This equation holds in every state $s^{t}$, hence, we obtain the Backus-Smith condition modified for discount factor shocks,

$$
\frac{Q_{t}}{\mathcal{B}_{t}} C_{t}^{-\sigma}=\mathrm{cst}=C_{s s}^{-\sigma}
$$

where the last line follows from the fact that $\mathcal{B}_{-1}=Q_{-1}=1$. This is equation (23).

Finally, taking the sum of (A.31) across all states, using $\frac{1}{1+i_{t}}=\sum_{s_{t+1}} M_{t, t+1}\left(s_{t+1}\right)$ and the Fisher equation $\frac{1}{1+i_{t}} \frac{P_{t+1}}{P_{t}}=\frac{1}{1+r_{t}}$, we recover the Euler equation

$$
C_{t}^{-\sigma}=\beta\left(1+r_{t}\right) C_{t+1}^{-\sigma}
$$

which is equation (24).

Steady states. Steady states in this model are characterized by 4-tuples $(Y, Q, C, \mathrm{nfa})$ that satisfy the same equations (A.26) and (A.27) as in the representative-agent model, while equation (A.25) is replaced by the steady state version of equation (23),

$$
Q C^{-\sigma}=C_{S S}^{-\sigma}
$$

As in section A.4, there is a unique steady state with $Q=1$, and this is the initial steady state.

Equivalence to Gali-Monacelli. Here, we log-linearize the equilibrium conditions in the spirit of Galí and Monacelli (2005). Denote $b_{t} \equiv d \log \frac{\mathcal{B}_{t}}{\mathcal{B}_{s s}}, c_{t} \equiv d \log \frac{C_{t}}{C_{s s}}, q_{t} \equiv d \log \frac{Q_{t}}{Q_{s s}}, e_{t} \equiv d \log \frac{\mathcal{E}_{t}}{\mathcal{E}_{s s}}$ and so on, for log deviations of aggregate variables from their steady state. The equation for the price index (3) log-linearizes as

$$
p_{t}=\alpha p_{F t}+(1-\alpha) p_{H t}
$$


so, using that $p_{F t}=e_{t}$ and $q_{t}=e_{t}-p_{t}$, we obtain

$$
p_{H t}-p_{t}=-\frac{\alpha}{1-\alpha} q_{t}
$$

in particular, the difference between PPI inflation $\pi_{H t}=p_{H t}-p_{H t-1}$ and CPI inflation $\pi_{t}=$ $p_{t}-p_{t-1}$ is given by

$$
\pi_{H t}-\pi_{t}=-\frac{\alpha}{1-\alpha} \Delta q_{t}
$$

where $\Delta q_{t}=q_{t}-q_{t-1}$. Log-linearizing the demand equation (26), we have

$$
y_{t}=(1-\alpha)\left(\eta \frac{\alpha}{1-\alpha} q_{t}+c_{t}\right)+\alpha \gamma \frac{1}{1-\alpha} q_{t}
$$

and using (A.35), together with the definition of $\chi$ in (9), we find that output is

$$
y_{t}=\frac{\alpha}{1-\alpha}(\underbrace{(1-\alpha) \eta+\gamma}_{\chi}) q_{t}+(1-\alpha) c_{t}
$$

Log-linearizing the Euler equation (24), we obtain

$$
c_{t}=c_{t+1}-\frac{1}{\sigma}\left(i_{t}-\pi_{t+1}-\rho\right)
$$

where $\rho=-\log \beta$, while the log-linearized Backus-Smith condition (23) reads

$$
c_{t}=\frac{1}{\sigma}\left(q_{t}-b_{t}\right)
$$

Finally, to derive the Phillips curve, combine equations (18) and (11) to obtain that $\pi_{H t}=\pi_{w t}$, with

$$
\pi_{H t}=\kappa_{w}\left(\frac{v^{\prime}\left(N_{t}\right)}{\frac{Z}{\mu \mu_{w}} \frac{P_{H t}}{P_{t}} u^{\prime}\left(C_{t}\right)}-1\right)+\beta \pi_{H t+1}
$$

Log-linearizing around the steady state with zero inflation so that $\frac{Z}{\mu \mu_{w}} \frac{P_{H}}{P} \frac{u^{\prime}(C)}{v^{\prime}(N)}=1$, this results in

$$
\pi_{H t}=\kappa_{w}\left(\varphi n_{t}+\sigma c_{t}-\left(p_{H t}-p_{t}\right)\right)+\beta \pi_{t+1}
$$

Combining this equation with production (10),

$$
y_{t}=n_{t}
$$

and the expression for the relative price of home goods in (A.35), we obtain

$$
\pi_{H t}=\kappa_{w}\left(\varphi y_{t}+\sigma c_{t}+\frac{\alpha}{1-\alpha} q_{t}\right)+\beta \pi_{H t+1}
$$

This is exactly equations (32) and (33) in Gali-Monacelli (since we do not consider productivity or foreign spending shocks, and the terms of trade in their notation is $s_{t}=e_{t}-p_{H t}=q_{t}+p_{t}-p_{H t}=$ $q_{t}+\frac{\alpha}{1-\alpha} q_{t}=\frac{1}{1-\alpha} q_{t}$ ). In particular there was no loss of generality in considering sticky wages rather 
than sticky prices. The equivalence between the slopes of the Phillips curves obtains provided that we set

$$
\kappa_{w}=\frac{(1-\beta \theta)(1-\theta)}{\theta}
$$

where $\theta$ is the Calvo probability of keeping a domestic price fixed in Gali-Monacelli.

Equations (A.36), (A.37), (A.38), (A.39), and (A.40), characterize the log-linear model, delivering $\pi_{t}, \pi_{H t}, y_{t}, c_{t}, q_{t}$ as a function of the foreign preference shock $b_{t}$ for a given monetary policy rule for $i_{t}$.

Reduced-form two-equation system. To see the connection with the equations derived in Galí and Monacelli (2005), observe that we can use the Backus-Smith condition (A.39) and the market clearing condition (A.37) to solve for $c_{t}$ and $q_{t}$ as a function of $y_{t}$ and the exogenous variable $b_{t}$. This gives us

$$
\left(\begin{array}{cc}
1 & -\frac{1}{\sigma} \\
1-\alpha & \frac{\alpha}{1-\alpha} \chi
\end{array}\right)\left(\begin{array}{l}
c_{t} \\
q_{t}
\end{array}\right)=\left(\begin{array}{c}
-\frac{1}{\sigma} b_{t} \\
y_{t}
\end{array}\right)
$$

which can be inverted to read

$$
\left(\begin{array}{c}
c_{t} \\
q_{t}
\end{array}\right)=(1-\alpha) \sigma_{\alpha}\left(\begin{array}{c}
-\frac{\alpha}{1-\alpha} \frac{\chi}{\sigma} b_{t}+\frac{1}{\sigma} y_{t} \\
\frac{1-\alpha}{\sigma} b_{t}+y_{t}
\end{array}\right)
$$

where we have defined, as in in Gali-Monacelli,

$$
\sigma_{\alpha} \equiv \frac{\sigma}{1-\alpha+\alpha \omega} \quad \text { with } \quad \omega \equiv \sigma \chi-(1-\alpha)
$$

This implies that

$$
\sigma c_{t}+\frac{\alpha}{1-\alpha} q_{t}=\sigma_{\alpha}\left(y_{t}-\frac{\alpha}{\sigma} \omega b_{t}\right)
$$

Since substituting (A.36) into the Euler equation (A.38) implies

$$
\sigma \Delta c_{t+1}+\frac{\alpha}{1-\alpha} \Delta q_{t+1}=\left(i_{t}-\pi_{H t+1}-\rho\right)
$$

we have, using (A.42), that

$$
\sigma_{\alpha} \Delta y_{t+1}=i_{t}-\pi_{H t+1}-\rho+\alpha \frac{\sigma_{\alpha}}{\sigma} \omega \Delta b_{t+1}
$$

Next, substituting (A.42) into (A.40), the Phillips curve is

$$
\pi_{H t}=\kappa_{w}\left(\left(\varphi+\sigma_{\alpha}\right) y_{t}-\alpha \frac{\sigma_{\alpha}}{\sigma} \omega b_{t}\right)+\beta \pi_{H t+1}
$$

Under flexible wages, output solves

$$
\left(\varphi+\sigma_{\alpha}\right) y_{t}^{n}=\alpha \frac{\sigma_{\alpha}}{\sigma} \omega b_{t}
$$


hence, the Phillips curve is

$$
\pi_{H t}=\kappa_{w}\left(\varphi+\sigma_{\alpha}\right)\left(y_{t}-y_{t}^{n}\right)+\beta \pi_{H t+1}
$$

which is exactly equation (36) in Galí and Monacelli (2005) augmented to include foreign discount factor shocks, which affect the natural output level $y_{t}^{n}$ according to (A.44). Finally, equation (A.43) implies that, defining the natural real interest rate as

$$
r_{t}^{n} \equiv \rho+\sigma_{\alpha} \Delta y_{t+1}^{n}-\alpha \frac{\sigma_{\alpha}}{\sigma} \omega \Delta b_{t+1}
$$

the Euler equation reads

$$
\Delta y_{t+1}=\sigma_{\alpha}^{-1}\left(i_{t}-\pi_{H t+1}-r_{t}^{n}\right)
$$

which is the counterpart of equation (37) in Galí and Monacelli (2005), where the natural PPI-based real rate of interest is affected by foreign discount factor shocks per equation (A.44).

\section{A.6 Representative-agent incomplete-market model}

In the incomplete-market representative-agent model (henceforth "RA-IM"), the domestic agent again maximizes the utility function (A.30), but now only has access to nominal bonds in both countries that cannot be indexed to aggregate shocks. As in the main text, we appeal to certainty equivalence for small shocks and solve this model from an ex-post perspective. Then, the representative agent solves

$$
\sum_{t=0}^{\infty} \beta^{t}\left\{u\left(C_{t}\right)-v\left(N_{t}\right)\right\}
$$

where $C_{t}$ is the consumption basket in (2), subject to the sequence of budget constraints

$$
P_{t} C_{t}+\frac{1}{1+i_{t}} B_{t+1}+\mathcal{E}_{t} \frac{1}{1+i_{t}^{*}} B_{t+1}^{*} \leq W_{t} N_{t}+D_{t}+B_{t}+\mathcal{E}_{t} B_{t}^{*}
$$

with initial portfolio $B_{0}=B_{0}^{*}=0$. Optimality immediately implies the UIP condition (13). Defining real wealth as $a_{t} \equiv \frac{B_{t}+\mathcal{E}_{t} B_{t}^{*}}{P_{t}}$, we then have

$$
C_{t}+\frac{1}{1+i_{t}} \frac{P_{t+1}}{P_{t}} a_{t+1} \leq \frac{W_{t}}{P_{t}} N_{t}+\frac{D_{t}}{P_{t}}+a_{t}
$$

using the Fisher equation (14), this rewrites as

$$
C_{t}+\frac{1}{1+r_{t}} a_{t+1} \leq \frac{W_{t}}{P_{t}} N_{t}+\frac{D_{t}}{P_{t}}+a_{t}
$$

Iterating on this equation, which clearly holds with equality, starting from $a_{0}=0$ delivers the country's present value budget constraint,

$$
\sum_{s \geq 0} q_{s} C_{s}=\sum_{s \geq 0} q_{s}\left(\frac{W_{s}}{P_{s}} N_{s}+\frac{D_{s}}{P_{s}}\right)
$$

where $q_{s} \equiv \Pi_{u=0}^{s-1} \frac{1}{1+r_{u}}$. Finally, using (29) and (30), we obtain the incomplete-market present value budget constraint, stating that the present value of the country's consumption must be equal to 
the present value of its real income,

$$
\sum_{s \geq 0} q_{s} C_{s}=\sum_{s \geq 0} q_{s} \frac{P_{H s}}{P_{s}} Y_{s}
$$

The first order condition for the choice of consumption delivers the standard Euler equation (24), and combining the usual equations we obtain the real UIP condition (16).

Steady states. In this model, a steady state is characterized by a 4-tuple $(Y, Q, C, \mathrm{nfa})$ that simultaneously satisfies equations (A.23) and (22), together with a long-run equation for the nfa ,

$$
\mathrm{nfa}=\lim _{t \rightarrow \infty} \frac{1}{q_{t}}\left(\sum_{s=0}^{t} q_{s}\left(p_{H}\left(Q_{s}\right) Y_{s}-C_{s}\right)\right)
$$

where, from (24),

$$
C_{s}=\prod_{s \geq t}\left(\frac{1+r_{s}}{1 / \beta}\right)^{-\frac{1}{\sigma}} C
$$

and, from (16),

$$
Q_{s}=\prod_{s \geq t}\left(\frac{1+i_{s}^{*}}{1+r_{s}}\right) Q
$$

Hence, the nfa depends on the entire sequence of shocks, contrary what happens to the HA model. This reflects the non-stationarity of the model. There is still a unique equilibrium with $Q=1$, but in contrast to the HA and complete market models, in general the long level of $(Y, C$, nfa) differs from the initial steady state.

\section{A.7 Two-agent complete-market model}

For the two-agent complete-market model (henceforth "TA model"), we assume that the household side of the model consists of a share $1-\lambda$ of agents with unfettered access to financial markets, denoted by superscript $u$ (for "unconstrained"), and a share $\lambda$ of agents without any access to financial markets, denoted by superscript $c$ (for "constrained").

The consumption behavior of unconstrained agents is determined just like the behavior of the representative agent in section A.5. We again take an "ex-ante" perspective, before any realization of shocks. Unconstrained agents solve

$$
\max \sum_{t=0}^{\infty} \sum_{s^{t}} \operatorname{Pr}\left(s^{t}\right) \cdot \beta^{t}\left\{u\left(c_{t}^{u}\right)-v\left(N_{t}^{u}\right)\right\}
$$

subject to the sequence of budget constraints

$$
P_{t} c_{t}^{u}+\sum_{s_{t+1}} M_{t, t+1}\left(s_{t+1}\right) B_{t+1}\left(s_{t+1}\right)+\mathcal{E}_{t} \sum_{s_{t+1}} M_{t, t+1}^{*}\left(s_{t+1}\right) B_{t+1}^{*}\left(s_{t+1}\right) \leq W_{t} N_{t}^{u}+D_{t}+B_{t}+\mathcal{E}_{t} B_{t}^{*}
$$

As in section A.5, this determines consumption of unconstrained agents according to the BackusSmith condition (23), that is

$$
\left(c_{t}^{u}\right)^{-\sigma}=\left(c_{s s}^{u}\right)^{-\sigma} \frac{\mathcal{B}_{t}}{Q_{t}}
$$


where $c_{s S}^{u}$ denotes steady state consumption of unconstrained agents, as well as the Euler equation,

$$
\left(c_{t}^{u}\right)^{-\sigma}=\beta\left(1+r_{t}\right)\left(c_{t+1}^{u}\right)^{-\sigma}
$$

Constrained agents do not have access to financial markets. Following similar notation, they solve

$$
\max \sum_{t=0}^{\infty} \beta^{t}\left\{u\left(c_{t}^{c}\right)-v\left(N_{t}^{c}\right)\right\}
$$

subject to

$$
P_{t} c_{t}^{c} \leq W_{t} N_{t}^{c}
$$

This pins down their consumption bundle as

$$
c_{t}^{c}=\frac{W_{t}}{P_{t}} N_{t}^{c}
$$

Aggregate consumption is given by

$$
C_{t}=(1-\lambda) c_{t}^{u}+\lambda c_{t}^{c}
$$

We assume the same equal rationing among the two types of agents that we assume among heterogeneous agents in our heterogeneous agent model of section 2. Thus,

$$
N_{t}^{u}=N_{t}^{c}=N_{t}
$$

This implies that steady state consumption for the two agents is given by

$$
\begin{aligned}
c_{s S}^{u} & =\frac{1}{1-\lambda} D_{s s}+\frac{W_{s s}}{P_{s S}} N_{s s}=\frac{1-\mu^{-1}}{1-\lambda}+\frac{1}{\mu} \\
c_{S S}^{c} & =\frac{W_{s s}}{P_{S S}} N_{s S}=\frac{1}{\mu}
\end{aligned}
$$

\section{B Proofs}

\section{B.1 Proof of proposition 1}

Linearizing the goods market clearing condition (26) around the steady state with $C=Y=Q=$ $P_{H}=P_{F}=\mathcal{E}=1$, we find

$$
d Y_{t}=(1-\alpha)(-\eta)\left(d P_{H t}-d P_{t}\right)+\alpha(-\gamma)\left(d P_{H t}-d \mathcal{E}_{t}\right)+(1-\alpha) d C_{t}
$$

Linearizing the equation defining the CPI (3), we have $d P_{t}=(1-\alpha) d P_{H t}+\alpha d \mathcal{E}_{t}$. Linearizing the equation defining the real exchange rate (6), we have $d Q_{t}=d \mathcal{E}_{t}-d P_{t}$. Combining, we find

$$
d P_{H t}=\frac{d P_{t}-\alpha d \mathcal{E}_{t}}{1-\alpha}=d P_{t}-\frac{\alpha}{1-\alpha} d Q_{t}
$$


Substituting (A.56) into (A.55), we find

$$
\begin{aligned}
d Y_{t} & =\alpha \eta d Q_{t}+\frac{\alpha}{1-\alpha} \gamma d Q_{t}+(1-\alpha) d C_{t} \\
& =\frac{\alpha}{1-\alpha}(\eta(1-\alpha)+\gamma) d Q_{t}+(1-\alpha) d C_{t} \\
& =\frac{\alpha}{1-\alpha} \chi d Q_{t}+(1-\alpha) d C_{t}
\end{aligned}
$$

where $\chi$ is defined in (9). Finally, in the representative-agent model, we know from the BackusSmith condition and the assumption that $Q_{\infty}=1$ that $d C_{t}=0$. This delivers equation (28).

\section{B.2 Proof of propositions 2 and 3}

In this section, we derive the "international Keynesian Cross" in its general form (38), which nests (32), allowing for shocks to foreign and domestic interest rates, $d i_{t}^{*}$ and $d r_{t}$.

To derive (38), we start from substituting the domestic and foreign demand equations (5) and (7) into the goods market clearing condition (21), using the price-setting equation for home goods abroad (8), and aggregating up,

$$
Y_{t}=(1-\alpha)\left(\frac{P_{H t}}{P_{t}}\right)^{-\eta} \mathcal{C}_{t}\left(\left\{r_{0}^{p}, r_{s}, \frac{W_{s}}{P_{s}} N_{s}\right\}\right)+\alpha\left(\frac{P_{H t}}{\mathcal{E}_{t}}\right)^{-\gamma} C^{*}
$$

In (A.58), we have made explicit the fact that aggregate demand for consumption $C_{t}$ depends only on the initial ex-post return $r_{0}^{p}$, reflecting valuation effects, the time path of real interest rates $r_{s}$ for $s \geq 0$ set by monetary policy (since, by (15), $r_{t+1}^{p}=r_{t}$ for all $t \geq 1$ ), and the path of real wages $w_{s} N_{s}$ for $s \geq 0$. We denote this general "consumption function" by $\mathcal{C}_{t}$. Note that $\mathcal{C}_{t}$ here is a more general object compared to our usage in Section 3.2. ${ }^{45}$

Substituting these mappings into (A.58) and using the value of real labor income in (29), we have

$$
Y_{t}=(1-\alpha)\left(p_{H}\left(Q_{t}\right)\right)^{-\eta} \mathcal{C}_{t}\left(\left\{r_{0}^{p}, r_{s}, \frac{1}{\mu} p_{H}\left(Q_{s}\right) Y_{s}\right\}\right)+\alpha\left(p_{H}^{*}\left(Q_{t}\right)\right)^{-\gamma} C^{*}
$$

Moreover, the valuation equation for assets, combined with (12), implies that share prices are

$$
p_{t}=\frac{D_{t+1}+p_{t+1}}{1+r_{t}}=\operatorname{PDV}\left(\left\{r_{s},\left(1-\frac{1}{\mu}\right) p_{H}\left(Q_{s}\right) Y_{s}\right\}\right)
$$

so that the initial revaluation $r_{0}^{p}$ also only depends on the path of $r_{s}, Q_{s}$, and $Y_{s}$.

We next differentiate (A.59) around the steady state with $C=C^{*}=Y=1$, and use the fact that (A.21) and (A.22) respectively imply $\frac{d\left(P_{H t} / P_{t}\right)}{P_{H t} / P_{t}}=-\frac{\alpha}{1-\alpha} \frac{d Q_{t}}{Q_{t}}$ and $\frac{d\left(P_{H t} / \mathcal{E}_{t}\right)}{P_{H t} / \mathcal{E}_{t}}=-\frac{1}{1-\alpha} \frac{d Q_{t}}{Q_{t}}$ to find

$$
d \mathbf{Y}=(1-\alpha)\left(\eta \frac{\alpha}{1-\alpha} d \mathbf{Q}+\mathbf{C}_{v} d r_{0}^{p}+\mathbf{C}_{r} d \mathbf{r}+\mathbf{C}_{Y} \frac{1}{\mu}\left(d \mathbf{Y}-\frac{\alpha}{1-\alpha} d \mathbf{Q}\right)\right)+\frac{\alpha}{1-\alpha} \gamma d \mathbf{Q}
$$

where $\mathbf{C}_{Y}$ is the Jacobian of aggregate consumption with respect to the path of output $Y_{s}, \mathbf{C}_{r}$ is the Jacobian of aggregate consumption with respect to real interest rates $r_{s}, \mathbf{C}_{v}$ is the column vector

\footnotetext{
${ }^{45}$ For details on why a function $\mathcal{C}_{t}$ exists, see Auclert, Rognlie and Straub (2018).
} 
representing the increased spending from revaluation $r_{0}^{p}$, and from (A.60) we have

$$
d r_{0}=\mathbf{J}_{r}^{\prime} d \mathbf{r}+\left(1-\frac{1}{\mu}\right) \mathbf{J}_{d}^{\prime}\left(d \mathbf{Y}-\frac{\alpha}{1-\alpha} d \mathbf{Q}\right)
$$

where $\mathbf{J}_{r}, \mathbf{J}_{d}$ are the Jacobians of the present discounted value with respect to the discount rate $r$ and dividends, respectively. ${ }^{46}$ Substituting in these valuation effects, we have

$$
\begin{aligned}
d \mathbf{Y}= & (1-\alpha)\left(\eta \frac{\alpha}{1-\alpha} d \mathbf{Q}+\mathbf{C}_{v} \mathbf{J}_{r}^{\prime} d \mathbf{r}+\left(1-\frac{1}{\mu}\right) \mathbf{C}_{v} \mathbf{J}_{d}^{\prime} d \mathbf{Y}\right) \\
& +(1-\alpha)\left(-\left(1-\frac{1}{\mu}\right) \mathbf{C}_{v} \mathbf{J}_{d}^{\prime} \frac{\alpha}{1-\alpha} d \mathbf{Q}+\mathbf{C}_{v} d \mathbf{r}+C_{Y} \frac{1}{\mu}\left(d \mathbf{Y}-\frac{\alpha}{1-\alpha} d \mathbf{Q}\right)\right) \\
& +\frac{\alpha}{1-\alpha} \gamma d \mathbf{Q}
\end{aligned}
$$

Hence

$$
\begin{aligned}
d \mathbf{Y}= & \underbrace{(1-\alpha)\left(\mathbf{C}_{r}+\mathbf{C}_{v} \mathbf{J}_{r}^{\prime}\right) d \mathbf{r}}_{\text {intertemporal subst. + valuation }}+\underbrace{\alpha\left(\eta+\frac{\gamma}{1-\alpha}\right) d \mathbf{Q}}_{\text {expenditure switching }} \\
& -\underbrace{\alpha\left(\frac{1}{\mu} \mathbf{C}_{Y}+\left(1-\frac{1}{\mu}\right) \mathbf{C}_{v} \mathbf{J}_{d}^{\prime}\right)}_{\text {real income }} d \mathbf{Q}+\underbrace{(1-\alpha)\left(\frac{1}{\mu} \mathbf{C}_{Y}+\left(1-\frac{1}{\mu}\right) \mathbf{C}_{v} \mathbf{J}_{d}^{\prime}\right) d \mathbf{Y}}_{\text {multiplier effect }}
\end{aligned}
$$

We next define

$$
\mathbf{M} \equiv \frac{1}{\mu} \mathbf{C}_{Y}+\left(1-\frac{1}{\mu}\right) \mathbf{C}_{v} \mathbf{J}_{d}^{\prime}
$$

for the overall Jacobian of spending with respect to income $\mathbf{Y}$. In the notation of section 3.2, $\mathbf{M}$ corresponds to the Jacobian of $\mathcal{C}_{t}$ with respect to $\left\{\mathcal{Y}_{s}\right\}$. Also, define

$$
\mathbf{M}^{r} \equiv \mathbf{C}_{r}+\mathbf{C}_{v} \mathbf{J}_{r}^{\prime}
$$

for the overall Jacobian of consumption to interest rates $\mathbf{r}$. Using the expression for the trade elasticity in (9), we have that

$$
d \mathbf{Y}=\underbrace{(1-\alpha) \mathbf{M}^{r} d \mathbf{r}}_{\text {int. subst + valuation }}+\underbrace{\frac{\alpha}{1-\alpha} \chi d \mathbf{Q}}_{\text {D }+ \text { F expenditure switching }}-\underbrace{\alpha \mathbf{M}}_{\text {real income }} d \mathbf{Q}+\underbrace{(1-\alpha) \mathbf{M}}_{\text {Multiplier effect }} d \mathbf{Y}
$$

where the response of the real exchange rate is given by

$$
d Q_{t}=\sum_{s \geq t} \frac{d i_{s}^{*}-d r_{s}}{(1+r)^{s-t+1}}
$$

Equation (A.62) is the international Keynesian cross. It is a fixed point equation for the sequence of output changes $d \mathbf{Y}$. The Jacobians $\mathbf{M}^{r}$ and $\mathbf{M}$ are infinite-dimensional matrices. By construction

${ }^{46}$ These have the simple expressions $\mathbf{J}_{d}^{\prime}=\frac{r}{D}\left(1 \frac{1}{1+r}\left(\frac{1}{1+r}\right)^{2} \cdots\right)$ and $\mathbf{J}_{r}^{\prime}=-\left(\frac{1}{1+r}\left(\frac{1}{1+r}\right)^{2} \cdots\right)$. 
$\mathbf{M}^{r} d \mathbf{r}$ has finite elements. We have assumed (and numerically verified) that $\mathbf{M}$ is positive. Since the columns of $\mathbf{M}$ have a present value of 1, this implies that $\mathbf{M} d \mathbf{Y}$ are finite for any present-value summable $d \mathbf{Y}$ since

$$
|\mathbf{M} d \mathbf{Y}| \leq \mathbf{M}|d \mathbf{Y}| \leq \mathbf{q}^{\prime} \mathbf{M}|d \mathbf{Y}| \leq \mathbf{q}^{\prime}|d \mathbf{Y}| \leq \sum_{t=0}^{\infty}(1+r)^{-t}\left|d Y_{t}\right|<\infty
$$

where we defined $\mathbf{q} \equiv\left((1+r)^{-t}\right)_{t>0}$. A similar argument establishes that $\mathbf{M} d \mathbf{Q}$ has finite elements. Thus, (A.62) is well-defined.

Let

$$
\mathbf{G} \equiv(\mathbf{I}-(1-\alpha) \mathbf{M})^{-1}=I+(1-\alpha) \mathbf{M}+(1-\alpha)^{2} \mathbf{M}^{2}+\cdots
$$

which is a well-defined infinite-dimensional, non-negative, bounded matrix (as $\mathbf{M}$ is non-negative and bounded). Then, the unique bounded solution to (A.62) must satisfy

$$
\begin{aligned}
d \mathbf{Y} & =(\mathbf{I}-(1-\alpha) \mathbf{M})^{-1} \cdot\left\{(1-\alpha) \mathbf{M}^{r} d \mathbf{r}+\alpha\left(\frac{\chi}{1-\alpha} \mathbf{I}-\mathbf{M}\right) d \mathbf{Q}\right\} \\
& =(1-\alpha) \mathbf{G} \mathbf{M}^{r} d \mathbf{r}+\alpha \frac{\chi}{1-\alpha} \mathbf{G} d \mathbf{Q}-\alpha \mathbf{G} \mathbf{M} d \mathbf{Q}
\end{aligned}
$$

\section{B.3 Proof of propositions 4 and 5}

Proof of proposition 4. We start with the solution to the international Keynesian cross (A.65). Without monetary policy shocks, $d \mathbf{r}=0$, we can rewrite the solution as

$$
d \mathbf{Y}=\frac{\alpha}{1-\alpha} \mathbf{G}(\chi \mathbf{I}-(1-\alpha) \mathbf{M}) d \mathbf{Q}
$$

which simplifies to

$$
d \mathbf{Y}=\frac{\alpha}{1-\alpha} d \mathbf{Q}+\frac{\alpha}{1-\alpha}(\chi-1) \mathbf{G} d \mathbf{Q}
$$

where the first term is just the output response in the complete-market RA model when $\chi=1$. Equation (A.66) immediately proves the neutrality result for $\chi=1$. The ranking for $\chi \gtrless 1$ for depreciations $d \mathbf{Q} \geq 0$ follows from the non-negativity of $\mathbf{G}$ (which itself is a consequence of the non-negativity of $\mathbf{M}$, see our discussion around (A.64)). The ranking for appreciations $d \mathbf{Q} \leq 0$ is flipped.

To obtain the equation for the trade balance (34), we linearize equation (A.24), obtaining

$$
d N X_{t}=\alpha\left(-\frac{\alpha}{1-\alpha} d Q_{t}+\frac{\gamma}{1-\alpha} d Q_{t}\right)-\alpha\left((1-\eta) d Q_{t}+d C_{t}\right)
$$

Here, we used the facts that $d p_{H t}=-\frac{\alpha}{1-\alpha} d Q_{t}$ and $d p_{H t}^{*}=-\frac{1}{1-\alpha} d Q_{t}$. Simplifying, we find

$$
d N X_{t}=\frac{\alpha}{1-\alpha}(\chi-1) d Q_{t}-\alpha d C_{t}
$$

which is (34).

Proof of proposition 5. To derive the result on present values, denoted by $P V(\cdot)$, we first point out 
that the columns of $\mathbf{M}$ each have a present value of 1, so that

$$
P V(\mathbf{M} d \mathbf{Q})=P V(d \mathbf{Q})
$$

A direct consequence is that

$$
P V(\mathbf{G} d \mathbf{Q})=\frac{1}{\alpha} P V(d \mathbf{Q})
$$

Using this result in conjunction with (A.66), we find

$$
P V(d \mathbf{Y})=\frac{\chi-(1-\alpha)}{1-\alpha} P V(d \mathbf{Q})
$$

This shows that $P V(d \mathbf{Y})<0$ in response to a depreciation $d Q_{t} \geq 0$ (with strict inequality in at least a single period).

When is $d Y_{0}<0$, i.e. the output response to the depreciation is contractionary on impact? Again, building on (A.66), we find

$$
d Y_{0}=\frac{\alpha}{1-\alpha} d Q_{0}+\frac{\alpha}{1-\alpha}(\chi-1) \sum_{t=0}^{\infty} G_{0, t} d Q_{t}
$$

The threshold $\chi^{*}$ for $\chi$ below which $d Y_{0}$ is negative can simply be determined to be

$$
\chi^{*}=1-\frac{d Q_{0}}{\sum_{t=0}^{\infty} G_{0, t} d Q_{t}}
$$

To bound this threshold, we can use (A.64) to find that

$$
\sum_{t=0}^{\infty} G_{0, t} d Q_{t} \geq G_{0,0} d Q_{0} \geq\left(1-(1-\alpha) M_{0,0}\right)^{-1} d Q_{0}
$$

Thus,

$$
\chi^{*} \geq(1-\alpha) M_{0,0}
$$

\section{B.4 Dollar currency pricing}

In this section, we derive (36). Consider a one-time depreciation $d Q_{0}$. This affects real income in period $s$ by

$$
d\left(\frac{P_{H s}}{P_{S}} Y_{s}\right)=-\frac{\alpha}{1-\alpha} 1_{\{s=0\}} d Q_{0}+d Y_{s}
$$

The effects on labor income is then simply

$$
d\left(\frac{W_{s}}{P_{s}} N_{s}\right)=\frac{1}{\mu} d\left(\frac{P_{H s}}{P_{s}} Y_{s}\right)=-\frac{\alpha}{1-\alpha} 1_{\{s=0\}} \frac{1}{\mu} d Q_{0}+\frac{1}{\mu} d Y_{s}
$$

while the effect on dividends (12) is given by

$$
d D_{s}=-\frac{\alpha}{1-\alpha} 1_{\{s=0\}}\left(1-\frac{1}{\mu}\right) d Q_{0}+\left(1-\frac{1}{\mu}\right) d Y_{s}+\frac{\alpha}{1-\alpha} 1_{\{s=0\}} d Q_{0}
$$


where the last term captures increased markups on exports that emerge with DCP. Following the steps in section B.2, we see that, by definition of $M_{t, s}$, the total date-0 consumption response to $\left\{d Y_{s}\right\}$ is given by $\sum_{s \geq 0} M_{0, s} d Y_{s}$.

To obtain the date- 0 consumption response to $d Q_{0}$ (the real income channel at date 0 ), denote by $M P C_{i}$ agent $i$ 's date- 0 MPC out of a transitory date- 0 transfer. Note that agent $i$ 's exposure to $d Q_{0}$ depends on its initial income state $e_{i 0}$ (its share of labor income) and initial share of wealth $\frac{a_{i 0}}{A_{\mathrm{ss}}}$, multiplied by the aggregate changes in labor income and dividends respectively. We collect these terms in an object we call net exchange rate exposure $N X E_{i}$,

$$
\frac{\alpha}{1-\alpha} N X E_{i} \equiv \frac{a_{i 0}}{A_{s s}} \cdot \frac{1}{\mu} \frac{\alpha}{1-\alpha}-e_{i 0} \cdot \frac{1}{\mu} \frac{\alpha}{1-\alpha}=\left(\frac{a_{i 0}}{A_{s s}}-e_{i 0}\right) \cdot \frac{1}{\mu} \frac{\alpha}{1-\alpha}
$$

The total date- 0 consumption response is then

$$
d C_{0}=\frac{\alpha}{1-\alpha} \mathbb{E}\left[M P C_{i} \cdot N X E_{i}\right] \cdot d Q_{0}+\sum_{s \geq 0} M_{0, s} d Y_{s}
$$

Observe that net exchange rate exposures average to zero, $\mathbb{E}\left[N X E_{i}\right]=0$, so that $\mathbb{E}\left[M P C_{i} \cdot N X E_{i}\right]=$ $\operatorname{Cov}\left(M P C_{i}, N X E_{i}\right)$. Substituting $d C_{0}$ into the linearized goods market clearing condition (A.57), we find (36).

International Keynesian cross with DCP. We can also derive a version of the (generalized) international Keynesian cross (38) with DCP. The main differences with the derivation in appendix B.2 are that expenditure switching by foreign households is absent, as if $\gamma=0$, but there is an additional term entering dividends, as in (A.67),

$$
d \mathbf{D}=\frac{\alpha}{1-\alpha} \frac{1}{\mu} d \mathbf{Q}+\left(1-\frac{1}{\mu}\right) d \mathbf{Y}
$$

The change in the ex-post return at date $0,(\mathrm{~A} .61)$, then becomes

$$
d r_{0}=\mathbf{J}_{r}^{\prime} d \mathbf{r}+\mathbf{J}_{d}^{\prime}\left(\left(1-\frac{1}{\mu}\right) d \mathbf{Y}+\frac{\alpha}{1-\alpha} \frac{1}{\mu} d \mathbf{Q}\right)
$$

Following the same steps as before, we then end up at

$$
\begin{aligned}
d \mathbf{Y}= & \underbrace{(1-\alpha)\left(\mathbf{C}_{r}+\mathbf{C}_{v} \mathbf{J}_{r}^{\prime}\right) d \mathbf{r}}_{\text {intertemporal subst. + valuation }}+\underbrace{\alpha \eta d \mathbf{Q}}_{\text {expenditure switching }} \\
& -\underbrace{\alpha\left(\frac{1}{\mu} \mathbf{C}_{Y}-\frac{1}{\mu} \mathbf{C}_{v} \mathbf{J}_{d}^{\prime}\right)}_{\text {real income }} d \mathbf{Q}+\underbrace{(1-\alpha)\left(\frac{1}{\mu} \mathbf{C}_{Y}+\left(1-\frac{1}{\mu}\right) \mathbf{C}_{v} \mathbf{J}_{d}^{\prime}\right) d \mathbf{Y}}_{\text {multiplier effect }}
\end{aligned}
$$

which is almost the same expression as before, except for reduced expenditure switching and real income channels. To interpret this equation, we define $\mathbf{M}^{r}, \mathbf{M}$ as before, but also define $\mathbf{M}^{w} \equiv \mathbf{C}_{Y}$ as the (intertemporal) MPCs out of labor income, and $\mathbf{M}^{D} \equiv \mathbf{C}_{v} \mathbf{J}_{d}^{\prime}$ as the (intertemporal) MPCs out of dividends. Then, the international Keynesian cross decomposition for the DCP model is

$$
d \mathbf{Y}=\underbrace{(1-\alpha) \mathbf{M}^{r} d \mathbf{r}}_{\text {int. subst }+ \text { valuation }}+\underbrace{\alpha \eta d \mathbf{Q}}_{\text {D expenditure switching }}-\underbrace{\frac{\alpha}{\mu}\left(\mathbf{M}^{w}-\mathbf{M}^{D}\right)}_{\text {real income }} d \mathbf{Q}+\underbrace{(1-\alpha) \mathbf{M}}_{\text {Multiplier effect }} d \mathbf{Y}
$$




\section{B.5 Proof of proposition 6}

Proof of the non-linear neutrality result for $\eta=\gamma=1$. We start by proving the neutrality result nonlinearly. To do so, we state an important property that comes out of the closed economy result in Werning (2015) based on its proof in Appendix A of Auclert, Rognlie and Straub (2020). The consumption function that we introduce in Section $4, C_{t}=\mathcal{C}_{t}\left(r_{t}, \mathcal{Y}_{t}\right)$, where we abbreviate real income by $\mathcal{Y}_{t} \equiv \frac{P_{H t}}{P_{t}} Y_{t}$, has the following property,

$$
\mathcal{C}_{t}\left(\left\{r_{s}, \mathcal{Y}_{s}\right\}\right)=\mathcal{Y}_{t} \cdot \mathcal{C}_{t}\left(\left\{\left(1+r_{s}\right) \cdot \frac{\mathcal{Y}_{s}}{\mathcal{Y}_{s+1}}-1,1\right\}\right)
$$

In particular, this implies that if an aggregate Euler equation relationship between $\mathcal{Y}_{t}$ and $r_{t}$ holds, that is, $\frac{1}{\mathcal{Y}_{s}}=\frac{1+r_{s}}{1+r_{s s}} \cdot \frac{1}{\mathcal{Y}_{s+1}}$, this simplifies to

$$
\mathcal{C}_{t}\left(\left\{r_{s}, \mathcal{Y}_{s}\right\}\right)=\mathcal{Y}_{t} \cdot C_{s s}
$$

where $C_{s s}=\mathcal{C}_{t}\left(r_{s s}, 1\right)$ denotes steady state consumption (normalized to 1 in our model).

With this in mind, we now prove the non-linear equivalence result with $\eta=\gamma=1$, that is, $Y_{t}=Y_{t}^{R A}$ in response to an arbitrary monetary policy shock $\left\{r_{t}\right\}$. We begin by deriving $C_{t}^{R A}, Y_{t}^{R A}$ and the path of aggregate real income $\mathcal{Y}_{t}^{R A} \equiv \frac{P_{H t}}{P_{t}} Y_{t}^{R A}$ in the RA model.

Since we are considering the Cole-Obstfeld case $\eta=1$, the CPI (3) is

$$
P_{t}=P_{H t}^{1-\alpha} \mathcal{E}_{t}^{\alpha}
$$

and the real exchange rate (6) is

$$
Q_{t}=\frac{\mathcal{E}_{t}}{P_{t}}=\frac{\mathcal{E}_{t}}{P_{H t}^{1-\alpha} \mathcal{E}_{t}^{\alpha}}=\left(\frac{\mathcal{E}_{t}}{P_{H t}}\right)^{1-\alpha}
$$

In particular, the relative price of home goods in units of the CPI is

$$
\frac{P_{H t}}{P_{t}}=\frac{P_{H t}}{P_{H t}^{1-\alpha} \mathcal{E}_{t}^{\alpha}}=\left(\frac{P_{H t}}{\mathcal{E}_{t}}\right)^{\alpha}=\left(Q_{t}\right)^{-\frac{\alpha}{1-\alpha}}
$$

Home output is therefore given by

$$
Y_{t}^{R A}=(1-\alpha) Q_{t}^{\frac{\alpha}{1-\alpha}} C_{t}^{R A}+\alpha Q_{t}^{\frac{1}{1-\alpha}}
$$

Observe that if the Backus-Smith condition $C_{t}^{R A}=Q_{t}$ holds, then (A.71) implies that aggregate real income is simply given by

$$
\mathcal{Y}_{t}^{R A}=\frac{P_{H t}}{P_{t}} Y_{t}^{R A}=Q_{t}^{-\frac{\alpha}{1-\alpha}} Y_{t}^{R A}=C_{t}^{R A}
$$

Moreover, aggregate consumption satisfies the Euler equation (24),

$$
\frac{1}{C_{t}^{R A}}=\frac{1+r_{t}}{1+r_{s S}} \frac{1}{C_{t+1}^{R A}}
$$


Combining (A.72) and (A.73), we see that $\mathcal{Y}_{t}^{R A}$ satisfies the same Euler equation,

$$
\frac{1}{\mathcal{Y}_{t}^{R A}}=\frac{1+r_{t}}{1+r_{S S}} \frac{1}{\mathcal{Y}_{t+1}^{R A}}
$$

To verify that $Y_{t}^{R A}, \mathcal{Y}_{t}^{R A}, C_{t}^{R A}$ are identical in the HA model, we need to show that

$$
C_{t}=\mathcal{C}_{t}\left(\left\{r_{s}, \mathcal{Y}_{s}^{R A}\right\}\right)=C_{t}^{R A}
$$

But (A.75) follows directly from property (A.69) of the consumption function, which simplifies to (A.70) here given (A.74). Since the other aggregate equations of the model are the same, the result holds under any monetary policy rule and applies to all aggregate prices and quantities. This concludes our proof.

Proof to first-order for general $\eta, \gamma$ such that $(1-\alpha) \eta+\gamma=2-\alpha$. We proceed in two steps. First we prove a helpful lemma.

Lemma 1. For our heterogeneous-agent model with $\sigma=1$, we have that

$$
\mathbf{M}^{r}=-(\mathbf{I}-\mathbf{M}) \mathbf{U}
$$

Proof to lemma 1. This result is the differential version of (A.69). To see this, construct, for any given path $\left\{r_{t}\right\}$ a path of real income $\left\{\mathcal{Y}_{t}\right\}$ defined recursively by

$$
\mathcal{Y}_{t}=\frac{1+r_{S S}}{1+r_{t}} \mathcal{Y}_{t+1}
$$

To first order, this equation implies that

$$
d \mathcal{Y}=-\mathbf{U} d \mathbf{r}
$$

where

$$
\mathbf{U} \equiv\left(\begin{array}{cccc}
1 & 1 & 1 & \cdots \\
0 & 1 & 1 & \cdots \\
0 & 0 & 1 & \cdots \\
\vdots & \vdots & \vdots & \ddots
\end{array}\right)
$$

Now we linearize (A.69). We find

$$
d \mathbf{C}=\mathbf{M}^{r} d \mathbf{r}+\mathbf{M} d \mathcal{Y}=d \mathcal{Y}
$$

Substituting $d \mathcal{Y}$ with (A.77), this can be restated as

$$
\mathbf{M}^{r} d \mathbf{r}-\mathbf{M U} d \mathbf{r}=-\mathbf{U} d \mathbf{r}
$$

As this holds for an arbitrary path $d \mathbf{r}$, we find

$$
\mathbf{M}^{r}-\mathbf{M U}=-\mathbf{U}
$$

which is equivalent to (A.76). 
We use lemma 1 to restate the generalized Keynesian cross (38), now with arbitrary $\eta, \gamma$ as

$$
d \mathbf{Y}=\left(\frac{\alpha}{1-\alpha} \chi+1-\alpha\right) d \mathbf{Q}-\mathbf{M} d \mathbf{Q}+(1-\alpha) \mathbf{M} d \mathbf{Y}
$$

where $d \mathbf{Q}$ continues to be given by (A.63) as the implied real exchange rate response to the monetary policy shock. Solving (A.79) as in section B.2, we find

$$
d \mathbf{Y}=d \mathbf{Y}^{R A}+\alpha \mathbf{G}(\chi-(2-\alpha)) d \mathbf{Q}
$$

Following the same steps as in section B.3, this allows us to sign the magnitude of the output response relative to the RA solution. For example, in response to monetary easing, inducing an exchange rate depreciation $d \mathbf{Q} \geq 0$, a value $\chi<2-\alpha$ results in an output response $d \mathbf{Y}$ that lies below the RA model's output response.

\section{B.6 Proof of proposition 7}

Proof. Linearizing (22) around the steady state (when $t>0$ ), we obtain

$$
d \mathrm{nfa}_{t}=\left(1+r_{s s}\right) d \mathrm{nfa}_{t-1}+d N X_{t}
$$

Iterating forward, this implies that for any $t \geq 0$,

$$
d \mathrm{nfa}_{t}=\sum_{s=1}^{\infty}\left(1+r_{s s}\right)^{-s} d N X_{t+s}
$$

Substituting equation (34) for $d N X_{t}$, this becomes

$$
d \mathrm{nfa}_{t}=\frac{\alpha}{1-\alpha}(\chi-1)\left(\sum_{s=1}^{\infty}\left(1+r_{s s}\right)^{-s} d Q_{t+s}\right)-\alpha\left(\sum_{s=1}^{\infty}\left(1+r_{s s}\right)^{-s} d C_{t+s}\right)
$$

In the case where $d Q_{t+s}=0$ for all $s \geq 1$, this simplifies to

$$
\sum_{s=1}^{\infty}\left(1+r_{s s}\right)^{-s} d C_{t+s}=\frac{1}{\alpha} d \mathrm{nfa}_{t}
$$

the desired expression for the present value of remaining consumption in terms of the NFA.

For all $t+s$ where $d Q_{t+s}=0$, we have $d Y_{t+s}=(1-\alpha) d C_{t+s}$, and therefore from (A.80) we get

$$
\sum_{s=1}^{\infty}\left(1+r_{s s}\right)^{-s} d Y_{t+s}=\frac{1-\alpha}{\alpha} d \mathrm{nfa}_{t}
$$

Proof. We also prove the statement here that the present value of the output response to monetary policy is negative whenever $\chi<1-\alpha$. To do so, consider equation (A.79) and take present values on both sides. Since $\mathbf{M}$ preserves present values, we find

$$
P V(d \mathbf{Y})=\left(\frac{\alpha}{1-\alpha} \chi+1-\alpha-1\right) P V(d \mathbf{Q})+(1-\alpha) P V(d \mathbf{Y})
$$


and, simplifying,

$$
P V(d \mathbf{Y})=\frac{\chi-(1-\alpha)}{1-\alpha} P V(d \mathbf{Q})
$$

This shows that the present value is negative, due to "stealing demand from the future", whenever $\chi<1-\alpha$.

\section{B.7 Representative-agent incomplete-market (RA-IM) model}

The RA-IM model is a special case of the derivations in appendices B.2-B.5, with specific $\mathbf{M}$ and $\mathbf{M}^{r}$. To derive the two matrices in this case, note first that a representative agent spends any marginal increase in the present value of its income stream by increasing consumption equally in all periods. That is, the Jacobians of consumption with respect to labor income $\mathbf{C}_{Y}$ and ex-post returns $\mathbf{C}_{v}$ are given by

$$
\mathbf{C}_{Y}=\left(\begin{array}{cccc}
1-\beta & (1-\beta) \beta & (1-\beta) \beta^{2} & \ldots \\
1-\beta & (1-\beta) \beta & (1-\beta) \beta^{2} & \ldots \\
1-\beta & (1-\beta) \beta & (1-\beta) \beta^{2} & \ldots \\
\vdots & \vdots & \vdots & \ddots
\end{array}\right) \quad \mathbf{C}_{v}=A\left(\begin{array}{c}
1-\beta \\
1-\beta \\
1-\beta \\
\vdots
\end{array}\right)
$$

Since total steady state wealth is given by $A=\frac{D}{r}$ and $\mathbf{J}_{d}^{\prime}=\frac{1}{A}\left(1 \beta \beta^{2} \cdots\right)$, we have that

$$
\mathbf{C}_{v} \mathbf{J}_{d}^{\prime}=\mathbf{C}_{Y}
$$

and therefore that

$$
\mathbf{M}=\mathbf{C}_{Y}=(1-\beta) \cdot \mathbf{1} \mathbf{q}^{\prime}
$$

where we use $\mathbf{q}=\left((1+r)^{-t}\right)_{t \geq 0}=\left(\beta^{t}\right)_{t \geq 0}$ as in appendix B.2. Observe that $\mathbf{q}^{\prime} \mathbf{1}=(1-\beta)^{-1}$, which is why $\mathbf{M}$ is idempotent in the RA-IM model, that is, $\mathbf{M}^{2}=\mathbf{M}$. From (A.64), we can then explicitly compute

$$
\mathbf{G}=\mathbf{I}+\frac{1-\alpha}{\alpha} \mathbf{M}
$$

To derive the matrix $\mathbf{M}^{r}$, observe that by the Euler equation (24), the consumption response to small interest rate changes $d r_{t}$ is given by

$$
d C_{t}=d C_{\infty}-\frac{1}{\sigma} \sum_{s \geq t} \frac{d r_{s}}{1+r}
$$

where, due to a zero NFA, the consumption response at infinity $d C_{\infty}$ is pinned down by the requirement that the present value of $d C_{t}$ adds to 0 , and so

$$
d C_{\infty}=\sum_{s=0}^{\infty}(1-\beta) \beta^{s} \frac{1}{\sigma} \sum_{s \geq t} \frac{d r_{s}}{1+r}
$$

In matrix notation, we can then write

$$
d \mathbf{C}=\underbrace{-\frac{1}{\sigma}(\mathbf{I}-\mathbf{M}) \mathbf{U}}_{\equiv \mathbf{M}^{r}} d \mathbf{r}
$$


where $\mathbf{U}$ is given by (A.78) as before. When $\sigma=1$, this is a special case of (A.76).

The solution (A.65) to the international Keynesian cross is then given by

$$
d \mathbf{Y}=-(1-\alpha) \frac{1}{\sigma}(\mathbf{I}-\mathbf{M}) \mathbf{U} d \mathbf{r}+\frac{\alpha}{1-\alpha} \chi d \mathbf{Q}+(\chi-1) \mathbf{M} d \mathbf{Q}
$$

Exchange rate shocks. Directly from (A.81), we obtain the following two results without monetary policy shocks, $d r_{t}=0$. First, when $\chi=1$, the output response reduces to the RA solution (28). This is an incarnation of our general neutrality result in proposition 4 . When $\chi \neq 1$, the RA-IM model has a non-trivial consumption response

$$
(1-\alpha) d \mathbf{C}=(\chi-1) \mathbf{M} d \mathbf{Q}=(1-\beta)(\chi-1) \mathbf{1} \mathbf{q}^{\prime} d \mathbf{Q}
$$

which accounts for the difference to our benchmark RA-CM model.

Second, when $d Q_{t}$ is decreasing towards zero, with $\operatorname{AR}(1)$ persistence $\rho \in(0,1)$, the entire output response $d Y_{t}$ is negative whenever

$$
\chi<(1-\alpha) \frac{1}{1+\alpha \beta \frac{1-\rho}{1-\beta}} \equiv \chi^{*}
$$

This is a special case of proposition 5 . The threshold $\chi^{*}$ lies below $1-\alpha$, potentially by a lot given that standard quarterly calibrations for $\rho$ are in the neighborhood of 0.85 , while calibrations for $\beta$ are in the neighborhood of 0.99 . For our baseline calibration,

$$
\chi^{*} \approx 0.14 \cdot(1-\alpha)=0.057
$$

This implies that contractionary depreciations are much less likely to be obtained in a RA-IM model than in a HA model.

Monetary policy shocks. When there are only monetary policy shocks, i.e. $d Q_{t}=-\sum_{s \geq t} \frac{d r_{s}}{1+r}$, the solution simplifies to

$$
d \mathbf{Y}=\frac{1}{1-\alpha} d \mathbf{Q}+\frac{1}{1-\alpha}\left(\alpha(\chi-(2-\alpha))+(1-\alpha)^{2}\left(\frac{1}{\sigma}-1\right)\right) d \mathbf{Q}+\left(\chi-1-(1-\alpha) \frac{1}{\sigma}\right) \mathbf{M} d \mathbf{Q}
$$

which immediately shows that, if $\sigma=1$ and $\chi=2-\alpha$, the solution collapses to the RA-CM model's solution, in line with our general result in proposition 6. More generally, neutrality is achieved if $\chi=1+\frac{1-\alpha}{\sigma}$.

\section{B.8 Two agent complete-markets (TA) model}

Here we analytically derive the solution to the two-agent complete-market model, and show how it fits into the general framework of the paper with a particular diagonal $\mathbf{M}$ matrix.

We start from equation (A.57), which holds in any model. To obtain $d C_{t}$, observe that from (A.53), we have

$$
d c_{t}^{u}=-\frac{1}{\sigma} c_{s s}^{u} \sum_{s \geq t} \frac{d r_{s}}{1+r}
$$


From (A.54), we find that

$$
d c_{t}^{c}=d\left(\frac{W_{t}}{P_{t}} N_{t}\right)=\frac{1}{\mu} d\left(\frac{P_{H t}}{P_{t}} Y_{t}\right)=\frac{1}{\mu}\left(-\frac{\alpha}{1-\alpha} d Q_{t}+d Y_{t}\right)
$$

where we have used (A.56). This implies

$$
d C_{t}=-\left(1-\frac{\lambda}{\mu}\right) \frac{1}{\sigma} \sum_{s \geq t} \frac{d r_{s}}{1+r}+\frac{\lambda}{\mu}\left(-\frac{\alpha}{1-\alpha} d Q_{t}+d Y_{t}\right)
$$

Substituting $d C_{t}$ into (A.57), we arrive at

$$
d Y_{t}=-(1-\alpha)\left(1-\frac{\lambda}{\mu}\right) \frac{1}{\sigma} \sum_{s \geq t} \frac{d r_{s}}{1+r}+\frac{\alpha}{1-\alpha} \chi d Q_{t}-\alpha \frac{\lambda}{\mu} d Q_{t}+(1-\alpha) \frac{\lambda}{\mu} d Y_{t}
$$

Solving (A.84) for $d Y_{t}$, we find that

$$
d Y_{t}=-\frac{(1-\alpha)\left(1-\frac{\lambda}{\mu}\right)}{1-(1-\alpha) \frac{\lambda}{\mu}} \frac{1}{\sigma} \sum_{s \geq t} \frac{d r_{s}}{1+r}+\frac{\alpha}{1-\alpha} \frac{\chi-(1-\alpha) \frac{\lambda}{\mu}}{1-(1-\alpha) \frac{\lambda}{\mu}} d Q_{t}
$$

Here, the factor $1 /\left(1-(1-\alpha) \frac{\lambda}{\mu}\right)$ is the Keynesian multiplier that hand-to-mouth agents induce, see Bilbiie (2020) and Auclert, Rognlie and Straub (2018) for similar multipliers in the context of fiscal policy. We now use equation (A.85) to derive analytically the response of the two agent model to exchange rate shocks and monetary policy shocks.

Exchange rate shocks. For exchange rate shocks, $d r_{t}=0$. Equation ((A.84)) is then a special case of equation (32), with $\mathbf{M}=\frac{\lambda}{\mu} \mathbf{I}$. Hence, proposition (2) holds with that $\mathbf{M}$ matrix. Comparing (33) with (A.85), we see that Proposition (3) also holds (here, $\mathbf{M}>0$ iff $\lambda>0$ ).

Moreover, observe from (A.85) that, when $\chi=1$, the value of $\lambda / \mu$ is irrelevant: the fraction $\frac{\chi-(1-\alpha) \frac{\lambda}{\mu}}{1-(1-\alpha) \frac{\lambda}{\mu}}$ collapses to 1 , and we obtain the RA solution $d Y_{t}=\frac{\alpha}{1-\alpha} d Q_{t}$ for any $\lambda / \mu$. The crosspartial with respect to $\chi$ and $\lambda / \mu$ is positive, implying that for $\chi>1$, the TA model's output response lies above the RA model's, while the opposite is true for $\chi<1$. Hence, Proposition 4 holds.

Finally, in response to a depreciation $d Q_{t} \geq 0$, the entire output response $d Y_{t}$ is negative for values of $\chi$ below $(1-\alpha) \frac{\lambda}{\mu}$. This shows that Proposition 5 holds, with $\chi^{*}=(1-\alpha) \frac{\lambda}{\mu}$. ${ }^{47}$

We illustrate both of these results in figure A.1. We choose $\lambda / \mu=0.384$ to match the quarterly MPC of our baseline model. The red dash-dotted line with $\chi=1$ illustrates the neutrality result: the output responses are identical across the TA and HA models. For lower values of $\chi$, the TA model also generates a contraction, albeit a significantly more modest one than the HA model. The intuition for this is that $\mathbf{M}=\frac{\lambda}{\mu} \mathbf{I}$ and hence misses all the off-diagonal entries that populate the intertemporal MPC matrix of the HA model.

\footnotetext{
${ }^{47}$ Note that the result in proposition 5 on the present value turning negative for $\chi<1-\alpha$ does not carry over to the TA model, due to the presence of complete markets between unconstrained agents and the rest of the world.
} 
Figure A.1: Output effect of exchange rate shocks by $\chi$
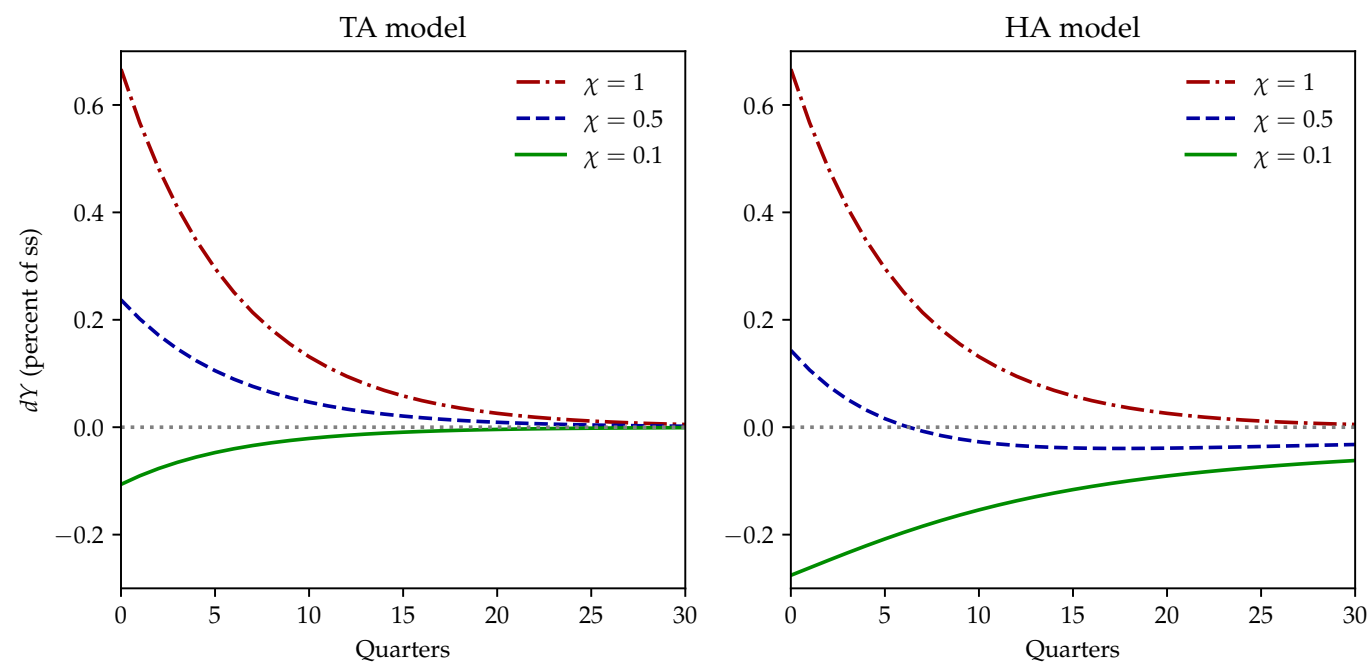

Note: impulse response in the TA and HA models to the shock to $i_{t}^{*}$ displayed in Figure 1 . The share of constrained agents in the TA model $\lambda$ is calibrated to match the quarterly MPC of the HA model.

Monetary policy shocks. With $\sigma=1$, but allowing for monetary policy shocks, equation (A.84) is a special case of (38), with $\mathbf{M}=\frac{\lambda}{\mu} \mathbf{I}$ and

$$
\mathbf{M}^{r}=-(\mathbf{I}-\mathbf{M}) \mathbf{U}=-\left(1-\frac{\lambda}{\mu}\right) \mathbf{U}
$$

where $\mathbf{U}$ is defined in (A.78) the triangular matrix with 1's above and on the diagonal, and zeros elsewhere. Observe that (A.86) is a special case of our general result in (A.76).

When there are only monetary policy shocks, i.e. $d Q_{t}=-\sum_{s \geq t} \frac{d r_{s}}{1+r}$, the solution simplifies to

$$
d Y_{t}=-\frac{1}{1-\alpha}\left(1+\frac{\alpha(\chi-(2-\alpha))+(1-\alpha)^{2}\left(\frac{1}{\sigma}-1\right)\left(1-\frac{\lambda}{\mu}\right)}{1-(1-\alpha) \frac{\lambda}{\mu}}\right) \sum_{s \geq t} \frac{d r_{s}}{1+r}
$$

When $\sigma=1$ and $\chi=2-\alpha$, the big fraction collapses to 0 , and we obtain the RA model's output response, irrespective of $\lambda / \mu$. This is a special case of the neutrality result in proposition 6 . The cross-partial with respect to $\chi$ and $\lambda / \mu$ is positive again (for accommodative monetary policy shocks), so that for $\chi>2-\alpha$, the TA model's output response lies above the RA model's, in line with our general result in proposition 6 .

We can also say what happens for $\sigma \neq 1$ in (A.87). When $\chi=2-\alpha$, and $\sigma>1$, the neutrality result fails in that the output response rises in the income share of constrained agents $\lambda / \mu$. The opposite holds for $\sigma<1$. One can also derive a $\sigma$-dependent neutrality threshold, for which $d Y_{t}$ is independent of $\lambda / \mu$, namely

$$
\chi=1+(1-\alpha) \frac{1}{\sigma}
$$

In the special case of $\sigma=1$, this collapses to $\chi=2-\alpha$. 


\section{B.9 Taylor rules}

In this section, we explore how the HA and RA models respond to shocks when the central bank follows a Taylor rule, as in (20), rather than the real interest rate rule (19). We first revisit the neutrality results for exchange rate depreciations and monetary policy, and then consider the response to productivity shocks as well.

Exchange rate depreciations. A depreciation $d Q_{t} \geq 0, d i_{t}^{*} \geq 0$, affects the demand for home goods and thus PPI inflation $\pi_{H t}=\pi_{w t}$ through the Phillips curve (18). CPI inflation is then determined by

$$
\pi_{t}=\pi_{H t}+\frac{\alpha}{1-\alpha}\left(d Q_{t}-d Q_{t-1}\right)
$$

and the real interest rate path by

$$
d r_{t}=d i_{t}-\pi_{t+1}=\phi \pi_{H t}-\pi_{H t+1}-\frac{\alpha}{1-\alpha}\left(d Q_{t+1}-d Q_{t}\right)
$$

As the Phillips curve involves endogenous variables, that themselves depend on $d r_{t}$, this situation is significantly less tractable than the case with a fixed real interest rate. Still, we can make progress by focusing on $\operatorname{AR}(1)$ shocks to $i_{t}^{*}$, with some fixed persistence $\rho \in(0,1)$. We show below that, in this case, there still exists a threshold value for $\chi$,

$$
\chi=1-\alpha \frac{1+\zeta \varphi}{1+\zeta(\varphi+\sigma)} \in(1-\alpha, 1), \quad \zeta \equiv \frac{\kappa_{w}(\phi-\rho)}{(1-\rho)(1-\beta \rho)}>0
$$

for which the responses of all aggregate variables, such as output, employment, and consumption are independent of $\mathbf{M}$, and hence the same for the RA and the HA model. ${ }^{48}$

Monetary policy shocks. The path of real rates is now no longer just a function of the path of monetary policy shocks $\epsilon_{t}$; it also depends on the response of inflation, and thereby also on the endogenous response of aggregate variables. However, the international Keynesian cross (38) still holds, and thus, for $\chi=2-\alpha$, the response of aggregates to the shock is still independent of $\mathbf{M}$ conditional on a given real interest rate path. This is why our neutrality result for monetary policy goes through unchanged for the Taylor rule (20).

Productivity shocks. The exact same logic applies to the case of productivity shocks $Z_{t}$. Those shocks affect home prices according to $P_{H t}=\mu W_{t} / Z_{t}$. This causes shifts in wage inflation via the Phillips curve (18) and thus shifts in real interest rates via (A.89). Since the responses in RA and HA models to changes in real interest rates are still identical when $\chi=2-\alpha$, the responses to productivity shocks in both models are also identical for this choice of $\chi$.

Proof of the result on exchange rate depreciations with a Taylor rule. We focus on AR(1) shocks here, such that $d Q_{t}=\rho d Q_{t-1}$ for some $\rho \in(0,1)$. The output response with a Taylor rule is determined by the following system of equations. The first is the international Keynesian cross (38),

$$
d \mathbf{Y}=-(1-\alpha)(\mathbf{I}-\mathbf{M}) \mathbf{U} d \mathbf{r}+\alpha \frac{\chi}{1-\alpha} d \mathbf{Q}-\alpha \mathbf{M} d \mathbf{Q}+(1-\alpha) \mathbf{M} d \mathbf{Y}
$$

simplified using (A.76). The second is the Phillips curve for wage inflation (18), in linearized terms given by

$$
\pi_{w t}=\kappa_{w}\left(\varphi d N_{t}+\sigma d C_{t}\right)+\beta \pi_{w t+1}
$$

\footnotetext{
${ }^{48}$ The response is also the same in the incomplete markets RA and the TA model.
} 
The third is the determination of the real interest rate through the Taylor rule (A.89),

$$
d r_{t}=d i_{t}-\pi_{t+1}=\phi \pi_{w t}-\pi_{w t+1}-\frac{\alpha}{1-\alpha}\left(d Q_{t+1}-d Q_{t}\right)
$$

and the forth is the determination of the real exchange rate as

$$
d Q_{t}=\sum_{s \geq t} \frac{d i_{s}^{*}-d r_{s}}{1+r}
$$

We guess and verify that all variables are exponentially decaying with the same persistence $\rho$. In this case,

$$
d \mathbf{r}=k \cdot d \mathbf{i}^{*}
$$

with an unknown $k=\frac{d r_{0}}{d i_{0}^{*}}$. From (A.93), we then get that

$$
d \mathbf{Q}=\frac{1}{1-\rho}\left(d \mathbf{i}^{*}-d \mathbf{r}\right)=\frac{k^{-1}-1}{1-\rho} d \mathbf{r}
$$

So we can rewrite (A.90) as

$$
d \mathbf{Y}=\left(\alpha \frac{\chi}{1-\alpha}-(1-\alpha) \frac{k}{1-k}\right) d \mathbf{Q}-\mathbf{M}\left(\alpha-(1-\alpha) \frac{k}{1-k}\right) d \mathbf{Q}+(1-\alpha) \mathbf{M} d \mathbf{Y}
$$

Rearranging,

$$
d \mathbf{Y}-\left(\alpha \frac{\chi}{1-\alpha}-(1-\alpha) \frac{k}{1-k}\right) d \mathbf{Q}=(1-\alpha) \mathbf{M}\left(d \mathbf{Y}-\frac{\alpha-(1-\alpha) \frac{k}{1-k}}{1-\alpha} d \mathbf{Q}\right)
$$

we see that the solution is independent of $\mathbf{M}$ precisely if and only if

$$
\alpha \frac{\chi}{1-\alpha}-(1-\alpha) \frac{k}{1-k}=\frac{\alpha-(1-\alpha) \frac{k}{1-k}}{1-\alpha}
$$

which is equivalent to

$$
\chi=1-(1-\alpha) \frac{k}{1-k}
$$

For $k=0$, we recover neutrality at $\chi=1$. For $k \rightarrow \infty$, the monetary response dominates the output response, so the threshold converges to $\chi \rightarrow 2-\alpha$. In case the neutrality result holds, the output response is given by

$$
d \mathbf{Y}=\left(\frac{\alpha}{1-\alpha}-\frac{k}{1-k}\right) d \mathbf{Q}
$$

Given the linear production function, this is equivalent to the employment response, $d \mathbf{N}=d \mathbf{Y}$. The aggregate consumption response is

$$
d \mathbf{C}=-\frac{k}{1-k} d \mathbf{Q}
$$


Substituting these formulas into the linearized wage Phillips curve (A.91), we find that

$$
\pi_{w t}=\frac{1}{1-\beta \rho} \kappa_{w}\left(\varphi d N_{t}+\sigma d C_{t}\right)=\frac{1}{1-\beta \rho} \kappa_{w}\left(\varphi\left(\frac{\alpha}{1-\alpha}-\frac{k}{1-k}\right)-\sigma \frac{k}{1-k}\right) d Q_{t}
$$

and therefore that

$$
d r_{t}=\left\{\frac{\phi-\rho}{1-\beta \rho} \kappa_{w}\left(\varphi\left(\frac{\alpha}{1-\alpha}-\frac{k}{1-k}\right)-\sigma \frac{k}{1-k}\right)+\frac{\alpha}{1-\alpha}(1-\rho)\right\} d Q_{t}
$$

Comparing this with (A.94), we find an equation for $k /(1-k)$,

$$
(1-\rho) \frac{k}{1-k}=\frac{\phi-\rho}{1-\beta \rho} \kappa_{w}\left(\varphi\left(\frac{\alpha}{1-\alpha}-\frac{k}{1-k}\right)-\sigma \frac{k}{1-k}\right)+\frac{\alpha}{1-\alpha}(1-\rho)
$$

We solve this equation for $k /(1-k)$

$$
\begin{gathered}
\left(1-\rho+\frac{\phi-\rho}{1-\beta \rho} \kappa_{w}(\varphi+\sigma)\right) \frac{k}{1-k}=\frac{\phi-\rho}{1-\beta \rho} \kappa_{w} \varphi \frac{\alpha}{1-\alpha}+\frac{\alpha}{1-\alpha}(1-\rho) \\
\left(1-\rho+\frac{\phi-\rho}{1-\beta \rho} \kappa_{w}(\varphi+\sigma)\right) \frac{k}{1-k}=\frac{\alpha}{1-\alpha}\left(1-\rho+\frac{\phi-\rho}{1-\beta \rho} \kappa_{w} \varphi\right) \\
\frac{k}{1-k}=\frac{\alpha}{1-\alpha} \cdot \frac{1+\frac{\kappa_{w}(\phi-\rho)}{(1-\rho)(1-\beta \rho)} \varphi}{1+\frac{\kappa_{w}(\phi-\rho)}{(1-\rho)(1-\beta \rho)}(\varphi+\sigma)}
\end{gathered}
$$

Note that the solution lies in $k \in(0, \alpha)$. The neutrality threshold is then given by

$$
\chi=1-\alpha \frac{1+\frac{\kappa_{w}(\phi-\rho)}{(1-\rho)(1-\beta \rho)} \varphi}{1+\frac{\kappa_{w}(\phi-\rho)}{(1-\rho)(1-\beta \rho)}(\varphi+\sigma)} \in(1-\alpha, 1)
$$

\section{Quantitative model details}

\section{C.1 Non-homothetic demand}

The Bellman equation (1) that incorporates the preferences in (39) reads

$$
\begin{aligned}
V_{t}(a, e)= & \max _{c_{F}, c_{H}, a^{\prime}} u\left(\left[\alpha^{1 / \eta}\left(c_{F}-\underline{c}\right)^{(\eta-1) / \eta}+(1-\alpha)^{1 / \eta} c_{H}^{(\eta-1) / \eta}\right]^{\eta /(\eta-1)}\right) \\
& -v\left(N_{t}\right)+\beta \mathbb{E}_{t}\left[V_{t+1}\left(a^{\prime}, e^{\prime}\right)\right] \\
\text { s.t. } \quad & \frac{P_{F t}}{P_{t}} c_{F}+\frac{P_{H t}}{P_{t}} c_{H}+a^{\prime}=\left(1+r_{t}^{p}\right) a+e \frac{W_{t}}{P_{t}} N_{t} \\
& a^{\prime} \geq \underline{a}
\end{aligned}
$$


Notice that, by relabeling $\widetilde{c_{F}} \equiv c_{F}-\underline{c}$, this is equivalent to

$$
\begin{aligned}
V_{t}(a, e)= & \max _{\widetilde{c_{F}}, c_{H}, a^{\prime}} u\left(\left[\alpha^{1 / \eta}\left(\widetilde{c_{F}}\right)^{(\eta-1) / \eta}+(1-\alpha)^{1 / \eta} c_{H}^{(\eta-1) / \eta}\right]^{\eta /(\eta-1)}\right) \\
& -v\left(N_{t}\right)+\beta \mathbb{E}_{t}\left[V_{t+1}\left(a^{\prime}, e^{\prime}\right)\right] \\
\text { s.t. } \quad & \frac{P_{F t}}{P_{t}} \widetilde{c_{F}}+\frac{P_{H t}}{P_{t}} c_{H}+a^{\prime}=\left(1+r_{t}^{p}\right) a+e \frac{W_{t}}{P_{t}} N_{t}-\frac{P_{F t}}{P_{t}} \underline{c} \\
& a^{\prime} \geq \underline{a}
\end{aligned}
$$

or, defining $\widetilde{c}=\left[\alpha^{1 / \eta}\left(\widetilde{c_{F}}\right)^{(\eta-1) / \eta}+(1-\alpha)^{1 / \eta} c_{H}^{(\eta-1) / \eta}\right]^{\eta /(\eta-1)}$, as simply

$$
\begin{aligned}
V_{t}(a, e)= & \max _{\widetilde{c}, a^{\prime}} u(\widetilde{c})-v\left(N_{t}\right)+\beta \mathbb{E}_{t}\left[V_{t+1}\left(a^{\prime}, e^{\prime}\right)\right] \\
\text { s.t. } \quad & \widetilde{c}+a^{\prime}=\left(1+r_{t}^{p}\right) a+e \frac{W_{t}}{P_{t}} N_{t}-\frac{P_{F t}}{P_{t}} \underline{c} \\
& a^{\prime} \geq \underline{a}
\end{aligned}
$$

where $P_{t}$ is the standard CES price index (3). Hence, this is the standard consumption-saving problem, only with a modified income process that subtracts $-\frac{P_{F t}}{P_{t}} \underline{c}$ to real income in every state of the world. The policy functions $\widetilde{c}_{t}(a, e), a_{t+1}(a, e)$ for this problem, as well as the aggregates $\widetilde{C_{F}}$ and $A_{t+1}$ of policies integrated against the time varying distribution, can be obtained from the sequence of inputs $\left\{r_{t}^{p}, \frac{W_{t}}{P_{t}} N_{t}, \frac{P_{F t}}{P_{t}} \underline{c}\right\}$ using standard tools. Since every agent's policy for $c_{F t}(a, e)=$ $\underline{c}+\widetilde{c_{F t}}(a, e)$, it follows that aggregate spending on foreign goods is simply

$$
\begin{aligned}
C_{F t} & =\underline{c}+\widetilde{C_{F t}} \\
& =\underline{c}+\alpha\left(\frac{P_{F t}}{P_{t}}\right)^{-\eta} \widetilde{C}_{t}
\end{aligned}
$$

while aggregate spending on domestic goods is

$$
C_{H t}=(1-\alpha)\left(\frac{P_{H t}}{P_{t}}\right)^{-\eta} \widetilde{C}_{t}
$$

Note that equations (A.96) and (A.97) only require the standard CES prices index $P_{t}$, which is the price index of an infinitely wealthy agent, and does not require the ideal price indices for agents at different points in the distribution $(a, e)$.

\section{C.2 Delayed substitution model}

We introduce delayed substitution as a modification of the household side of the model, both in the domestic economy and in the rest of the world. The basic idea is to assume that each household has only an iid probability $1-\theta$ in each period of being able to adjust the composition of its consumption bundle $\mathbf{x}$. With probability $\theta$, the household is required to keep the same consumption bundle $\mathbf{x}$, and consume each good in proportion to it, i.e. $c_{k}=x_{k} c$, where $x_{k}$ is the amount of $k$ in the consumption bundle and $c$ is total consumption.

First we work out the analytics, in a general static problem where consumption is some constantreturns-to-scale aggregate of many goods, of the optimal bundle given the prices of each good. 
Then we show how this can problem be embedded in the dynamic incomplete markets problem that the households in our model solve, and work out the first-order equations characterizing household behavior. Finally, we specialize the consumption side to the nested CES of home and foreign goods in our model, and derive the consequences.

Static problem: the optimal bundle in terms of prices. Suppose that a household has preferences that aggregate consumption goods using some constant-returns-to-scale aggregator $F$

$$
c=F\left(c_{1}, \ldots, c_{K}\right)
$$

We define a bundle $\left\{x_{k}\right\}$ as anything that gives a total consumption of one

$$
1=F\left(x_{1}, \ldots, x_{K}\right)
$$

and say that the price index $P\left(\left\{x_{k}\right\},\left\{P_{k}\right\}\right)$ corresponding to this bundle is just its cost:

$$
P\left(\left\{x_{k}\right\},\left\{P_{k}\right\}\right)=\sum_{k} P_{k} x_{k}
$$

The cost of the bundle that minimizes (A.100) subject to (A.99) is the ordinary price index $P$.

Consider the optimal bundle $\left\{\hat{x}_{k}\right\}$ given some prices $\left\{P_{k}\right\}$, i.e. the solution to the problem of minimizing price (A.100) subject to (A.99). The Lagrangian is

$$
\sum_{k} P_{k} \hat{x}_{k}-\lambda\left(F\left(\hat{x}_{1}, \ldots, \hat{x}_{K}\right)-1\right)
$$

and first-order conditions are

$$
P_{k}=\lambda F_{k}
$$

(Note that since $F$ is constant-returns-to-scale, the marginal cost $\lambda$ equals the conventional price index $P$.)

Log-differentiating gives

$$
\begin{aligned}
d \log P_{k} & =d \log \lambda+d \log F_{k} \\
& =d \log \lambda+\sum_{k^{\prime}} \frac{F_{k k^{\prime}} \hat{x}_{k^{\prime}}}{F_{k}} d \log \hat{x}_{k^{\prime}}
\end{aligned}
$$

Log-differentiating the condition $F\left(\hat{x}_{1}, \ldots, \hat{x}_{k}\right)=1$ gives

$$
\sum_{k} \frac{F_{k} \hat{x}_{k}}{F} d \log \hat{x}_{k}=0
$$

We note that $\sum_{k^{\prime}} \frac{F_{k k^{\prime}} \hat{x}_{k^{\prime}}}{F_{k}}=0$ by Euler's identity: a proportional shift in all $\hat{x}_{k}$ does not change any partial derivatives. This means that the matrix $\mathbf{F} \equiv\left[\frac{F_{k k^{\prime}} \hat{k}_{k^{\prime}}}{F_{k}}\right]_{k k^{\prime}}$ has a null vector of ones. By the envelope theorem, we also know that $d \lambda=\sum_{k} d P_{k} \hat{x}_{k}$, or that $d \log \lambda=\sum_{k} \alpha_{k} d \log P_{k}$, where $\alpha_{k} \equiv P_{k} \hat{x}_{k} / P$ is the share of good $k$ in the bundle. So then we need to find the solution $\hat{x}$ to

$$
\mathbf{F} d \log \hat{\mathbf{x}}=d \log \mathbf{P}-\left(\alpha^{\prime} d \log \mathbf{P}\right) \mathbf{1}
$$

such that (A.103) holds, i.e. $\sum_{k} \frac{F_{k} \hat{x}_{k}}{F} d \log \hat{x}_{k}=0$. Given one such solution $d \log \hat{\mathbf{x}}$ to (A.104), we can 
find exactly one that satisfies (A.103), since $\mathbf{1}$ is in the null-space of $\mathbf{F} .{ }^{49}$ Let us denote the linear map from $d \log \mathbf{P}$ to this solution $d \log \hat{\mathbf{x}}$ by the matrix $\mathbf{G}$ :

$$
d \log \hat{\mathbf{x}}=\mathbf{G} d \log \mathbf{P}
$$

Incomplete markets dynamic problem. Now consider a household who is solving a generalization of the standard incomplete markets problem in (1), where consumption within each period $t$ is given by an aggregator (A.98) of goods with prices $\mathbf{P}_{t}=\left\{P_{k t}\right\}$. We assume that the household picks a bundle $\mathbf{x} \equiv\left\{x_{k}\right\}$ of goods giving an aggregate of 1 as in (A.99), and must consume in proportion to that bundle until it receives a Calvo option to reset the bundle, which has probability $1-\theta$ in each period. (Since the bundle has aggregate value 1 , consumption of each good in each period is given by $c_{i k t}=x_{k} c_{i t}$.)

The value function given an inherited $\mathbf{x}$ at date $t$ is then

$$
\begin{aligned}
V_{t}(a, e, \mathbf{x})= & \max _{E, a^{\prime}} U\left(E \cdot \frac{P_{t}}{\bar{P}\left(\mathbf{x}, \mathbf{P}_{t}\right)}\right)+\beta \theta \mathbb{E}_{t}\left[V_{t+1}\left(a^{\prime}, e^{\prime}, \mathbf{x}\right)\right]+\beta(1-\theta) \mathbb{E}\left[\max _{\mathbf{x}^{\prime}} V_{t+1}\left(a^{\prime}, e^{\prime}, \mathbf{x}^{\prime}\right)\right] \\
& E+a^{\prime}=\left(1+r_{t}^{p}\right) a+e \frac{W_{t}}{P_{t}} N_{t} \\
& a^{\prime} \geq \underline{a}
\end{aligned}
$$

where the choice is made over expenditure in real units deflated at the ordinary price index $P_{t}$, but consumption may be less because the actual cost of consumption at the fixed bundle $x$ is $\bar{P}\left(\mathbf{x}, \mathbf{P}_{t}\right)$.

Note that the envelope condition for $x$, which appears only in the objective (A.106), is

$$
\begin{aligned}
\frac{\partial V_{t}(a, e, \mathbf{x})}{\partial \mathbf{x}} & =-U^{\prime}\left(c_{t}\right) c_{t} \frac{\partial \log \bar{P}\left(\mathbf{x}, \mathbf{P}_{t}\right)}{\partial \mathbf{x}}+\beta \theta \mathbb{E}_{t}\left[\frac{\partial V_{t+1}\left(a^{\prime}, e^{\prime}, \mathbf{x}\right)}{\partial \mathbf{x}}\right] \\
& =-U^{\prime}\left(c_{t}\right) c_{t} \mathbf{P}_{t}+\beta \theta \mathbb{E}_{t}\left[\frac{\partial V_{t+1}\left(a^{\prime}, e^{\prime}, \mathbf{x}\right)}{\partial \mathbf{x}}\right]
\end{aligned}
$$

where we use $\frac{\partial \log \bar{P}\left(\mathbf{x}, \mathbf{P}_{t}\right)}{\partial \mathbf{x}}=\mathbf{P}_{t}$ from (A.100) to simplify and denote real consumption, i.e. the aggregate in (A.98), by $c_{t}$. Recursively expanding this out and subsuming the states $a$ and $e$ into the subscript $i \equiv(a, e)$, we get

$$
\frac{\partial V_{i t}\left(\mathbf{x}_{i t}\right)}{\partial \mathbf{x}}=\mathbb{E}_{i t} \sum_{s=0}^{\infty}(\beta \theta)^{s} U^{\prime}\left(c_{i t+s}\right) c_{i t+s} \mathbf{P}_{t+s}
$$

Now suppose that we are maximizing over feasible $\hat{\mathbf{x}}_{i t}$, i.e. solving the problem which has Lagrangian

$$
V_{i t}(\hat{\mathbf{x}})-\lambda\left(F\left(\hat{x}_{1}, \ldots, \hat{x}_{K}\right)-1\right)
$$

where for simplicity we suppress the $i$ and $t$ subscripts on $\hat{\mathbf{x}}$. The first-order condition with respect to each $\hat{x}_{k}$ is

$$
\mathbb{E}_{i t} \sum_{s=0}^{\infty}(\beta \theta)^{s} U^{\prime}\left(c_{i t+s}\right) c_{i t+s} P_{k, t+s}=\lambda F_{k}
$$

\footnotetext{
${ }^{49}$ In more detail: assuming that $\mathbf{F} \equiv\left[\frac{F_{k k^{\prime}} \hat{x}_{k^{\prime}}}{F_{k}}\right]_{k k^{\prime}}$ otherwise has full rank, i.e. its rank is $K-1$, then we note that $\alpha^{\prime} \mathbf{F}=0$, so that the range of $\mathbf{F}$ is the space orthogonal to $\alpha$. The right side of (A.104) is always orthogonal to $\alpha$. There is therefore always a one-dimensional space of solutions to (A.104), with the difference between any two solutions given by a multiple of $\mathbf{1}$, and exactly one of these solutions will satisfy (A.103) as well.
} 
In an aggregate steady state, with constant prices $P_{k, t+s}=P_{k}$, this simplifies to $P_{k}=\left(\mathbb{E}_{i t} \sum_{s=0}^{\infty}(\beta \theta)^{s} U^{\prime}\left(c_{i t+s}\right) c_{i t+s}\right)^{-1}$ which is the same as the static first-order condition (A.101) but with an extra factor rescaling $\lambda$. The constraint (A.99) is also the same as in the static problem. Therefore the steady-state solution is the same (with a bundle independent of $i$ ), and while $\lambda$ equaled the conventional price index $P$ in the static problem, it now equals $P$ times an extra factor:

$$
P\left(\mathbb{E}_{i t} \sum_{s=0}^{\infty}(\beta \theta)^{s} U^{\prime}\left(c_{i t+s}\right) c_{i t+s}\right)=\lambda
$$

Now consider linearizing (A.110) around the steady-state prices $P$ and bundle $\hat{\mathbf{x}}$. We get

$$
P_{k} \mathbb{E}_{i t} \sum_{s=0}^{\infty}(\beta \theta)^{s} d\left(U^{\prime}\left(c_{i t+s}\right) c_{i t+s}\right)+\mathbb{E}_{i t} \sum_{s=0}^{\infty}(\beta \theta)^{s} U^{\prime}\left(c_{i t+s}\right) c_{i t+s} d P_{k, t+s}=\lambda F_{k}\left(d \log \lambda+d \log F_{k}\right)
$$

and then, noting that $\sum_{k} d F_{k} \hat{x}_{k}=0$ and $\sum_{k} P_{k} \hat{x}_{k}=P$, we can sum this weighted by $\hat{x}_{k}$ to obtain

$$
P \mathbb{E}_{i t} \sum_{s=0}^{\infty}(\beta \theta)^{s} d\left(U^{\prime}\left(c_{i t+s}\right) c_{i t+s}\right)+\mathbb{E}_{i t} \sum_{s=0}^{\infty}(\beta \theta)^{s} U^{\prime}\left(c_{i t+s}\right) c_{i t+s} \sum_{k} \hat{x}_{k} d P_{k, t+s}=\lambda d \log \lambda
$$

Now, if we multiply both sides of (A.113) by $F_{k}$, use $P_{k}=P F_{k}$, and subtract it from (A.112), the first term on both sides cancels and we get

$$
\mathbb{E}_{i t} \sum_{s=0}^{\infty}(\beta \theta)^{s} U^{\prime}\left(c_{i t+s}\right) c_{i t+s}\left(d P_{k, t+s}-F_{k} \sum_{k^{\prime}} \hat{x}_{k^{\prime}} d P_{k^{\prime}, t+s}\right)=\lambda F_{k} d \log F_{k}
$$

Now, divide both sides by $P_{k}=P F_{k}$, we we get

$$
\mathbb{E}_{i t} \sum_{s=0}^{\infty}(\beta \theta)^{s} U^{\prime}\left(c_{i t+s}\right) c_{i t+s}\left(d \log P_{k, t+s}-\sum_{k^{\prime}} \alpha_{k^{\prime}} d \log P_{k^{\prime}, t+s}\right)=\frac{\lambda}{P} d \log F_{k}
$$

and finally, using (A.111), we get

$$
d \log F_{k}=\frac{\mathbb{E}_{i t} \sum_{s=0}^{\infty}(\beta \theta)^{s} U^{\prime}\left(c_{i t+s}\right) c_{i t+s}\left(d \log P_{k, t+s}-\sum_{k^{\prime}} \alpha_{k^{\prime}} d \log P_{k^{\prime}, t+s}\right)}{\mathbb{E}_{i t} \sum_{s=0}^{\infty}(\beta \theta)^{s} U^{\prime}\left(c_{i t+s}\right) c_{i t+s}}
$$

for each $k$, which in vector form (using $\mathbf{F} \equiv\left[\frac{F_{k k^{\prime}} \hat{x}_{k^{\prime}}}{F_{k}}\right]_{k k^{\prime}}$ from the static problem) can be stacked as

$$
\mathbf{F} d \log \hat{\mathbf{x}}=\frac{\mathbb{E}_{i t} \sum_{s=0}^{\infty}(\beta \theta)^{s} U^{\prime}\left(c_{i t+s}\right) c_{i t+s}\left(d \log \mathbf{P}_{t}-\left(\alpha^{\prime} d \log \mathbf{P}_{t}\right) \mathbf{1}\right)}{\mathbb{E}_{i t} \sum_{s=0}^{\infty}(\beta \theta)^{s} U^{\prime}\left(c_{i t+s}\right) c_{i t+s}}
$$

The solution $\hat{\mathbf{x}}$ is whatever satisfies (A.114) and also satisfies $\sum_{k} \frac{F_{k} \hat{x}_{k}}{F} d \log \hat{x}_{k}=0$.

In the static problem, we obtained the matrix $\mathbf{G}$ that mapped $d \log \mathbf{P}$ to $d \log \hat{\mathbf{x}}$ in order to solve $\mathbf{F} d \log \hat{\mathbf{x}}=d \log \mathbf{P}-\left(\alpha^{\prime} d \log \mathbf{P}\right) \mathbf{1}$, subject to the same condition $\sum_{k} \frac{F_{k} \hat{x}_{k}}{F} d \log \hat{x}_{k}=0$, for a single change in $\log$ prices $d \log \mathbf{P}$. Using linearity, we can combine this with (A.114) and move G inside 
the numerator to obtain

$$
\begin{aligned}
d \log \hat{\mathbf{x}}_{i t} & =\frac{\mathbb{E}_{i t} \sum_{s=0}^{\infty}(\beta \theta)^{s} U^{\prime}\left(c_{i t+s}\right) c_{i t+s} \mathbf{G} d \log \mathbf{P}_{t}}{\mathbb{E}_{i t} \sum_{s=0}^{\infty}(\beta \theta)^{s} U^{\prime}\left(c_{i t+s}\right) c_{i t+s}} \\
& =\frac{\mathbb{E}_{i t} \sum_{s=0}^{\infty}(\beta \theta)^{s} U^{\prime}\left(c_{i t+s}\right) c_{i t+s} \cdot d \log \hat{\mathbf{x}}_{t+s}^{\text {static }}}{\mathbb{E}_{i t} \sum_{s=0}^{\infty}(\beta \theta)^{s} U^{\prime}\left(c_{i t+s}\right) c_{i t+s}}
\end{aligned}
$$

where we define $d \log \hat{\mathbf{x}}_{t+s}^{\text {static }}=\mathbf{G} d \log \mathbf{P}_{t+s}$ to be the statically optimal bundle given prices at time $t+s$, ignoring the adjustment friction, and restore the explicit $i$ and $t$ subscripts.

(A.115) is our primary result: the log change around the aggregate steady state in optimum bundle for individual $i$ at time $t$, given the adjustment friction, is a weighted average of the log change around the aggregate steady state in future static optimum bundles, with the weight on each future date $t+s$ being $(\beta \theta)^{s} U^{\prime}\left(c_{i t+s}\right) c_{i t+s}$.

Special cases (representative agent and log preferences). (A.115) is somewhat complex, but there are two special cases where it simplifies dramatically. First, if there is a representative agent, then in the aggregate steady state, consumption $c_{i t+s}$ in (A.115) is constant over time. Second, if $U(c)=\log c$, then $U^{\prime}(c) c=1$. In both cases, (A.115) collapses to just

$$
d \log \hat{\mathbf{x}}_{t}=(1-\beta \theta) \mathbb{E}_{t} \sum_{s=0}^{\infty}(\beta \theta)^{s} d \log \hat{\mathbf{x}}_{t+s}^{\text {static }}
$$

These correspond to the cases we will consider in this paper: log preferences for the heterogeneous agents in the domestic economy, and a representative agent in foreign economies. Note that even in the former case, the $i$ subscripts now disappear: all agents want to set the same bundle. ${ }^{50}$

Evolution of aggregate bundle. Note that in (A.106), the bundle $\mathbf{x}$ only enters the problem in $\bar{P}\left(\mathbf{x}, \mathbf{P}_{t}\right)$, which is second-order in $\mathbf{x}$ around the steady-state optimum. Heterogeneity in $\mathbf{x}$ therefore has a second-order impact on total consumption $c_{i t+s}$ of each individual.

Disregarding these second-order terms, in period $t$, aggregate consumption of good $k$ is

$$
\begin{aligned}
C_{k t} & =\int\left((1-\theta) \sum_{s=0}^{\infty} \theta^{s} \hat{x}_{k t-s} c_{i t}\right) d i=\left((1-\theta) \sum_{s=0}^{\infty} \theta^{s} \hat{x}_{k t-s}\right) \int c_{i t} d i \\
& =\underbrace{\left((1-\theta) \sum_{s=0}^{\infty} \theta^{s} \hat{x}_{k t-s}\right)}_{\equiv x_{k t}} C_{t}
\end{aligned}
$$

where $\int d i$ denotes aggregation over the idiosyncratic state space $i=(s, a)$ (using the distribution of agents from the aggregate steady state). For each $i$, the mass $(1-\theta) \theta^{s}$ of agents whose bundle were last updated in period $t-s$ consume $\hat{x}_{k t-s} c_{i t}$ of good $k$. Aggregating over all $s$, factoring out, and defining $x_{k t} \equiv \sum_{s=0}^{\infty} \theta^{s} \hat{x}_{k t-s}$ to be the "average" bundle at date $t$, we have simply $C_{k t}=x_{k t} C_{t}$.

\footnotetext{
${ }^{50}$ In the general case, without the simplification (A.116), for each agent type $i$ in the state space, $\mathbb{E}_{i t}(\beta \theta)^{s} U^{\prime}\left(c_{i t+s}\right) c_{i t+s}$ can be calculated recursively for increasing $s$ using the law of iterated expectations. With this, we can implement (A.115) and can calculate how, for each $i, d \log \hat{\mathbf{x}}_{i t}$ depends on the path of $\hat{\mathbf{x}}_{t+s}^{\text {static }}$. (Note that this only depends on $i$ and $s$, not on $t$, due to translation invariance.) Similar tricks are needed to aggregate below into an effective average bundle $d \log \mathbf{x}_{t}$ at each date, since the choice of $d \log \hat{\mathbf{x}}_{i t}$ is no longer independent of expected consumption $c_{i t+s}$.
} 
In $\log$ deviations from steady state, we have $d \log C_{k t}-d \log C_{t}=d \log x_{k t}$, where stacking and log-linearizing the definition of $\mathbf{x}_{t}$ immediately yields

$$
d \log \mathbf{x}_{t}=(1-\theta) \sum_{s=0}^{\infty} \theta^{s} d \log \hat{\mathbf{x}}_{k t-s}
$$

Summarizing the system. We can rewrite (A.116) and (A.117) in AR(1) form as

$$
\begin{aligned}
& d \log \hat{\mathbf{x}}_{t}=(1-\beta \theta) d \log \hat{\mathbf{x}}_{t}^{\text {static }}+\beta \theta \mathbb{E}_{t} d \log \hat{\mathbf{x}}_{t+1} \\
& d \log \mathbf{x}_{t}=(1-\theta) d \log \hat{\mathbf{x}}_{t}+\theta d \log \mathbf{x}_{t-1}
\end{aligned}
$$

After calculating the statically optimal bundles $d \log \hat{\mathbf{x}}_{t}^{\text {static }}$, one can iterate backward on (A.118) to obtain all $d \log \hat{\mathbf{x}}_{t}$, and then iterate forward on (A.119) to obtain all $d \log \mathbf{x}_{t}$.

Application to our nested CES case. Suppose that the consumption aggregator function $F$ takes the form

$$
F\left(c_{H}, c_{F 1}, \ldots, c_{F n}\right)=\left((1-\alpha)^{1 / \eta} c_{H}^{(\eta-1) / \eta}+\alpha^{1 / \eta} c_{F}\left(c_{F 1}, \ldots, c_{F n}\right)^{(\eta-1) / \eta}\right)^{\eta /(\eta-1)}
$$

where

$$
c_{F}\left(c_{F 1}, \ldots, c_{F n}\right)=\left(\frac{1}{n} \sum_{i=1}^{n} c_{F i}^{(\gamma-1) / \gamma}\right)^{\gamma /(\gamma-1)}
$$

and the steady-state prices are assumed to be $P_{H}=1$ and $P_{F i}=\frac{1}{n}$ for all $i$.

It follows directly from standard CES demand that the statically optimal quantities in a bundle (i.e. the most efficient way to achieve a value $F=1$ ) obey

$$
\begin{aligned}
& d \log \hat{x}_{H}^{\text {static }}=-\eta d \log \left(P_{H} / P\right) \\
& d \log \hat{x}_{F}^{\text {static }}=-\eta d \log \left(P_{F} / P\right) \\
& d \log \hat{x}_{F i}^{\text {static }}=d \log \hat{x}_{F}^{\text {static }}-\gamma d \log \left(P_{F i} / P_{F}\right)
\end{aligned}
$$

where $d \log P_{F}=\frac{1}{n} \sum d \log P_{F i}$ and $d \log P=(1-\alpha) d \log P_{H}+\alpha d \log P_{F}$ are the standard price indices. We interpret the limit $n \rightarrow \infty$ as the case in this paper, with a continuum of foreign countries.

Specializing to the two sources of demand for home country goods in our paper, we can combine (A.120) and (A.118) to obtain

$$
d \log \hat{x}_{H t}=-(1-\beta \theta) \eta d \log \left(P_{H t} / P_{t}\right)+\beta \theta d \log \hat{x}_{H t+1}
$$

and, looking from the perspective of a foreign country demanding the home good (which to it is one of a continuum of home goods), we can combine (A.122) and (A.118), and use the fact that there are no aggregate shocks affecting foreign countries (so that the first term on the right in (A.122) is zero) to obtain

$$
d \log \hat{x}_{H t}^{*}=-(1-\beta \theta) \gamma d \log \left(P_{H t} / \mathcal{E}_{t}\right)+\beta \theta d \log \hat{x}_{H t+1}^{*}
$$

Both also satisfy (A.119), i.e. $d \log x_{H t}=(1-\theta) d \log \hat{x}_{H t}+\theta d \log x_{H t-1}$ and $d \log x_{H t}^{*}=(1-$ $\theta) d \log \hat{x}_{H t}^{*}+\theta d \log x_{H t-1}^{*}$, where $C_{H t}=x_{H t} C_{t}$ and $C_{H t}^{*}=x_{H t}^{*} C_{t}^{*}$. 
Note that one feature of this model is that the elasticities are not just time-dependent, but also shock-dependent: $d \log \hat{x}_{H t}$ and $d \log \hat{x}_{H t}^{*}$ are forward-looking, and they are therefore of greater magnitude when the shocks to $d \log \frac{P_{H t}}{P_{t}}$ and $d \log \frac{P_{H t}}{\mathcal{E}_{t}}$ are more persistent. This leads to a greater response of $d \log x_{H t}$ and $d \log x_{H t}^{*}$ to persistent shocks, and it can explain, for instance, why permanent tariff changes can have different effects on export volumes than shocks to exchange rates due to capital flows, as estimated in Fitzgerald and Haller (2018) and Cavallo, Gopinath, Neiman and Tang (2021).

\section{C.3 Calibrating openness and price pass-through}

This appendix provides data from a representative set of countries that experienced a large depreciation. This includes Mexico, which we use as our main calibration target, as well as eight other countries with a depreciation episode studied in Burstein and Gopinath (2015).

Calibrating $\alpha$. We start by providing recent data on the import/GDP ratio from the IMF International Financial Statistics in the top panel of Table A.1. The import-GDP ratio informs the choice of $\alpha$ in our benchmark model, or of the aggregate $\frac{C_{F}}{C}$ in our quantitative model with nonhomothetic demand. This justifies our calibration to $\alpha=0.4$ for Mexico.

Calibrating $\theta_{F}$. To calibrate price stickiness parameters, we use information from the country's large devaluation episode to inform our choice of exchange rate pass-through. For this exercise, we proceed as follows. We start from the equations describing the dynamics of import prices $P_{F t}$ in response to an exchange rate change, (41). Note that this equation delivers price dynamics as a pure function of the exchange rate path $\mathcal{E}_{t}$ and parameters $\theta_{F}$ and $r$, independently of the rest of the model. In particular, (41) implies that the linearized price dynamics of $p_{F t}=\log P_{F t}$ in response to an impulse to the exchange rate of $e_{t}=\log \mathcal{E}_{t}$ are

$$
p_{F t}-p_{F t-1}=\frac{\left(1-\frac{1}{1+r} \theta_{F}\right)\left(1-\theta_{F}\right)}{\theta_{F}}\left(e_{t}-p_{F t}\right)+\frac{1}{1+r}\left(p_{F t+1}-p_{F t}\right)
$$

We conceptualize the exchange rate depreciations experienced by each country in our case study as a one-time permanent shock to the exchange rate, from its initial level of $e_{-1}=0$ to $e_{t}=\bar{e}$ for $t \geq 0$. Though stylized, this provides a useful approximation to the behavior of the nominal exchange rate in these episodes (see e.g. Burstein, Eichenbaum and Rebelo 2005, figure 1). It is easy to verify that the solution for $p_{F t}$ under this particular path for $e_{t}$ in (A.125) is:

$$
p_{F t}=\bar{e}\left(1-\theta_{F}^{t}\right)
$$

Equation (A.126) delivers a simple way to back out the Calvo price rigidity coefficient as a function of the import price pass-through as of date $t$,

$$
\theta_{F}=\left(1-\frac{p_{F t}}{\bar{e}}\right)^{\frac{1}{t}}
$$

To perform this calculation for each of our countries, we need a measure of the pass-through to the retail price of imported goods, $p_{F t} / \bar{e}$ at some date $t$ following the depreciation at $t=0$. Burstein, Eichenbaum and Rebelo (2005) (henceforth BER) measured pass-through at 24 months, corresponding to $t=8$, but only for dock prices, tradable retail prices and nontradable retail prices. 


\begin{tabular}{cccccccccc}
\hline & Mexico & Argentina & Brazil & Korea & Thailand & Finland & Sweden & Italy & UK \\
\hline \hline Latest data & 2019 & 2019 & 2019 & 2019 & 2019 & 2019 & 2019 & 2019 & 2019 \\
\hline Imports/GDP & $40 \%$ & $15 \%$ & $14 \%$ & $37 \%$ & $51 \%$ & $40 \%$ & $44 \%$ & $29 \%$ & $32 \%$ \\
\hline \hline Depreciation year & 1994 & 2001 & 1998 & 1997 & 1997 & 1992 & 1992 & 1992 & 1992 \\
\hline Dock PT & $107 \%$ & $87 \%$ & $126 \%$ & $60 \%$ & $68 \%$ & $116 \%$ & $76 \%$ & $63 \%$ & $141 \%$ \\
Tradable retail PT & $82 \%$ & $36 \%$ & $36 \%$ & $30 \%$ & $28 \%$ & $64 \%$ & $29 \%$ & $32 \%$ & $22 \%$ \\
Nontradable PT & $30 \%$ & $7 \%$ & $11 \%$ & $11 \%$ & $25 \%$ & $6 \%$ & $14 \%$ & $19 \%$ & $41 \%$ \\
\hline Imported retail PT & $122 \%$ & $63 \%$ & $52 \%$ & $46 \%$ & $28 \%$ & $102 \%$ & $34 \%$ & $38 \%$ & $-15 \%$ \\
Implied $\theta_{F}$ & 0.00 & 0.78 & 0.91 & 0.93 & 0.96 & 0.00 & 0.95 & 0.94 & 1.00 \\
\hline \hline$d Y_{0}$ & -0.35 & -0.03 & 0.00 & -0.01 & 0.00 & -0.35 & 0.00 & -0.01 & -0.01 \\
$\sum_{t=0}^{7} d Y_{t}$ & -1.81 & -0.42 & -0.10 & -0.11 & 0.03 & -1.81 & -0.02 & -0.08 & 0.01 \\
\hline
\end{tabular}

Notes: data on dock and retail pass-through are taken from Table 7.5 in Burstein and Gopinath (2015), using the ratio of the increase in dock import prices and retail prices at 24 month to the trade weighted exchange rate at 24 month. Data on imports and international investment position (assets, liabilities and NIP) are taken from the IMF International Financial Statistics. The bottom two rows replicate the exercise of Table 2 for these countries.

Table A.1: Imported price pass-through, openness, and international positions for selected countries

We convert this information into a measure of the retail price of imported goods following BER's framework. Specifically, we assume that $(\log )$ traded goods prices $p_{T t}$ are made up of imported goods prices and local goods, whose price is well proxied by the price of non-traded goods, so that

$$
p_{T t}=(1-\phi) p_{F t}+\phi p_{N t}
$$

Following BER, we assume $\phi=1 / 2$, and use equation (A.128) to back out $p_{F t} .{ }^{51}$

The bottom row of Table A.1 reports the result of this exercise. The first two rows report $p_{D t} / \bar{e}$, $p_{T t} / \bar{e}$ and $p_{N t} / \bar{e}$ for $t=8$ quarters. The next row reports $p_{F t} / \bar{e}$ backed out from (A.128), and the final row reports the implied quarterly $\theta_{F}$ from equation (A.127). As can be seen, the devaluations suggest a lot of heterogeneity in imported price pass-through in each episode. In Mexico, this procedures infers full price pass-through, given the large movements in tradable retail prices and limited movement in nontradable prices. This is consistent with the large amount of price passthrough observed at the dock in that episode. In other episodes tradable retail prices move a lot less, so our procedure infers much more limited import price pass-through.

Calibrating $\theta_{w}$. We also use information from Table A.1 to calibrate the wage stickiness parameter $\theta_{w}$. We use information from the time path of non-traded good prices, which in our model correspond to $p_{H t}$, in order to discipline that parameter. Note that, in contrast to $\theta_{F}$, which is identified directly from the price pass-through data, $\theta_{w}$ depends on the entire structure of the model, and in particular on the relationship between monetary policy and domestic economic activity. Moreover, the path of $p_{H t}$ does not separately identify the stickiness of wages $\theta_{w}$ and the

\footnotetext{
${ }^{51}$ We obtain similar results if we assume that the retail price of imported goods is a mix $p_{F t}=$ $(1-\phi) p_{D t}+\phi p_{N t}$ of dock prices and non-traded goods prices.
} 
Figure A.2: Calibrating $\theta_{w}$
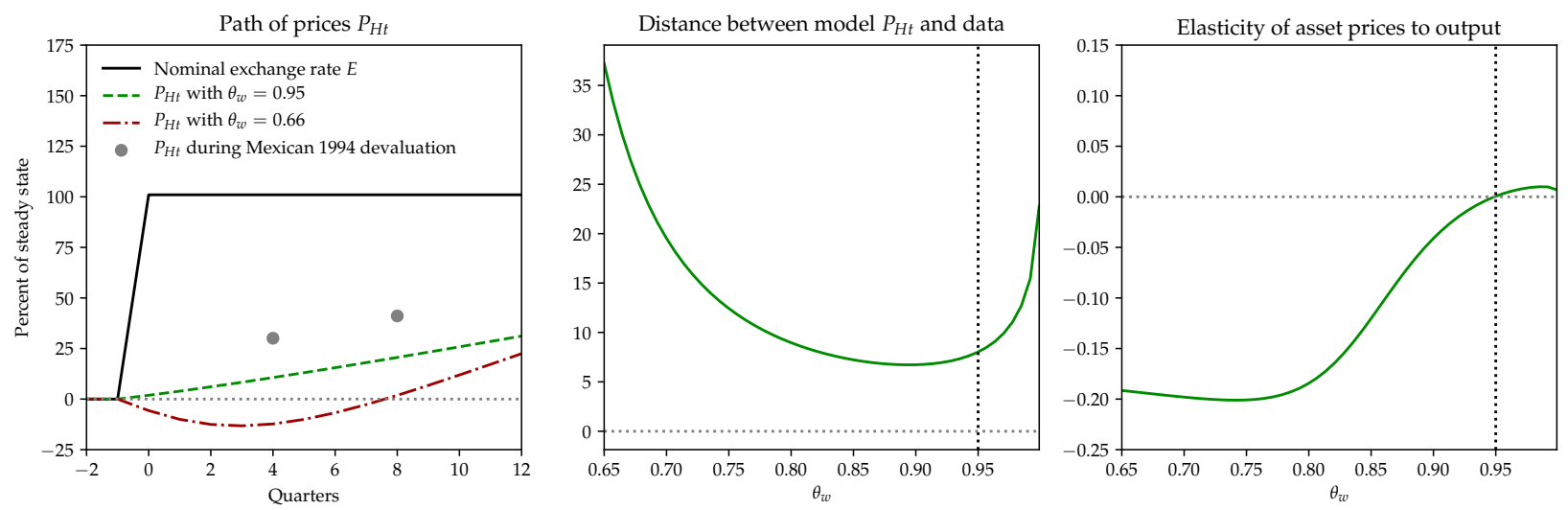

Note: The left panel shows the impulse response of home goods prices $P_{H t}$ following a permanent change in the nominal exchange rate $E_{t}$.The data is taken from Table 7.5 in Burstein and Gopinath (2015). The middle panel plots the sum of square distance between model and data at $t=4$ and $t=8$, for different values of the calvo parameter $\theta_{w}$. The right panel shows the reduced-form elasticity of the asset price to output, for different values of the Calvo parameter $\theta_{w}$.

stickiness of prices $\theta_{H}$. We therefore follow the standard in the literature and set $\theta_{H}$ to imply a price duration of 3 quarters. We then find $\theta_{w}$ to match two features of the data. First, we look for the best fit in terms of the path of prices in response to the pure devaluation shock as described above. Second, we look for a coefficient that implies a reasonable degree of cyclicality of stock prices in response to a monetary policy shock.

Figure A.2 shows the outcome of that exercise. The left panel plots the path of prices $P_{H t}$ after the devaluation in the model and in our data, the middle panel plots the sum of square distance between model and data at $t=4$ and $t=8$, and the right panel plots the reduced-form elasticity of asset prices induced by a contractionary shock to capital flows. When wages are relatively flexible $\left(\theta_{w}=0.66\right)$, home goods prices initially go down in response to the devaluation shock, because this shock induces a recession in the short run. This does not match the path of prices that we observed in the Mexican devaluation. Our model infers that wages are stickier than this, in the range of $\theta_{w}=0.85$ or above. Second, at $\theta_{w}=0.85$, stock prices are still countercyclical, going up after a contractionary capital outflow. We pick $\theta_{w}=0.95$ because it hits a tradeoff between making asset prices roughly acyclical in response to capital flow shocks, and getting a path of prices $p_{H t}$ that lines up well with the data.

We use the calibration in this section to consider the effect of depreciations in other countries than our benchmark of Mexico, which featured high openness and full import pass-through. We recalibrate our model to hit their import-GDP ratio and their degree of import price pass-through, but keeping the MPCs the same. The bottom two rows of the table illustrates that the effects of the same exchange rate shock are very heterogeneous across countries. Countries with lower import price pass-through have much less of an immediate impact on output, since the real income effect is really muted. Openness has a non-monotonic effect, since the immediate effect of an exchange rate depreciation is not as large in an economy that is more closed, but the general equilibrium effect of any open international position is much larger, through the logic of Proposition 7.

\section{C.4 Currency mismatch in balance sheets}

To incorporate currency mismatch in the net foreign asset position, we proceed as follows. We expand the setting in section A.1 by allowing countries to invest in long-duration foreign currency 
assets, modeled as bonds with nominal coupons that exponentially decay at a rate $\delta$, and a foreign currency price of $\mathcal{Q}_{t}^{*}$, where $\delta$ is calibrated to empirical duration data.

Investment through the mutual fund. We first assume that foreign currency exposures are held through the mutual fund. Suppressing the choice of domestic nominal bonds and foreign stocks for simplicity, the beginning-of-period valuation equation for the mutual fund (A.1) becomes

$$
\left(1+i_{t}^{p}\right) \mathcal{A}_{t-1}=\left(D_{t}+p_{t}\right) P_{t} s_{t-1}^{H}+\mathcal{E}_{t}\left(1+\delta \mathcal{Q}_{t}^{*}\right) \Lambda_{t-1}^{F}
$$

where $\Lambda_{t}^{F}$ is the number of foreign-currency asset coupons held in period $t$, while the end-of period valuation equation $\mathrm{A} .2$ is

$$
\mathcal{A}_{t}=p_{t} P_{t} s_{t}^{H}+\mathcal{E}_{t} \mathcal{Q}_{t}^{*} \Lambda_{t}^{F}
$$

Optimal investment now requires, in addition to the equations in (A.4), that

$$
1+i_{t}^{*}=\frac{1+\delta \mathcal{Q}_{t+1}^{*}}{\mathcal{Q}_{t}^{*}}
$$

which gives the valuation equation for the foreign currency bond price $\mathcal{Q}_{t}^{*}$. The real value of mutual fund assets (A.9) is now

$$
\left(1+r_{t}^{p}\right) A_{t-1}=\left(D_{t}+p_{t}\right) s_{t-1}^{H}+\left(1+i_{t-1}^{*}\right) Q_{t} \frac{\Lambda_{t-1}^{F}}{P^{*}}
$$

In the steady state, this now reads

$$
A_{s S}=p_{s s} S_{-1}^{H}+\left(1+\delta \mathcal{Q}_{s S}^{*}\right) \Lambda_{-1}^{F}=p_{s s} s_{-1}^{H}+\underbrace{\left(1+i_{s S}^{*}\right) \mathcal{Q}_{s s}^{*} \Lambda_{-1}^{F}}_{\equiv f_{Y}}
$$

We continue to calibrate the steady state of the model so that $\mathrm{nfa}_{-1}=0$, and hence $A_{s s}=p_{s s}$, but now allow for a gross currency mismatch, where the country has a share $f_{Y}$ of foreign currency assets in excess of foreign currency liabilities, relative to its GDP. Combining (A.131) with $A_{s s}=$ $p_{s s}$, we have:

$$
f_{Y}=p_{s s}\left(1-s_{-1}^{H}\right)
$$

In other words, if $f_{Y}>0$, then the country has foreign currency assets that are offset by foreign direct investment in the domestic stock market $\left(s_{-1}^{H}<1\right)$, while if $f_{Y}<0$, the country has borrowed in foreign currency and holds a levered position in its domestic stock market, $s_{-1}^{H}>1$.

After a depreciation induced by a change in the path of $i_{t}^{*}$ for $t \geq 0$, the country experiences an adverse valuation effect to its liabilities. We use equation (A.129) to calculate the induced new bond price $\mathcal{Q}_{0}^{*}$ (note that when $\delta>0$, the increase in foreign interest rates reduces the present value of liabilities in foreign currency term), and (16) to calculate the new real exchange rate $Q_{0}$. Together with our calibration of $f_{Y}$, this determines $r_{0}^{p}$ via equation (A.130) and therefore the magnitude of the valuation effect.

Investment through the government balance sheet. When foreign currency investments are done through the mutual fund, the valuation effects are distributed in the population according to their holdings of mutual fund shares. To quantify the effect of alternative distribution rules, we now assume that the government holds the country's gross currency exposure, and rebates it 
Figure A.3: Calibrating $f_{Y}$
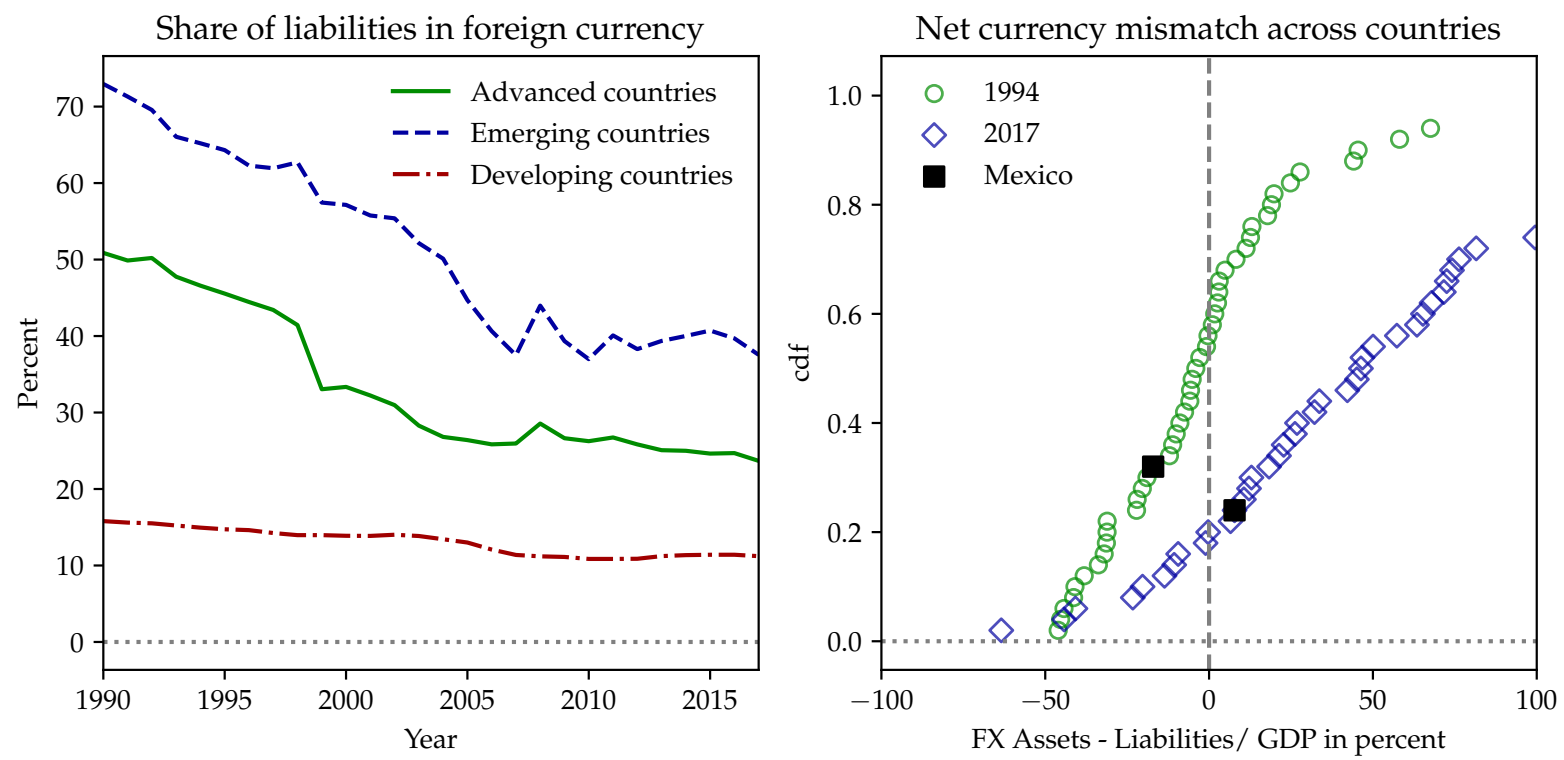

Note: The left panel shows the fraction of liabilities denominated in foreign currency as a share of total liabilities, on average across advanced, emerging and developing countries, respectively. The right panel shows the distribution, in a set of 50 countries, of the difference between foreign currency assets and liabilities ("gross currency mismatch"), as a share of GDP. Source: Bénétrix et al. (2020), updating an earlier study by Lane and Shambaugh (2010).

according to various schemes. We add a government, with shares $s_{t}^{G}$ in domestic assets and $\Lambda_{t-1}^{G}$ coupons in foreign bonds, and budget constraint

$$
B_{t}=\left(1+r_{t-1}\right) B_{t-1}-T_{t}+\left(1+i_{t-1}^{*}\right) Q_{t} \frac{\Lambda_{t-1}^{G}}{P^{*}}+s_{t}^{G}\left(D_{t}+p_{t}\right)
$$

where $T_{t}$ are aggregate taxes. We distribute those taxes by modifying the household budget constraint (1) to read

$$
\frac{P_{F t}}{P_{t}} c_{F}+\frac{P_{H t}}{P_{t}} c_{H}+a^{\prime}=\left(1+r_{t}^{p}\right) a+e \frac{W_{t}}{P_{t}} N_{t}-T_{t} \frac{e^{1-\lambda}}{\mathbb{E}\left[e^{1-\lambda}\right]}
$$

$\lambda=1$ represents lump-sum taxes, while $\lambda=0$ are proportional taxes. The higher $\lambda$, the more regressive the tax system is. Finally we assume the fiscal rule

$$
B_{t}=\left(\rho_{B}\right)^{t} B_{t-1}
$$

When $\rho_{B}=0$, through (A.132), the government immediately must adjust taxes to shore up its balance sheet loss from foreign liabilities after a depreciation. When $\rho_{B}>0$, the government builds up debt and taxes later, which mitigates the immediate effect on spending. 
Calibrating $\delta$ and $f_{Y}$. To calibrate the coupon $\delta$, we note that the duration of a bond with price (A.129) is given by

$$
D=\frac{1+i^{*}}{1+i^{*}-\delta}
$$

We calibrate $\delta$ to hit a liability duration of $D=18$ quarters, as implied by Doepke and Schneider (2006)'s estimates for the U.S.

We calibrate $f_{Y}$ to data on from Lane and Shambaugh (2010) and Bénétrix et al. (2020). Lane and Shambaugh (2010) documented aggregate foreign currency exposures for 1994 to 2004 for a sample of 117 counties; Bénétrix et al. (2020) subsequently updated their data to 2017 for a sample of 50 countries. These studies measure foreign currency exposure as the difference between county $i$ 's gross foreign currency assets and gross foreign currency liabilities. ${ }^{52}$ The right panel of figure A.3 shows the distribution of these currency exposures, normalized by GDP, from the most recent study by Bénétrix et al. (2020). As emphasized by these authors, countries have dramatically reduced the aggregate currency mismatch in their balance sheets since the 1990s: for instance, while Mexico used to have around 25\% more foreign currency liabilities than assets as a share of its GDP, it now has around 5\% more foreign currency assets than liabilities (the left panel illustrates that this has tended to happen via a reduction in the fraction of the share of liabilities that are in foreign currency.) In the latest 2017 data, only three countries in the dataset have foreign currency liabilities exceeding assets by more than $40 \%$ of GDP: Tunisia (-63\%), Egypt (-44\%) and Sri Lanka $(-40 \%)$. In our exercise of section 5.6 , we set $f_{Y}=-50 \%$. This calibration therefore represents an upper bound on the size of valuation effects.

\section{Alternative models}

This appendix presents three extensions of our baseline model, which we show can be reinterpreted as versions of our baseline model with different parameters. Appendix D.1 adds produced nontradable goods in addition to tradable goods. Appendix D.2 adds imported intermediate goods. Both of these can be directly reinterpreted as our baseline model with an appropriate reparameterization of the openness parameter $\alpha$ and the elasticity of substitution between home and foreign goods $\eta$. Appendix D.3 considers a tradable-nontradable model of a commodity exporter, which takes as given the price of exports. We show that in the standard case where a fixed quantity of tradables (commodities) is being produced each period, akin to a fixed endowment of tradable goods, this can be reinterpreted as our model with dollar currency pricing.

\section{D.1 Nontradable goods}

We first add nontradable goods to the model. Instead of (2), assume that household consumption is now an aggregate between tradable goods and (home-produced) nontradable goods,

$$
c=\left[\phi^{1 / \zeta} c_{T}^{(\zeta-1) / \zeta}+(1-\phi)^{1 / \zeta} c_{H, N T}^{(\zeta-1) / \zeta}\right]^{\zeta /(\zeta-1)}
$$

\footnotetext{
${ }^{52}$ Lane and Shambaugh (2010)'s headline measure of currency exposure for country $i$ at time $t, F X_{i t}^{A G G \text {, }}$ is normalized by the sum of assets and liabilities, but the supplementary data in both Lane and Shambaugh (2010) and Bénétrix et al. (2020) report measures normalized by GDP, which correspond exactly to our $f_{Y}$.
} 
where the tradable bundle is a mix of imported tradables and home-produced tradable goods,

$$
c_{T}=\left[\alpha^{1 / \eta} c_{F}^{(\eta-1) / \eta}+(1-\alpha)^{1 / \eta} c_{H, T}^{(\eta-1) / \eta}\right]^{\eta /(\eta-1)}
$$

Here, $\phi$ is the tradable share, while $1-\alpha$ is home bias within tradables; $\zeta$ is the elasticity of substitution between tradables and nontradables (which is plausibly quite low), while $\eta$ is the elasticity of substitution between home and foreign goods within tradables. For this section, we assume that the production functions for tradables and nontradables are identical, so that they always have the same price, and that all that matters is the sum of $c_{H, T}$ and $c_{H, N T}$.

With this demand system, total demand for home goods coming domestic residents is

$$
c_{H} \equiv c_{H, T}+c_{H, N T}=\left((1-\alpha)\left(\frac{P_{H}}{P_{T}}\right)^{-\eta} \phi\left(\frac{P_{T}}{P}\right)^{-\zeta}+(1-\phi)\left(\frac{P_{H}}{P}\right)^{-\zeta}\right) c
$$

At the steady state where all prices are 1, the overall home and foreign shares of consumption are therefore

$$
\frac{c_{H}}{c}=(1-\alpha) \phi+(1-\phi) \equiv 1-\bar{\alpha} ; \quad \frac{c_{F}}{c}=\alpha \phi \equiv \bar{\alpha}
$$

In response to a shock to prices around the steady state, we log-linearize and find that this relative demand changes by

$$
\hat{c}_{H}-\hat{c}=-\frac{(1-\alpha) \phi}{(1-\alpha) \phi+(1-\phi)}\left(\eta\left(\hat{p}_{H}-\hat{p}_{T}\right)+\zeta\left(\hat{p}_{T}-\hat{p}\right)\right)-\frac{1-\phi}{(1-\alpha) \phi+(1-\phi)} \zeta\left(\hat{p}_{H}-\hat{p}\right)
$$

Noting that $\hat{p}=\phi \hat{p}_{T}+(1-\phi) \hat{p}_{H}$, we can write

$$
\begin{aligned}
\hat{p}_{H}-\hat{p}_{T} & =\phi^{-1}\left(\hat{p}_{H}-\hat{p}\right) \\
\hat{p}_{T}-\hat{p} & =-\phi^{-1}(1-\phi)\left(\hat{p}_{H}-\hat{p}\right)
\end{aligned}
$$

and substitute these into (A.137) to obtain

$$
\begin{aligned}
-\frac{\hat{c}_{H}-\hat{c}}{\hat{p}_{H}-\hat{p}} & =\frac{(1-\alpha) \phi}{(1-\alpha) \phi+(1-\phi)}\left(\eta \phi^{-1}-\zeta \phi^{-1}(1-\phi)\right)+\frac{1-\phi}{(1-\alpha) \phi+(1-\phi)} \zeta \\
& =\frac{(1-\alpha) \eta+(1-\phi) \alpha \zeta}{(1-\alpha)+(1-\phi) \alpha} \equiv \bar{\eta}
\end{aligned}
$$

Note that the elasticity $\bar{\eta}$ in (A.138) is a weighted average of the primitive elasticities $\eta$ and $\zeta$.

Define the consumption aggregator function $\bar{c}\left(c_{F}, c_{H}\right)$ to maximize $c$ subject to (A.133), (A.134) and $c_{H}=c_{H, T}+c_{H, N T}$. It is immediate that this has constant returns to scale. We can view total foreign and home consumption (as calculated above) as optimizing this function subject to prices $P_{F}$ and $P_{H}$.

For steady-state $P_{F}=P_{H}=P=1$, we found $c_{F}$ and $c_{H}$ in (A.136), with $\bar{\alpha}=\alpha \phi$ the steady-state foreign share and $1-\bar{\alpha}$ the home share. In (A.138) we calculated the local elasticity of substitution of the consumption aggregator function, $\bar{\eta}$.

To first order in aggregate shocks, therefore, our model remains the same when nontradables are introduced; we need only replace the openness parameter $\alpha$ and elasticity of substitution between home and foreign goods $\eta$ with their counterparts $\bar{\alpha}$ and $\bar{\eta}$ in (A.136) and (A.138). ${ }^{53}$ The

\footnotetext{
${ }^{53}$ The problem of allocating within $c_{F}$ between different countries' varieties is unchanged; the elasticity
} 
two implications of this equivalence mapping are the following.

First, the import-to-GDP ratio is now $\frac{c_{F}}{c}=\alpha \phi=\bar{\alpha}$. Hence, even in the presence of nontradables, it is appropriate to calibrate $\bar{\alpha}$ to that ratio.

Second, $\bar{\eta}$ is a weighted average of $\eta$ (elasticity between home and foreign within tradables, which could be relatively high) and $\zeta$ (the elasticity between nontradable and tradable, which could plausibly be much lower), with a larger weight on $\zeta$ when the nontradable share is higher. Hence, $\bar{\eta}$ itself could plausibly be relatively low.

\section{D.2 Imported intermediates}

We now return to the consumption basket in (2), but change the production structure to allow for imported intermediate goods. Specifically, suppose that the continuum of firms in each country now produce an intermediate good $X$ using the technology $X=Z N$, and that the final good $Y$ in each country is a CES aggregate of the country's own intermediate good and the foreign intermediate good.

Concretely, for the home country, suppose that production of the final good is given by

$$
Y=\left[\phi^{1 / \zeta} X_{F}^{(\zeta-1) / \zeta}+(1-\phi)^{1 / \zeta} X_{H}^{(\zeta-1) / \zeta}\right]^{\zeta /(\zeta-1)}
$$

where $X_{H}$ is the home country's demand for the home intermediate, and $X_{F}$ is the home country's demand for imported intermediates. Suppose further that $X_{F}$ (analogous to $c_{F}$ ) is a CES aggregate of each other country's intermediate, with elasticity $v$. As before, normalize all prices and quantities at the steady state to 1 , and assume that foreign prices and quantities do not change. Note that a country's total value added, or GDP, equals its $X$.

It follows that total demand for the home country's intermediate $X$ is

$$
X=(1-\phi)\left(\frac{P_{H}^{X}}{P_{H}}\right)^{-\zeta} Y+\phi\left(\frac{P_{H}^{X}}{\mathcal{E}}\right)^{-v} Y^{*}
$$

where demand for $Y$ is the same as before

$$
Y=(1-\alpha)\left(\frac{P_{H}}{P}\right)^{-\eta} C+\alpha\left(\frac{P_{H}}{\mathcal{E}}\right)^{-\gamma} C^{*}
$$

Equations (29) and (30) continue to hold, replacing $Y$ by $X$ and $P_{H}$ by $P_{H}^{X}$. Totally differentiating (A.140), we get

$$
\begin{aligned}
d X= & -(1-\phi)(1-\alpha) \eta\left(d P_{H}-d P\right)-(1-\phi) \alpha \gamma\left(d P_{H}-d \mathcal{E}\right) \\
& -(1-\phi) \zeta\left(d P_{H}^{X}-d P_{H}\right)-\phi v\left(d P_{H}^{X}-d \mathcal{E}\right)+(1-\phi)(1-\alpha) d C
\end{aligned}
$$

As in appendix B.1, linearizing the CPI equation, we have $d P=(1-\alpha) d P_{H}+\alpha d \mathcal{E}$. Linearizing the price index corresponding to (A.139), we get $d P_{H}=(1-\phi) d P_{H}^{X}+\phi d \mathcal{E}$.

Writing all the relative prices in (A.142) in terms of the real exchange rate $d Q=d \mathcal{E}-d P$, we

there remains $\gamma$. 
have

$$
\begin{aligned}
d P_{H}-d P & =-\frac{\alpha}{1-\alpha} d Q \\
d P_{H}-d \mathcal{E} & =-\frac{1}{1-\alpha} d Q \\
d P_{H}^{X}-d P_{H} & =\frac{\phi}{1-\phi}\left(d P_{H}-d \mathcal{E}\right)=-\frac{\phi}{1-\phi} \frac{1}{1-\alpha} d Q \\
d P_{H}^{X}-d \mathcal{E} & =\frac{1}{1-\phi}\left(d P_{H}-d \mathcal{E}\right)=-\frac{1}{1-\phi} \frac{1}{1-\alpha} d Q
\end{aligned}
$$

and can plug this into (A.142) to obtain

$$
d X=\left((1-\phi) \alpha \eta+(1-\phi) \frac{\alpha}{1-\alpha} \gamma+\phi \zeta \frac{1}{1-\alpha}+\frac{\phi}{1-\phi} v \frac{1}{1-\alpha}\right) d Q+(1-\phi)(1-\alpha) d C
$$

If we define $\bar{\alpha} \equiv 1-(1-\phi)(1-\alpha)$, and $\bar{\chi} \equiv \frac{1-\bar{\alpha}}{\bar{\alpha}}\left((1-\phi) \alpha \eta+(1-\phi) \frac{\alpha}{1-\alpha} \gamma+\phi \zeta \frac{1}{1-\alpha}+\frac{\phi}{1-\phi} v \frac{1}{1-\alpha}\right)$, then (A.143) becomes just

$$
d X=\frac{\bar{\alpha}}{1-\bar{\alpha}} \bar{\chi} d Q+(1-\bar{\alpha}) d C
$$

which is identical to equation (A.57) in appendix B.1, but with $\bar{\alpha}, \bar{\chi}$, and $d X$ replacing $\alpha, \chi$, and $d Y$. With these substitutions, the International Keynesian Cross remains the same, and our analysis in the main body of the paper goes through. The two implications of this equivalence mapping are the following.

First, $\bar{\alpha}=\alpha+\phi-\alpha \phi$, while the import-to-GDP ratio is $\alpha+\phi$. Hence, provided $\alpha$ and $\phi$ are not too large, $\bar{\alpha}$ is close to the import-to-GDP ratio, though an ideal calibration would subtract the reexported good-to-GDP ratio $\alpha \phi$.

Second, the trade elasticity $\bar{\chi}$ is now a more complex amalgam of four primitive elasticities: substitution between home and foreign final goods $\eta$, substitution between different countries' final goods $\gamma$, substitution between home and foreign intermediates $\zeta$, and substitution between different countries' intermediates $v$.

\section{D.3 Commodity exporter model}

As our last alternative model, we consider a model of a commodity exporter, who takes as given the price of tradable goods. We set this up as in Uribe and Schmitt-Grohé (2017), by assuming that the economy possesses a constant stream of tradable goods $Y^{T}$ that it can sell in the world market at fixed prices. Vice versa, there are non-tradable goods that the economy does not export. We describe the main changes in this economy relative to the one in section 2 and argue that this model is identical to the DCP model in section 3.4 in which dollar prices of exports are fully rigid.

Households. Domestic households are assumed to behave as in section 2, except that they consume tradable and non-tradable goods, rather than foreign and domestic goods. $P_{T t}$ is the price of tradables and $P_{N t}$ is the price of non-tradables. The utility function $u\left(c_{T}, c_{N}\right)$ is the same as before, with $c_{T}$ and $c_{N}$ entering a CES basket with elasticity $\eta$ and a consumption share of tradables of $\alpha$, analogous to (2). The CPI is analogous to (3), individual demands analogous to (4)-(5). Foreign households elastically buy or sell tradables at a fixed dollar price $P_{T}^{*}=1$. 
Production. Non-tradables are produced using the linear production function

$$
Y_{N t}=Z_{N} N_{N t}
$$

and sold by a continuum of firms charging flexible prices at a markup $\mu . N_{N t}$ is labor demand by non-tradable producers. Tradables are produced by the Leontief production function

$$
Y_{T t}=Z_{T} \min \left\{N_{T t}, L\right\}
$$

where $L>0$ is a fixed factor the country is endowed with, such as the land on which natural resources can be found. Again we assume $Y_{T t}$ is sold by a continuum of firms charging flexible prices at markup $\mu$. $N_{T t}$ is labor demand by tradable producers.

We assume here that (A.145) is Leontief in line with the idea that tradables are basically an endowment of the economy, $Y_{T t}=Z_{T} L=$ const. The only reason why we do not outright assume that $Y_{T t}$ is an endowment is that in a heterogeneous-agent context, it matters whose endowment $Y_{T t}$ is. (A.145) provides us with a simple way to split the proceeds from selling $Y_{T t}$ into labor and profit income.

Rest of the model. All the remaining model ingredients are identical. For example, all firms' dividends (tradable and non-tradable alike)

$$
D_{t}=\frac{P_{N t} Y_{N t}-W_{t} N_{N t}}{P_{t}}+\frac{\mathcal{E}_{t} P_{T}^{*} Y_{T t}-W_{t} N_{T t}}{P_{t}}
$$

are capitalized and traded, just like domestic firms' dividends before. Unions and wage stickiness, notation for exchange rates, market structure, and monetary policy are all identical.

Market clearing for non-tradable goods is given by

$$
Y_{N t}=(1-\alpha)\left(\frac{P_{N t}}{P_{t}}\right)^{-\eta} C_{t}
$$

essentially (26) without the second term, as non-tradable goods are not exported. We normalize all prices $\mathcal{E}_{s s}, Q_{s s}, P_{s s}, P_{N s s}, P_{T s s}$ to 1 , and quantities $C_{s s}=1, Y_{N s s}=1-\alpha, Y_{T s s}=\alpha$ in the steady state of the model.

Consumption function. We can write consumption as function of real labor income and dividends $C_{t}=\mathcal{C}_{t}\left(\left\{\frac{W_{s}}{P_{s}} N_{s}, D_{s}\right\}\right)$ just like before.

Model analysis and equivalence to DCP model. Define real GDP as

$$
Y_{t} \equiv \frac{P_{T s s}}{P_{s s}} Y_{T t}+\frac{P_{N s s}}{P_{s s}} Y_{N t}=Y_{T}+Y_{N t}
$$

We can write dividends as

$$
D_{t}=\frac{P_{N t} Y_{t}-W_{t} N_{t}}{P_{t}}+\frac{\mathcal{E}_{t} P_{T}^{*}-P_{N t}}{P_{t}} \alpha
$$

which is identical to (12) in the case of DCP with fully rigid dollar export prices, where $C_{H}^{*}=\alpha$ and $P_{H}^{*}=P_{T}^{*}=1$. Just like before, aggregate labor income is given by

$$
\frac{W_{t}}{P_{t}} N_{t}=\frac{1}{\mu} \frac{P_{N t}}{P_{t}} Y_{t}
$$


Rewriting (A.146), we find that

$$
Y_{t}=(1-\alpha)\left(\frac{P_{N t}}{P_{t}}\right)^{-\eta} C_{t}+\alpha
$$

which is identical to the goods market clearing condition (26) with DCP. Given that (A.147)-(A.149) are the same as in the model with DCP (section 3.4), and the consumption function is unchanged, this proves that the model with tradable and non-tradable goods is isomorphic to the DCP model.

International Keynesian cross. Due to the equivalence with the DCP model, we can derive an international Keynesian cross decomposition for the commodity exporter model that is analogous to (A.68). For a similar decomposition of the RA consumption response in a version of the commodity exporter model see Bianchi and Coulibaly (2021). 